\title{
An Exploration of Elementary School Counselors' Perceptions of Students' Exposure to Violent Video Games
}

\author{
Tammy Lynn Woody \\ West Virginia University
}

Follow this and additional works at: https://researchrepository.wvu.edu/etd

\section{Recommended Citation}

Woody, Tammy Lynn, "An Exploration of Elementary School Counselors' Perceptions of Students' Exposure to Violent Video Games" (2010). Graduate Theses, Dissertations, and Problem Reports. 2997. https://researchrepository.wvu.edu/etd/2997

This Dissertation is protected by copyright and/or related rights. It has been brought to you by the The Research Repository @ WVU with permission from the rights-holder(s). You are free to use this Dissertation in any way that is permitted by the copyright and related rights legislation that applies to your use. For other uses you must obtain permission from the rights-holder(s) directly, unless additional rights are indicated by a Creative Commons license in the record and/ or on the work itself. This Dissertation has been accepted for inclusion in WVU Graduate Theses, Dissertations, and Problem Reports collection by an authorized administrator of The Research Repository @ WVU. For more information, please contact researchrepository@mail.wvu.edu. 
An Exploration of Elementary School Counselors’ Perceptions of Students’ Exposure to Violent Video Games

\author{
Tammy Lynn Woody
}

\author{
Dissertation submitted to the \\ College of Human Resources and Education \\ at West Virginia University \\ in partial fulfillment of the requirements \\ for the degree of \\ Doctor of Education \\ in \\ Curriculum and Instruction
}
Ardeth Deay, Ph.D., Chair
Joy Saab, Ed.D.
Michael Yura, Ph.D.
Samuel Stack, Ph.D.
Perry Phillips, Ph.D.

College of Human Resources and Education

\author{
Morgantown, West Virginia \\ 2010
}

Keywords: Elementary School Counselors; Violent Video Games; Perceptions and Observations of Student Behaviors; Gaming Habits of Elementary Students; Professional Development

Copyright 2010 Tammy Lynn Woody 


\begin{abstract}
An Exploration of Elementary School Counselors' Perceptions of Students' Exposure to Violent Video Games

Tammy Lynn Woody
\end{abstract}

This study explored elementary school counselors' perceptions of working with students exposed to violent video games. Certified elementary school counselors participated in both an online survey and individual interviews, revealing their observations regarding elementary school children and the phenomenon of gaming. An emphasis was placed on information about violent video games and how playing these games appear to impact the students in their schools.

The study addressed the overarching question of whether or not elementary school counselors have concerns about student exposure to violent video games and how they respond to student generated discussions of playing violent video games. The study also focused on gathering information about professional development and training opportunities in regard to working with students who play violent video games. The intent of this study was to provide insight about elementary school counselors' experiences and viewpoints in relationship to student behaviors and thought processes that may be impacted by violence in video games. Participant responses from both the surveys and the individual interviews were analyzed and coded in an effort to capture predominant trends and themes and to share these findings with the educational community. The results from this research suggest that elementary school counselors are concerned about young children's exposure to video game violence and confirm the need for further research about the developmental and socio-emotional ramifications of playing violent video games. 


\section{TABLE OF CONTENTS}

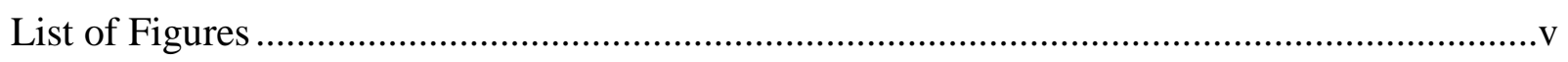

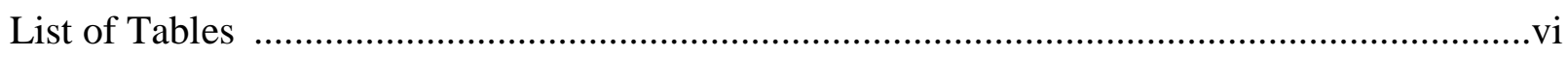

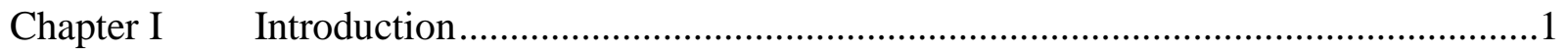

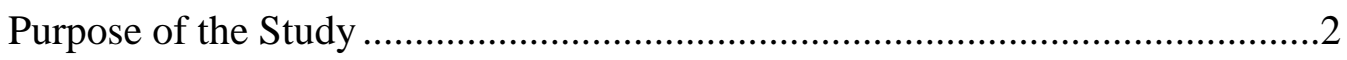

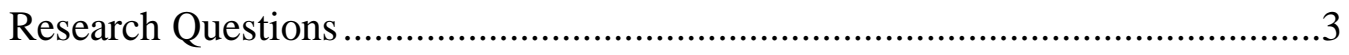

Statement of the Problem........................................................................

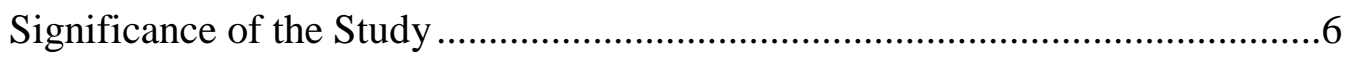

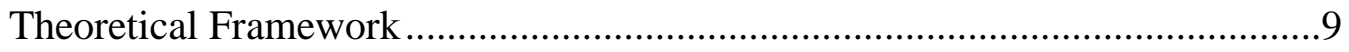

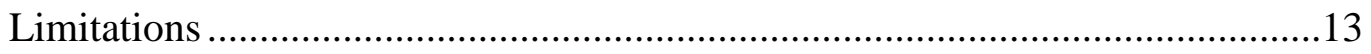

Chapter II L Literature Review................................................................................ 16

Literature Focus on Video Games .............................................................16

Literature Focus on the Effects of Playing Violent Video Games......................24

Literature Focus on Violence Prevention Programs .......................................28

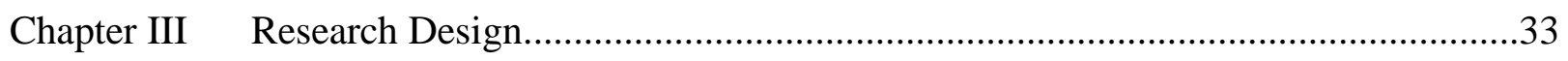

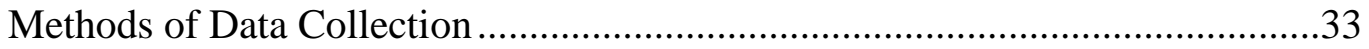

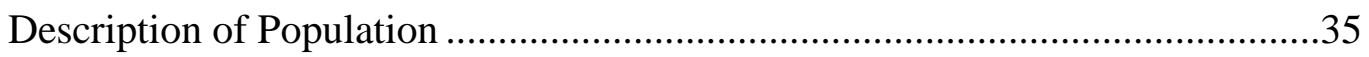

Survey of Elementary School Counselors ...................................................38

Interview of Selected Participants ...........................................................42

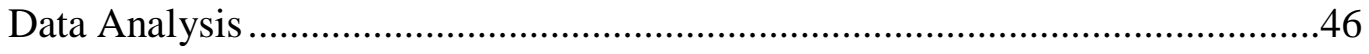

Methodology Framework...................................................................4

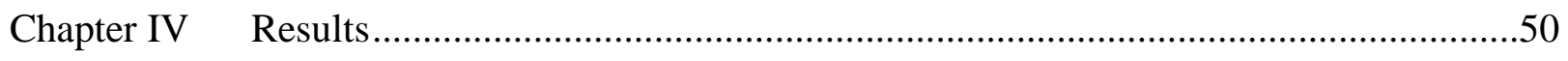

Overview of Data Collection and Analysis ..................................................50 
Survey Data Collection and Analysis ........................................................51

Individual Interview Data Collection and Analysis......................................64

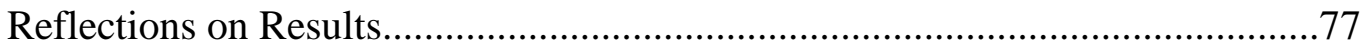

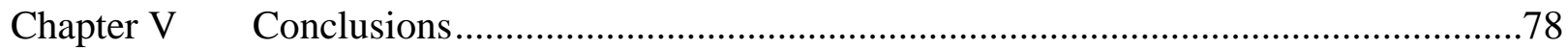

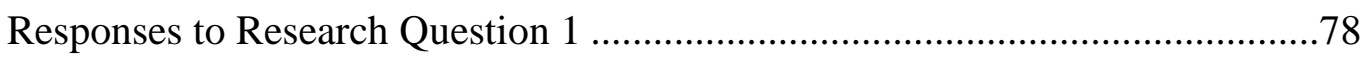

Responses to Research Question 2 ...........................................................79

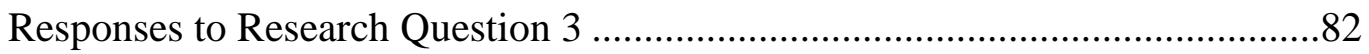

Responses to Research Question 4 ............................................................84

Responses to Research Question 5 ............................................................86

Responses to Research Question 6 ..........................................................8

Implications for Future Professional Development ........................................89

Implications for Future Research ..........................................................94

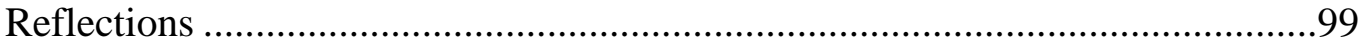

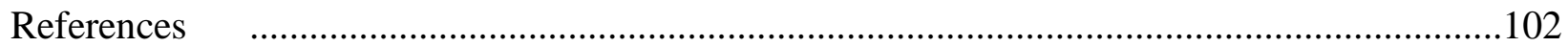

Appendix A

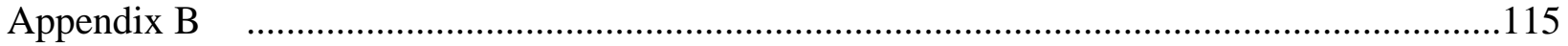

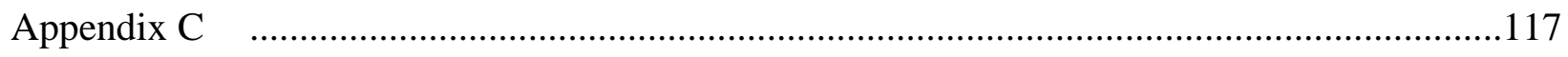

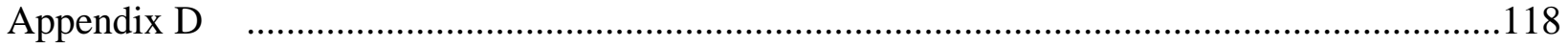

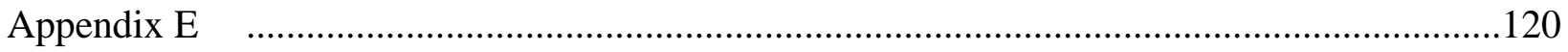




\section{LIST OF FIGURES}

Figure

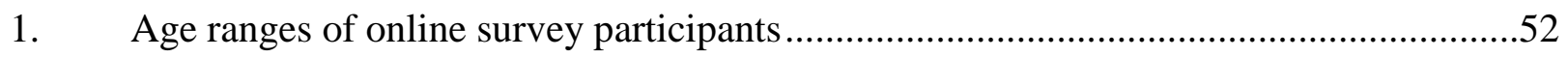

2. Online survey participants’ years of work experience as an elementary school counselor

3. Online survey participants' frequency of gaming for recreation .54

4. Online survey participants' responses to the prompt, "Students frequently discuss playing video games in my presence” displayed by age ranges

5. Online survey participants’ familiarity with popular video game titles .56

6. The number of video game titles online survey participants named when asked to list games that students discuss.

7. Online survey participants’ responses to the prompt, “My school does not have resources available which name and describe common video games”

8. Online survey participants' responses to the prompt, “There is research readily available about how playing video games may impact children”.

9. Online survey participants' responses to the prompt, “There is a need to educate adults about children’s exposure to violent video games”

10. Behaviors online survey participants believe may be related to playing violent video games

11. Online survey participants' typical responses when students initiate the topic of video games in counseling sessions.

12. Common themes found in online survey participants' open-ended responses when asked how they believe video game violence impacts students 


\section{LIST OF TABLES}

Table

1. Survey participant demographic information ...................................................41

2. Interview participant demographic information .................................................43 


\section{CHAPTER I}

\section{INTRODUCTION}

The classroom environment and pupils of a $21^{\text {st }}$ century educator often differ noticeably from those of previous generations of school counselors and teachers. Access to information, ideas, opinions, and entertainment, both positive and negative, has never been so easy to obtain. A relatively new form of entertainment that has garnered a much of attention is video games. In the past, entertainment, especially entertainment with elements of violence, was not constantly accessible. There were a variety of constraints that curbed exposure to violent entertainment. Now that children have more leisure time, a plethora of activities are available for their amusement and playing video games is currently one of the most popular pastimes (Woodard \& Gridina, 2000). This raises an important point about the nature of play today, which differs from how children have played in previous centuries. Entertainment is becoming increasingly mediated, constructed, and interactive, and children have less opportunity to create their own forms of entertainment. Comic books, radio shows, and television shows such as cartoons started the trend of entertainment that was directed towards a youthful audience, and through the years, these forms of entertainment have become increasingly violent in nature. The earliest versions of these forms of entertainment were more heavily censored and the violent acts they contained were conveyed in a humorous manner that minimized the impact of the violence (Gunter \& Furnham, 1984). Due to the increasingly graphic and realistic violence that is portrayed in these forms of entertainment, there has been concern that children may be negatively impacted by these violent images and aggressive acts (Kirsh, 2006).

The concern about a connection between viewing violence and aggressive behaviors is not new. Throughout history, there have been protests about children's exposure to questionable 
materials. For example, as early as 1873 the Comstock Law was passed in the United States, which was an "Act for the Suppression of Trade in, and Circulation of, Obscene Literature and Articles for Immoral Use.” This law was passed partially out of concern for “dirty books” and other materials that were considered inappropriate for any individual, but was specifically aimed at children. Anthony Comstock founded the New York Society for the Suppression of Vice and felt strongly that children should not be exposed to violence or sexually suggestive materials as they were particularly vulnerable (Bates, 1995). His name is synonymous with the zealous protection of the innocent, and his attitude about children's exposure to explicit violence reflects our puritanical roots as a nation.

Concern about violence as entertainment has been prevalent in our society. However, the advent of first person interactive video games has complicated the matter as children previously did not have the ability to immerse themselves in violence with visuals and auditory components (Kutner \& Olson, 2008). This has created unique concerns that have never been faced before in our schools and communities. There are ongoing questions about how children exposed to violence function in society at large and in the educational system. There are fears about whether children are being irrevocably primed towards aggression and how this would impact families, communities, and classrooms. These concerns have created a need for research about whether students who are exposed to violence are behaving in discernibly different ways in schools than their predecessors.

\section{Purpose of the Study}

This study reflects a genuine curiosity about how elementary school counselors are responding to children's deep interest in video game violence and whether they are changing their counseling practices due to student gaming habits. Specifically, this study entails reports of 
school counselors' discussions with students about video game violence and opinions about behavioral changes. While it must be acknowledged that a variety of factors can cause attitude changes, it is worthwhile to consider whether elementary school counselors feel they are seeing changes that, in their opinions, may be related to playing violent video games.

This study is relevant and timely given the need for awareness both about whether school counselors perceive that student behavior is changing due to exposure to video game violence and how counselors are being trained to work with these students. Also, it is important to determine if there are resources that address this issue. Thus far, researchers have focused more on the potential ramifications of gaming with students, not on the professionals who serve them. This study will explore and attempt to relate the perceptions of school counselors about media violence, particularly video game violence. Surveys and individual interviews will be used to examine and analyze how elementary school counselors process and respond to students' exposure to video game violence. The purpose of this study is to answer the research questions described in the following section.

\section{Research Questions}

Research Question One: When elementary school counselors encounter student generated discussions of video games, what are the most frequently mentioned game names and game activities?

Research Question Two: What do elementary school counselors observe students saying and/or doing that may be related to playing violent video games?

Research Question Three: How do elementary school counselors respond when students initiate conversations about violent video games? 
Research Question Four: How do elementary school counselors respond to actions and behaviors that appear to be related to playing violent video games?

Research Question Five: What kinds of professional development do elementary school counselors see as valuable in helping to work with students who play violent video games?

Research Question Six: Is demographic data generated by elementary school counselors related to how they answer survey and interview questions?

The research questions for this study were born out of a conscious awareness that educators in general, and elementary school counselors in particular, needed data that would help them make informed decisions when working with this population of students.

\section{Statement of the Problem}

There is an understandable need to examine whether children's recreational activities are detrimental to their academic, emotional, and social well-being. The popularity of video games that are violent warrants such an examination, and it is necessary to consider the opinions of those individuals who are in direct contact with these children. Specifically, there is a lack of research in regards to elementary aged students' exposure to violent video games. This dissertation will examine what their school counselors are observing due to said exposure and how they are responding to students who play violent video games.

It is not within the scope of this study to delve deeply into why and how "gaming," as it is frequently called, has become one of the most dominant features of our collective consciousness in America. Much attention has been given to the birth and growth of the video game phenomenon, and research is ongoing as to why individuals, young and old alike, play video games and what behavioral changes may occur due to gaming. Seminal research studies 
have been conducted over the last three decades and continue to yield cause for debate (Anderson, 2004; Gentile \& Anderson, 2006; Kutner \& Olson, 2008; Nicoll \& Kieffer, 2005). This dispute about whether video game violence is harmful to students will likely continue unabated. While there are numerous studies that do suggest an increase in aggression and hostile attribution bias after a child has been exposed to media violence, concerns have been raised about the validity of these and other studies that seek to show definitively that playing violent video games is harmful to youth (Huesmann \& Guerra, 1997; Paik \& Comstock, 1994).

In contrast with the aforementioned researchers, other scientists such as John Sherry (2001) and Jonathan Freedman (2002) have found no correlation between children's exposure to media violence and increased aggressive or violent acts, and have suggested that the research environment itself creates the correlation and that it does not exist in naturally occurring situations. To complicate the matter even further, there is not agreement on how to define violence in video games and how to determine what is developmental appropriate and inappropriate violence. It has been very challenging to decide what constitutes "violence" in a way that is agreeable to all stake-holders (i.e. game developers, parents, educators, and policy makers). Part of the discrepancies in the research of proponents and opponents of violent video games centers around this problem of quantifying and measuring aggression and violent acts; the definitions and tools used by both sides remain debated and contested. The two opposing viewpoints will be explored in greater detail in the literature review; however, this study examines whether those elementary school counselors who work directly with students see any differences in behaviors, attitudes, and actions that may, in part, be attributed to exposure to video game violence. By the nature of their job duties and responsibilities, school counselors are in a unique position to observe and notice changes in the children they educate and counsel. 


\section{Significance of the Study}

What is of particular concern in this study is the amount and type of violence that is contained in video games that students typically play and how exposure to violence may potentially change children from a developmental and psychosocial viewpoint as perceived by elementary school counselors. It is important to know whether or not elementary school counselors are perceiving changes in student populations due to exposure to video game violence and if so, what changes they describe and how they are responding. Educators and caregivers recognize that sometimes children appear to identify more deeply with fictional, media-generated characterizations than with real life role models (Jones, 2002). School counselors, in particular, often have a deep grasp of to whom a student relates due to the nature of counseling.

Understandably, there is cause for concern when a student identifies with aggressive and violent role models, whether real or fictional. There seems to be a common belief that students notice and emulate negative behavior more frequently than good behavior. Particularly in the context of visual media representation and video games, the more violent and disturbing an image or action, the more talk it seems to generate among students. Because students are often vocal about enjoying violent video games, there is an opportunity to learn from their impressions and discussions about gaming. The researcher feels it is of particular value to compare notes between counselors to see whether their experiences with students share similarities. This observation was validated during the researcher's experience as a practitioner. During monthly counselors meetings, discussions would ensue regarding what students were saying about playing video games. Here are some examples of elementary students' comments about playing video games as recalled by their school counselors during meetings at which the researcher was present: 
“It's like being God 'cause you're the boss of everyone."- $3^{\text {rd }}$ grader

"You can hurt anyone you want and not get in trouble."- $2^{\text {nd }}$ grader

"When I'm mad at my teacher, I can pretend to kill her over and over and then I feel

better." $-5^{\text {th }}$ grader

These types of comments warrant a new direction in school counselor training and/or professional development for educators. Students now have the ability to assume a first person shooter role in violent video games, and repeatedly kill other humans in graphic detail. In a virtual persona, they can beat people to death, commit rape, go on crime sprees, and act in antisocial ways. Although elementary aged students are not intended to have access to video games with "mature" content, there is research suggesting that young students may view M-rated video games as "forbidden fruit" and seek out these inappropriate games (Bijvank, Konijn, Bushman, \& Roelofsma, 2009). Given that many students do have access to inappropriate games, educators and elementary aged students need to have authentic dialogue about the violent acts being viewed so that students have the opportunity to compare the actions of video game characters with actions of real people. Specifically, critical reflection on video game violence and discussion regarding the real world consequences of violence seems to be absent both in schools and at home, as evidenced by the fact that few studies on this topic can be located. There were also no studies to be found on the concerns that elementary school counselors may have regarding changing ethics, moral values, and/or pro-social beliefs in students who play violent video games. It appears that the media in instances of the recent school shootings, tends to portray individuals who enjoy playing violent video games as more apt to commit crimes and harm others; it will be beneficial to examine whether elementary school counselors reference this perceived outcome. 
In order to delve more deeply into this topic, an important question needs to be addressed. Within the context of traditional programs initiated by school counselors to prevent relational aggression, bullying, violence, discipline referrals, and disrespect in schools programs, is students' exposure to video game violence being formally addressed or even considered? This issue should be considered because elementary school counselors are held accountable for character education, improving social skills, helping children achieve their highest academic potential, and teaching conflict resolution. Yet, if children are spending increasingly larger amounts of time outside of school engaging in activities featuring violent acts that are at odds with these goals, these actions could potentially impact counselor efficacy. This reinforces the need to know whether or not students' recreational activities are perceived as hindering elementary counselors' efforts at fostering social and emotional development. There is a lack of exploration into elementary school counselor perceptions and attitudes about children’s exposure to video game violence and how they are responding to these children; to that end, this study seeks to examine what elementary school counselors think about student exposure to violent video games.

While it is presumptuous to ignore or disregard research suggesting there is absolutely no impact on students who play violent video games, a better approach may be based on nonmalfeasance or the old adage, "An ounce of prevention is worth a pound of cure.” It seems reasonable to assume that most children with whom elementary school counselors work will have at least been exposed to media violence, if not violence in video games. Preventive actions by trained individuals could create intervention measures for all facets of the child's environment, should they be warranted due to harmful effects from viewing violence. At the very least, it seems responsible and rational to discuss children's perceptions of playing video 
games in a constructive and non-judgmental way so that educators, parents, caregivers and other stakeholders can better understand reactions to the gaming environment in which children revel. For this reason, it is appropriate to question the professionals who delve deeply into children's experiences and discover what they think about students who play violent video games and whether it has altered the way these professional counselors practice and/or are trained.

\section{Theoretical Framework}

As stated earlier, the pervasiveness of gaming in our modern day culture has become undeniable. Since the introduction of video games to the public, the amount of time that both children and adults spend playing video games has steadily increased and will probably continue to do so (Anderson, Gentile, \& Buckley, 2007). While the use of educational video games is becoming more popular and commonplace in today's schools, most often gaming is done outside of the educational setting (Becker \& Jacobsen, 2005). Since the focus of this study is about violent video games, not educational video games, important points should be addressed in regard to playing violent video games and how that may impact violence prevention programs, which are implemented in many of today's school districts.

When physical violence does occur in schools, there is often intense scrutiny of the perpetrator's predilection for playing violent video games, along with the assumption that exposure to such games made the aggressors more willing and efficient at harming innocent bystanders and targets. While these violent incidences have not occurred at the elementary level, school tragedies such as the shootings at Columbine High School, Heath High School, and Virginia Tech have been linked in the public mind to the attackers' obsession with video game violence; the supposition is that these deadly attacks are the outcomes of students imitating the shooter in violent video games (Goldstein, 2001). It is worth noting that there is extensive 
debate on the topic of whether playing violent video games does in fact cause students to harm themselves or others. Some researchers have focused their studies of the impact of video gaming in the context of learning. There has been research examining how well violent video games serve as teachers (Gentile \& Gentile, 2008); those results suggest that violent video games are exceptionally well-suited for creating learning. When considering the role of teaching and learning that video games may play, it is important to discuss social learning theories as the theoretical framework that addresses how elementary students may be impacted by exposure to video game violence.

Social learning theories have played a vital role in the conceptualization of this study. A social scientific approach in general could be used to seek answers to the basic question, "Why do individuals enjoy playing video games?” When the focus is narrowed to why and how games may influence those who play, it is necessary to look to theories that may explain the breadth and reach of video game playing. Two main theorists who have influenced the researcher's beliefs about how and what elementary aged students learn are Albert Bandura and Lev Vygotsky. It is important to focus on Bandura’s and Vygotsky’s beliefs about the nature of learning in relationship to modeling and imitating within a social context. Given the intent of this study, it is necessary to examine developmental theories, which may in part explain why children gravitate towards playing video games. Generally, it is agreed that research about violence in the $20^{\text {th }}$ century has been guided in part by social learning and/or social cognitive theories (Ferguson, in press). The researcher of this study chose to focus specifically on social learning and social cognitive theories as those theoretical frameworks are often foundational in school counselor preparation. Pre-service counselors and teachers should have exposure to the preeminent social learning and social cognitive learning theorists in order to increase their understanding of the 
developmental milestones and phases through which children progress. This knowledge in turn will hopefully assist in working effectively with students in a therapeutic sense. Familiarity with social learning and social cognitive models also comes into play when the school counselor serves as an academic coach; some of the more prominent conceptualizations from social cognitive and learning theories are applicable to how and why students learn in an educational setting. At the root of the social cognitive and social learning theories is the belief that children learn and develop through collaboration with more knowledgeable others. For the purpose of this study, it is interesting to note that while originally these theories focused on children's interactions with other humans, later research supported the idea that a characters in media and video games could serve as mentors and teachers (Bandura, 2006; Gentile \& Gentile, 2008). Relating this assertion to the initial emergent theories about learning as a primarily social endeavor requires a review of the pioneers in this field.

Perhaps the most well known social learning theorist is Albert Bandura. He is often credited with articulating the tenets of social learning theory, which suggests that individuals primarily learn through modeling or imitating the behaviors of those around them. Bandura became famous for the "Bo Bo Doll” experiments of the 1960's in which he researched aggression and children. He departed from the behaviorist school of thought and developed "social learning theory,” which has been called a bridge between behaviorist and cognitive learning theories because it addresses a triad of factors (cognitive, behavioral, and environmental) that Bandura believed impact learning (Bandura, Ross, \& Ross, 1961). Bandura posited that individuals learn from observing others' attitudes, behaviors, and actions. His theories have been frequently referenced as an aid to understanding aggression in humans as his research was purported to demonstrate that children become more aggressive in response to 
seeing aggression modeled. According to Bandura, "social cognitive theory emphasizes the role of modeling, the child's imitation of adult speech, adult reinforcement, and corrective feedback" (Eggen \& Kauchak, 2001, p. 64). Based on his studies, it is assumed that modeled aggression in the form of characters on television and in video games will also be imitated by children. In particular, his belief in the importance of self-efficacy seems to reflect the appeal of mastering video games and may answer some of the questions as to why children enjoying gaming. Bandura's social learning theory continues to influence and shape current research on how playing violent video games may promote learning of unintended norms and beliefs (Gee, 2003).

Another individual who had a profound impact on the field of social learning theory is the Russian theorist, Lev Vygotsky. Vygotsky is renowned for his research on human development, which has been labeled as a sociocultural approach. Vygotsky believed that all development and learning occur due to social interactions with others. He felt strongly that individual growth and ability reflected the collective wisdom and shared knowledge of the community in which an individual existed. As explained by Scherba de Valenzuela (2002), "Vygotsky described learning as being embedded within social events and occurring as a child interacts with people, objects, and events in the environment” (p. 287).

Vygotsky influenced both educational and psychological fields as he had a varied professional background. Initially, he trained to become a lawyer but became a school teacher instead of practicing law and then eventually, became a psychologist (Ratner, 1998). Of particular interest to this study are the key concepts embedded in Vygotsky's sociocultural theory of learning, such as scaffolding, the zone of proximal development, and the idea of a more knowledgeable other (MKO). Each of these concepts has alignment in regard to how children 
master video games and why some children appear to enjoy video games more than other activities.

It is important to note that social cognitive/learning theories focus on mastery, reinforcement and self-efficacy in terms of the intrinsic motivators that propel learning. In other words, children are more likely to practice and become better at tasks in which there is the opportunity to be rewarded and demonstrate proficiency. In doing so, children's internal beliefs about their personal competencies and abilities greatly increase their sense of self-worth. Because video games are designed in a way that maximizes opportunities for feeling capable and being challenged to become better at the game through rewards, children enjoy playing them. It is interesting to consider that video games, even violent video games, exemplify the concepts that shape social cognitive and social learning theories.

Given that violent video game characters may be viewed as role models, discussion with children about minimizing real life aggression and violence is warranted and necessary, particularly in school settings. Research shows that children are exposed to nearly 200,000 violent images on television alone by the time they enter college (Strasburger \& Wilson, as cited in Gentile, 2003). Additionally, there is some research proposing that younger students are particularly vulnerable to modeling and imitating aggressive actions, which lends credence to the need to educate both elementary students and educators about the impact of viewing violence (Goldstein, 2001).

\section{Limitations}

Due to the specific population of participants used in this mixed methods study, the findings of the study should not be generalized to a larger population. First, the number of participants may be too small to accurately reflect all elementary school counselors’ perceptions. 
Also, participants in this study were not selected randomly, and as such, the research will reflect trends and themes on the sub-population of elementary school counselors who were willing to participate. Lastly, the participants were all from the same geographic region and as such, may have perceptions that differ from elementary school counselors in other regions.

Another possible limitation would be due to social desirability bias (Kreuter, Presser, \& Tourangeau, 2008). Some participants may express views that are inconsistent with their personal beliefs in an effort to conform to what they assume the researcher is studying and thus, their responses may not accurately reflect their experiences. Additionally, there is the possibility that the qualitative themes that emerge could be subject to alternative interpretations. Particularly in the case of data collection from the interviews, a correct analysis is highly dependent on the skills of the interviewer and rests upon the interpersonal exchanges between the researcher and the participants. The experiences and training of the researcher should mitigate this particular limitation, but it is an important point to consider in future replications of the study as a limitation. The quantity and quality of the data that emerge from these interviews are a reflection of the researcher's ability to categorize and make meaning from these conversations with respect to both common themes and specific insights gained from the interviewees.

Acknowledging these limitations from the start of the conceptualization of the topic of study has allowed the researcher to plan carefully and design a research project that will contribute an original body of knowledge to an area that has largely been overlooked in the literature regarding student exposure to violent video games.

In conclusion, this study differs from previous research, because it targets a different audience and population as there is little evidence of studies about elementary school counselors and their perceptions of students' exposure to video game violence. The next chapter, which 
reviews available literature, illustrates the paucity of research on this specific topic and supports the appropriateness of this important contribution to the research field. 


\section{CHAPTER II}

\section{LITERATURE REVIEW}

This chapter focuses on the current research in the field that relates to violent video games and elementary students. Due to the fact that the specific topic of this study is emergent, a broad overview of trends and relevant studies were examined in this literature review. This chapter serves to reinforce the value of this particular study and is organized according to themes about video game violence, which are germane and informative. Overall, as the literature review progressed, a focus on three major constructs naturally emerged. The first section reviews the history and gives an overview of the most popular video games, with special attention paid to violent video games. The purpose of this section is to address the research question about the frequency of video game playing among students and to illustrate the pervasiveness of video game playing as modern day cultural entertainment. The second section examines research about the effects of playing violent video games on students. The final section provides a review of violence prevention programs currently used in schools. This section was included because a topic of future research for this study involves whether violence prevention programs address media and/or video game violence. For that reason, it is important to discuss the theoretical models and objectives of current violence prevention programs used in schools. The particular topics that comprise this literature review serve to foster a greater understanding of the findings of this study.

\section{Literature Focus on Video Games}

Video gaming is a relatively new phenomenon in our society, but like other forms of social media, video games have had a large cultural impact on the lives of many American adults and children. While video games have been around for decades, most people view the 1970's as 
the time that video games were introduced to the public. During the 1980's and 1990's, the increasing popularity of games started to garner attention from concerned individuals (Center for Media Literacy, n.d.) As both the violence and the realism of video games became greater, questions were posed by parents, educators, researchers, and prominent citizens regarding the pros and cons of video gaming.

There is a plethora of information about the rise of the video game culture in the United States; however, there is a lesser amount of scholarly work on this topic. The acknowledged expert on the subject of the history of gaming is a video game designer and reviewer named Steven L. Kent. His book, The First Quarter: A 25-year History of Video Games (2000) provides a very thorough overview of the history and development of video games and is commonly referenced as the most comprehensive book about gaming. The first chapter of the book discusses the evolution of recreational gaming, outlining the trajectory from pinball machines to the development of video games in the late 1950s. While there is some debate about who actually created the first video game, it is generally accepted that a series of events paved the way for the invention of video games as we know them today. Thomas T. Goldsmith, Jr. filed a patent in 1947 on the first interactive electronic game. Using a cathode ray tube, the game was designed as a missile simulater, with the goal of the game being to shoot down images of airplanes by a player controlled beam (Hevesi, 2009).

Next, electronic games that mimiced traditional board games such as chess and tic-tac-toe made an appearance in the early 1950's. William Higinbotham is credited with creating one of the first video games purposely built for entertainment. Tennis for Two was introduced to the public at Brookhaven National Laboratory in 1958 as a demonstration for one of the annual visitors’ days (Gettler, n.d.). 
These early prototypes laid the foundation for the development of arcade games. Nolan Bushnell is given credit for creating the first arcade game in 1971. It was called Computer Space and was based on a previous game named Spacewar (CED Magic, n.d.). These gradual developments led Bushnell to the invention of PONG, which is often what the public remembers as the first video game (Wolf, 2008). By 1976, the idea of gaming had proved to be profitable and interchangeable cartridges were made available to the public. Around this period, violence in video games also became more evident.

\section{Violence in Video Games}

In considering the history of violence in video games, it is important to note that violence became a predominant feature fairly early in video game development. It is generally agreed upon that the first video game that was violent enough to warrant public attention was Death Race (Gonzalez, 2010). Death Race was released in 1976 as an arcade game; it was based on the hit movie Death Race 2000 and the purpose was to complete as many hit and runs as possible. Players got points for running over "gremlins." Upon its release, there was such public outcry that the game publisher, Exidy, voluntarily pulled Death Race from store shelves. It is interesting to note that while the business plan was to sell around 1,000 arcade machines of Death Race, the ensuing controversy created more profit. Approximately, 10,000 arcade units were sold (Kent, as cited in Gonzalez, 2010). The next game that caused major concern was Custer's Revenge, which was released in 1982. This game is considered one of the first attempts at "X-rated" adult-oriented games and has the distinction of being the one of the first video games to simulate human copulation (Honeywell, n.d.) In addition to the anti-social behaviors that were reinforced, video gaming in the 1980's and 1990's also featured an emphasis on sharp shooter skills and killing enemies. Mortal Kombat, Doom, and Battlezone are examples of this 
type of video game. Some opponents of first person shooter games, such as David Grossman, have suggested that first person shooter video games were designed to train civilians and soldiers to kill more effectively. Grossman (1995), a military psychologist, wrote a book entitled On Killing: The Psychological Cost of Learning to Kill in War and Society, which concludes with the assertion that social media employs some of the same techniques and strategies that the military uses to train soldiers to kill enemies. The research that supported this book was incorporated into his continuing study of the subject, and he later co-authored another book titled, Stop Teaching Our Kids to Kill: A Call to Action Against TV, Movie and Video Game Violence (Grossman \& DeGaetano, 1999). The premise of this book is that the current social medias are desensitizing children to violence and that violent video games are teaching the mechanics of how to kill efficiently with weapons.

Additionally, fantasy action adventure games that featured character slaying, such as The Legend of Zelda and Assassin's Creed also became increasingly popular. These trends of more violence in video games may have been due in part to greater plot lines and storytelling development from game designers. Along with better storylines came the ability to display increasingly life-like depictions of violence due to breakthoughs in graphics technology (Wolf, 2002). This brings us to the more modern day violent video games, which have been the source of much controversy.

\section{Popular Video Games of the $21^{\text {st }}$ Century}

According to Bill Loguidice, Super Mario Bros., Sims, and Grand Theft Auto are among the most influential video games in history (Loguidice \& Barton, 2009). While Super Mario Bros. and Sims are considered less violent than many other popular games, there are still concerns about the amount of time students spend playing these games as opposed to other 
recreational activities. Grand Theft Auto, on the other hand, has been critized as one of the most potentially harmful video games that students can play due to the anti-social, violent acts that are rewarded in the game. There are numerous versions of Grand Theft Auto, but the storyline remains the same. Because the goal of the protagonist in the game is to rule the criminal underworld through aggression and criminal acts, there are frequent depictions of crime, sex, and illegal activities in the game. While intended for mature audiences, a study conducted by Kutner and Olson (2008) revealed that many students under 18 play games rated for adults. In their research, they discovered that approximately $68 \%$ of middle school aged boys and $29 \%$ of middle school aged girls had played a mature-rated video game frequently during the preceding six months. Furthermore, among the male students surveyed, the Grand Theft Auto series was the most popular. There have been at least two lawsuits involving the designers and distributors of Grand Theft Auto (Mansfield, 2003; Smith, 2005). Recently, The Guiness Book of World Records named the game as the most controversial video game of all time (Guinness World Records, 2009).

\section{Prevalence of Video Games}

Given the evidence that younger students are playing games with inappropriate content, it is important to review the research, which both supports and refutes the concern that students are negatively impacted by playing violent video games. Firstly, there will be an overview of the statistics revealing who plays video games and how often they play, as the frequency of video gaming by elementary students is relevant to this study. There is also information about how parents monitor and restrict video gaming.

American children now spend a significant amount of time playing video games. According to Carnagey, Anderson and Bartholow (2007) in Media Violence and Social 
Neuroscience: New Questions and New Opportunities, American children spend more than five hours per day consuming media such as television, movies, and video games (p. 178). It is noteworthy that this is nearly the same amount of time children spend in the classroom on a daily basis. In 2006, Drs. Gentile and Anderson conducted research that focused strictly on video game usage. According to their research in that year, boys spent on average 13 hours per week and girls spent five hours per week playing video games (Gentile \& Anderson, 2006).

In a developmental context, this brings us to a large gender discrepancy in the history of video game usage and possible negative effects of gaming. Discussion surrounding exposure to video game violence often focuses on the predominance of boys gaming and the bulk of the research conducted has been focused more on male responses to video games and media violence. There has been speculation that girls and women prefer socializing and building relationships over playing video games (Anderson, Gentile, \& Buckley, 2007). Another factor is that the majority of game developers are men, and the nature of video games are possibly more appealing to boys for that reason. Lastly, the violence in video games seems to be enjoyed more by males than females. There does appear to be a growing inclination for females to game; this could be due to marketing responses to female interests in video games (Acuff, 2005).

One of the more commonly referenced sources of video gaming statistics is produced by the Entertainment Software Association (ESA) in the form of an annual report entitled "Essential Facts.” For a number of years the ESA has released the findings of their commissioned studies on video gaming; this association pays the research firm, Ipos MediaCT, to conduct a study on the demographics of gamers and related statistics on an annual basis. The data is compiled from the consumer survey results of approximately 1,200 households in the United States that are considered representative of national households (Entertainment Software Association [ESA], 
2009). One important factor to note is that only the respondents who self-identify as owning a video game console and/or a computer used to play games are included in this study. Another consideration is that the ESA does not publish the methodology used to generate the data for this report, nor are they specific about the age ranges of the participants. The following is an overview of gaming statistics that are applicable to the general U.S population, according to the ESA.

In the 2009 “Essential Facts” report, 68\% percent of American households reported playing video and/or computer games. The average age of a game player in the United States is 35 years and $25 \%$ of gamers were adults over the age of 50 . In terms of gender and gamers, $60 \%$ of game players are male and $40 \%$ are female. This report also showed evidence that gaming is becoming an increasingly social activity. Sixty-two percent of gamers reported play games in the presence of other gamers as a joint activity. The social aspect of gaming appears to be increasing as $59 \%$ of gamers played games with others in 2008 , and $56 \%$ of gamers played with other gamers in 2007 (ESA, 2009).

When looking specifically at the topic of parents and video gaming, 92\% of parents polled in the 2009 survey reported being present at the time of a video game purchase or rental and 94\% of parents reported "always" or "sometimes" monitoring the games their children play. Also, parents reported that they give permission to their children $83 \%$ of the time before purchasing or renting a game. Of the parents represented in the study, $63 \%$ stated that they believe games are a positive part of their children's lives. In terms of controlling the amount of gaming and using parental controls, this data suggest that parents are enforcing limits. Survey results showed that $79 \%$ of parents said they place time limits on gaming and $77 \%$ reported that the parental controls installed on new video game consoles are useful. Parents also report 
playing video games with their children for a variety of reasons: $82 \%$ of parents polled said they believe it is a fun recreational activity; $81 \%$ of parents said they play at their children's request; $78 \%$ said it is a good opportunity to socialize and spend time with their child; and $63 \%$ of parents felt that gaming with their children gives them the ability to monitor game content (ESA, 2009). The ESA recognizes 12 different types of video game genres. These are: action, adventure, arcade, children’s entertainment, family entertainment, fighting, flight, racing, role-playing, shooter, sport games, and strategy. According to research from the NPD group, in 2008 the bestselling genre was action, followed by family entertainment, sport games, and shooter games (ESA, 2009). An additional method of categorizing video games was created in response to the proposed Video Game Rating Act of 1994; the following section provides information on the video game rating system that is currently recognized in the United States.

\section{Rating Systems of Video Games in the United States}

Due to public concern about children's exposure to inappropriate content, the Video Game Rating Act was introduced in 1993. This action was preceded by a joint Congressional Hearing, which was the result of Senator Joe Lieberman's concerns over the seemingly irresponsible actions of the gaming industry. At that time, Mortal Kombat was the subject of an extensive debate due to the very graphic depictions of violence (Kohler, 2009). The game industry was given the directive to design and implement a voluntary rating system within one year of the congressional hearing; otherwise, a commission established by the Rating Act would enforce its own rating system on the industry and the Video Games Rating Act would become a law if passed. The response from the gaming industry was swift and two rating systems were created. Both the Recreational Software Advisory Council (RSAC) and the Entertainment Software Rating Board (ESRB) devised rating systems that were presented for review. 
Eventually, the ESRB rating system was adopted as the standard rating system as it was viewed as the more objective system by both the gaming industry and opponents of violent video games. The initial rating system was loosely based on the movie industry rating system and contained five age-based rating categories (Everyone, Early Childhood, Teen, Mature, Adults Only), which also included content descriptions such as "Blood and Gore.” The system has evolved to include six rating symbols. These include: EC - Early Childhood/ages 3+, E - Everyone/ages 6+, E10+ Everyone/ages 10+, T - Teen/ages13+, M - Mature/ages 17+, and AO - Adults Only/ages 18+ (ESRB, n.d.)

According to one study conducted by Peter D. Hart Research Associates in 2009, 87\% of parents knew about the rating system and 76\% said that they routinely check the rating information before making a video or computer game purchase. Also, a study published by the Federal Trade Commission in 2007 found that $87 \%$ of parents reported being "somewhat” to "very” satisfied with the ESRB ratings. Lastly, the ESRB reported that the Kaiser Family Foundation conducted a study on parental views of media rating systems in 2007 and found that the majority of parents see the value in the ESRB rating system, with $91 \%$ stating that the system with either "very useful” or "somewhat useful” (ESRB, n.d.).

\section{Literature Focus on the Effects of Playing Violent Video Games on Children}

There are strong opinions about whether or not playing violent video games has an impact on children. Research on the topic of both gaming in general and violence in gaming has been ongoing since the introduction of video games, and there have been different types of studies conducted in an effort to gather more information. On one hand, there are researchers who assert that meta-analytic reviews of data and longitudinal studies have shown that playing violent video games does increase aggression and hostility and decreases pro-social behaviors 
(Anderson, Gentile, \& Buckley, 2007; Bushman \& Anderson, 2001). Two of the most vocal opponents and prolific researchers, Brad Bushman and Craig Anderson conducted a metaanalytic review of all of the research on video game violence in 2001 and concluded that, "Indeed, this effect of violent video games on aggression is as strong as the effect of condom use on risk of HIV infection” (p. 357). Their meta-analysis included 33 studies (with a total of 3,033 research participants). When they averaged the effects of all 33 tests, they found statistically significant effects, which supported the hypothesis that playing violent video games increased aggressive behavior. In 2004, Carnagey and Anderson completed a literature review on violent video game exposure and aggression, which provided a summary of previous media violence studies and discussed the differences between viewing violence on television and viewing violence in a video game. They stated:

Because violent video games are a rather new type of violent media, the literature examining its negative effects on players is rather small, but a rather clear consensus has already been reached. This consensus is virtually identical to the conclusions reached in the violent television literature: playing violent video games increases aggression. (p. 7) It is important to note that many of the meta-analyses conducted combine all of the research available, as opposed to grouping the studies based on the age range of the participants. This makes it difficult to discern whether there are developmental differences in the effects of violent video games based on the age of the players. More recent research has focused specifically on the nation's youth. In 2007, Anderson, Gentile and Buckley produced a book entitled, Violent Video Game Effects on Children and Adolescents; Theory, Research and Public Policy. The book was one of the first to summarize the findings of the empirical research to date on the effects of playing violent video games in relationship to children and adolescents. 
In contrast, there have been studies that found no effects on players of violent video games. Particularly in the period between 1990's-2002, there were very discrepant research findings between opponents of video games and those who felt there were no ill effects from playing. In 2001, researcher John L. Sherry conducted a study entitled, “The effects of violent video games on aggression: A meta-analysis,” which asserted that there is a smaller effect of violent video games on aggression than has been found with television violence on aggression. In his article, “Evaluating the research on violent video games,” Jonathan L. Freedman (2001) strongly questions the findings of the previously mentioned Anderson and Bushman study. In his review of their study, he clarifies that out of the 35 studies included in the meta-analysis conducted by these researchers, only nine studies dealt with aggressive behaviors. Additionally he states that because their research was not designed and conducted without fault, it contained far too little evidence to reach firm conclusions. He also posits in the same article that a plausible explanation for findings of increased aggression among those who play violent video games is that "people with a more aggressive personality like violent video games and also engage in more aggressive behavior. Playing the games does not cause the aggression, nor does the aggression cause the preference for violent games. They are both caused by another factorthe person's personality" (p. 3). He is not the first, nor last, researcher to reference the "chicken or the egg” debate, as there have been questions about exposure to violence and whether it leads to aggressive actions well before violent video games were designed.

More recently, Dr. Anderson has responded to those who claim there are no ill effects to children from the violence in video games. In 2004, he wrote an article for the Journal of Adolescence titled, “An update on the effects of playing violent video games.” He states, "Basically, the scientific debate over whether media violence has an effect is over, and should 
have been over by 1975” (Anderson, 2004, p. 114). Anderson lists several reasons why there has been a lack of research specifically on video game violence. He draws particular emphasis to the fact that at the time his article went to press, the U.S. government had not funded any research on the subject. Considering that in 2007, U.S. computer game software sales were at $\$ 9.5$ billion (ESA, n.d.), there are concerns about whether our government appears to condone video games, regardless of ill-effects to players, due to profitability.

A review of more recent studies shows that the debate is still ongoing. Rebuttals of any connection between violent acts and playing violent video games have been offered by numerous researchers (Olson, 2004; Sherry, 2007; Unsworth, Devilly \& Ward, 2007). The research of Chris Ferguson is often referenced by those stake-holders who assert that violent video games do not negatively impact the players. Ferguson wrote an article entitled, "Evidence for publication bias in the video game violence effects literature: A metal-analytic review” in 2007. He states: The search for video game violence effects is a reasonable one. However, researchers must be prepared to test their assumptions and the quality of the data that they are producing. When tragedies such as the Columbine High School shooting occur, it is tempting to look for "scapegoat" answers to a complex problem. It is incumbent on researchers that they not let themselves be side-tracked by a prior hypothesis that may distract the scientific community and the general public from the real biological, social and family influences on violent behavior. (p. 481)

The research team of Kutner and Olson have also published findings that suggest that there is no conclusive evidence that playing violent video games increases aggressive acts. In their book, Grand Theft Childhood; The Surprising Truth about Violent Video Games and What Parents Can Do, one of the authors states: 
I have read nearly all the published English-language research on electronic games, which includes video and computer games, CD Rom and online games. Neither the quantity nor the quality of research on video games does much to inspire confidence in solid conclusions about their effects (Kindle location 1049-57, Kutner \& Olson, 2008) It seems safe to state that there will be continued disagreement over if and how violence in video and computer games impacts elementary aged children. As increasingly sophisticated methods of data collection and measures of violence and aggression are created, more information will be available to assist researchers, parents, educators and other stake-holders in making informed decisions. In recent conversations on this topic of opposing "camps", it was noted that if the researchers themselves can't agree on any conclusions, then it is very challenging for educators, parents, and the general public to do so. Specifically, the debate between researchers centers on the magnitude of effects, unstandardized aggression measures, inclusion criteria for studies included in meta-analyses, and the interplay of complex variables that may strengthen an individual's penchance for violent video games (Ferguson, in press). While researchers continue to study and explore these aspects, there is agreement that it is important to strive towards a more complete and accurate understanding of how playing violent video games may impact individuals both in the short term and in the long term (Bushman, Rothstein \& Anderson, 2010). As the body of research continues to grow on this important topic, studies such as this one will contribute to an increased understanding of the impact violent video games may have on children.

\section{Literature Focus on Violence Prevention Programs}

Most people view our schools as safe havens from harm. Given the amount of time students spend in schools compared to the amount of documented violence that occurs there, that 
perception is warranted. During the formative years of our nation's public education system, there were few documented concerns about schools being unsafe. Around the mid-20th century, the focus on violence started to sharpen. Some have attributed the increase in aggression in schools to the widespread viewing of television, which was introduced to society in the 1950's. At any rate, by 1974 Congress mandated a national study of school violence. The results from that study eventually led to the Safe Schools Study conducted by the National Institute of Education (NIE) in 1986 (Flannery, 1997). The trend in studying best practices in violence prevention in schools continues growing due to some recent tragedies. While some individuals feel strongly that playing violent video games contributed to some of the recent school shootings, there is no conclusive evidence to support that assertion. However, implementing violence prevention programs seems to be a preventative measure that is warranted given the current climate in some of the nation's schools. Unfortunately, in recent years, injuries and even deaths on school grounds have become more commonplace. To combat this trend, violence prevention programs have become a proposed panacea. Due to the highly covered incidences of school violence, like Dublane, Columbine, Virginia Tech, etc., educators and parents alike have demanded that educators focus on conflict resolution and violence prevention in our schools (Hoagwood, 2000).

The aim of violence prevention programs is to avert these tragedies, and traditionally school counselors are responsible for implementation of these programs via guidance curricula and classroom lessons. They also serve as facilitators and trainers for adult staff members. Given the elementary school counselor's role in crisis management, violence prevention, and creating a culture and climate of respect, it is important to examine some of the frameworks and programs used to support these goals. Because school counselors are expected to take a 
leadership role in the selection and implementation of an appropriate violence prevention program, they need to understand theoretical models that shape these programs.

\section{Theoretical Framework of Violence Prevention Programs}

According to Park-Higgerson, Perumean-Chaney, Bartolucci, Grimley, and Singh (2008).

there are several variations on the theoretical training models on which many violence

prevention programs are based, but most programs share common core statements that shape

them. One of the first challenges in considering violence prevention is agreement on the definition of "violence" in the context of the school environment. Examples of types of violence include: physical, sexual/gender, media, and cultural/racial. By understanding categorization and what constitutes violence, there are more appropriate measures to prevent it from occurring. Another challenge lies in whether the school system and stakeholders accept the responsibility of full implementation of the program and thorough training of those who will be utilizing it. Finally, a firm understanding of the components and strategies that comprise the violence prevention programs are critical considerations given the needs of the students. Because many violence prevention programs are based loosely on the terminology of the public health field, it is important to train the educators who will be implementing the programs on the terminology and concepts. Typically, interventions are commonly referred to as being primary, secondary, and tertiary. This aligns neatly with the common structure of elementary guidance curriculum, which has three main components: classroom guidance lessons, small group guidance and individual student planning (American School Counselor Association [ASCA], 2003). Counseling theorist, D’Andrea (2004) offered another interpretation or framework of violence prevention programs when they proposed the idea that there are four main service components: direct student services, direct school services, indirect student services and indirect school services. Again, this aligns 
well with most student services offered in a comprehensive elementary school counseling program.

\section{Objectives of Violence Prevention Programs}

Researchers and educators often identify and agree upon the main service components of violence prevention programs and the levels of intervention, yet there is not agreement about best practices and what constitutes an exemplary violence prevention program. Until recently, there seemed to be a consensus that most of the programs that are rated as worthwhile and effective are derived from cognitive behavioral principals (Guerra, Boxer, \& Kim, 2008; Wilson, Lipsey, \& Derzon, 2003). However, a recent meta-analysis conducted by Park-Higgerson, et al. (2008) contradicts previous findings about the effects of theory-driven violence prevention programs. Their study showed that non-theory based interventions had a slightly stronger effect than theory driven programs. Even though there is conflicting data on which theoretical models of violence prevention are most effective, for the most part, violence prevention programs are a beneficial addition to school counseling curricula.

There was very little reference to media violence and more specifically, video game violence in the most popular violence prevention programs. One of the only sources of information about media violence in the context of creating safer learning environments is the second edition of the Guide for Preventing and Responding to School Violence. This document is produced by the Bureau of Justice Assistance (n.d.) and includes a section with recommendations for executives in media industries, including electronic games. Specifically, it suggests that: video games should depict the actual consequences of violence instead of rewarding and glorifying violence; games should not be produced that will most likely contribute to the anti-social or violent acts by youth; and games should be developed that promote positive 
rather than negative social interactions and values. While these recommendations represent an ideal, given the current popularity and profitability of violent video games, it may be more realistic to educate school counselors about the potential negative effects of childhood exposure to violent video games. The best case scenario would be that well-trained school counselors could incorporate elements of media violence awareness into established violence prevention programs (Perkins, Brumfield, Collins, \& Norris, 2010).

In conclusion, this literature review serves to reinforce the premise that there is research that remains to be conducted on this specific topic. As the public discourse on gaming continues to grow, there is a need for scholarly resources and empirical studies that will assist in working with students who play violent video games. 
CHAPTER III

\section{RESEARCH DESIGN}

This chapter outlines and describes the data sources and methods of analysis that were used to examine elementary school counselors’ perceptions of students' exposure to violent video games. Specifically, this chapter contains the following sections: 1) population and sample of survey respondents, 2) survey instrument design and development, 3) survey procedures, 4) description of survey respondents, 5) description of interview participants, 6) interview protocol development, 7) interview procedures, and 8) data analysis. A brief introduction about the methods of data collection and protocol precedes these sections and pertinent information about mixed methods studies concludes this chapter.

\section{Methods of Data Collection}

The purpose of this preliminary study was to explore elementary school counselors’ perceptions of working with students exposed to video game violence. The importance of exploring participants' views for both common themes and divergent conceptions is the foundation of this unique contribution to the fields of both counselor education and curriculum and instruction. This process is largely inductive by nature and accomplished by asking openended questions and facilitating dialogue among participants, followed by deductive analysis, which creates a holistic and spiraling interpretation towards a bigger picture. A mixed methods study was chosen for a variety of reasons. The topic of study was born out of training and a discipline in the social sciences. As Creswell (2003) states in his book, Research Design:

These procedures developed in response to a need to clarify the intent of mixing quantitative and qualitative data in a single study (or program of study). With the inclusion of multiple methods of data and multiple forms of analysis, the complexity of 
these designs calls for more explicit procedures. These procedures also developed in part to meet the need to help researchers create understandable designs out of complex data and analyses (p. 208).

Mixed methods/descriptive studies have been used successfully in situations where there is reason to explore a research problem and explain what is already known about the phenomena being studied. For the purposes of this study, surveys are appropriate because they describe participant experiences, while the interviews examined feelings and opinions associated with those experiences. Thus, there was a legitimate reason for gathering quantitative data in the form of survey responses, which could show general trends relevant to demographics. Survey responses were also categorized to elucidate counselor beliefs because this remains a new topic of study. For further examination into the topic, individual interviews provided qualitative data and the opportunity to explore more deeply the personal experiences and concerns as voiced and expressed by the participants.

A self-report survey and interview protocol were designed expressly for the purpose of examining elementary school counselor demographics and experiences. These two data collection tools were created in response to the overarching questions and main concepts that guided this study. The intent was to discern what elementary counselors are thinking, observing and doing in relation to student exposure to violent video games. All protocols required by the Institutional Review Board (IRB) to ensure confidentiality were followed. An email containing the informed consent, instructions, and the link to the survey were sent to membership services in four professional counselor organizations.

There were two forms of data collection. The first form of data was the online survey created by the researcher using SimpleForms (see Appendix A). This then naturally led to the 
second phase of the data collection, which was the development a flexible interview protocol (see Appendix B). For this reason, there are elements of both emergent design flexibility and purposeful sampling in the design strategy itself. This strategy calls for open-ended, conversational interviews to determine emerging themes as opposed to using a script with predetermined responses. The data collection and fieldwork techniques flowed naturally towards recognition of personal experience and engagement with the participants in a very authentic way. As suggested by Patton (2002), empathetic neutrality and mindfulness when interviewing are hallmarks of good qualitative inquiry. At both stages, the researcher made every effort to preserve confidentiality and anonymity to adhere to the guidelines set by the IRB.

\section{Description of Population}

The population for this study consists of state certified elementary school counselors who hold membership in one or more professional counseling organizations at the state, national and/or regional level. The sample was generated from current participation and membership in the following associations: American School Counselor Association (ASCA), Virginia Counselors Association (VCA), West Virginia Counseling Association (WVCA) and Apple Valley Counselors Association (AVCA).

Following is a description of the professional counseling associations chosen for the purpose of recruiting volunteers. ASCA is a division of the American Counseling Association (ACA), and has a membership of over 25,000 school counseling professions. Members span across all educational levels, including pre-K through college. ASCA is known for its theme of one vision and one voice for school counselors and is the premiere professional resource and membership organization for school counselors (http://www.schoolcounselor.org). The researcher became a moderator for the elementary school counselors' group forum and posted 
the IRB approved letter (see Appendix C) to forum members to seek volunteers to complete the survey.

The Virginia Counselors Association (VCA) is a state branch of the American Counseling Association (ACA) and is made up of various types of counselors, including community counselors, therapists, licensed professional counselors and school counselors. It was founded in Richmond in 1930 and the focus of the organization is to meet the needs of Virginia counselors who work in a variety of settings. VCA divides its membership into specialty divisions to meet specific needs of different types of counselors. There are currently nine divisions, which cater to a variety of counseling specializations. Additionally, there are 19 chapters that make up regional counselors' associations (http://www.vcacounselors.org). Permission was given to the researcher to contact local chapter presidents to disseminate the IRB approved letter.

For the recruiting purposes of this study, the division of particular interest was the Virginia School Counselor Association (VSCA), which serves over 1,200 counselors who work with K-12 students. VSCA was founded in 1962 and serves a varied group of counselors, including counselor educators, graduate students, school division supervisors, and counselors working in public and private K-12 schools and post-secondary settings. The focus of VSCA is both professional development/resources and legislative representation. They host an annual conference that is specifically geared towards meeting school counselor needs and providing networking and support opportunities. VSCA has five divisions based on work settings, which are: elementary, middle/junior high, secondary, post-secondary and student (http://www.vsca.org). The researcher attended the 2010 annual conference for the purpose of professional development and to seek participants. By attending the elementary school 
counselors' division meeting at the conclusion of the conference, email addresses were collected from those individuals who expressed an interest in the study after seeing the IRB approved advertisement (see Appendix D). After receiving IRB approval, the approved letter and survey link were emailed to conference attendees who provided contact information.

The West Virginia Counseling Association (WVCA) is a smaller organization than the Virginia Counselors Association. For this membership year, there are approximately 100 members. Due to the decreased number of members, this is a very intimate and close-knit community of counselors. The organization is celebrating over 58 years of service and features an annual conference, which was attended by the researcher in the past year (http://wvschoolcounselor.net). The IRB approved letter explaining the purpose of the study and the advertisement was sent to the President-elect who volunteered to forward the email to elementary school counselors who were WVCA members. As she is a resident of the Eastern Panhandle of West Virginia, she mentioned that it was most likely that local elementary counselors in her region would respond to the invitation to participate as opposed to elementary counselors in other regions of the state.

Apple Valley Counselors Association (AVCA) was chartered in 1969 and is comprised of community and school counselors from Clarke County, Frederick County, Rappahannock County, Warren County, and Winchester City Public Schools. The current president is a practicing elementary school counselor and a practicing licensed professional counselor; there are 6 current board members, including the researcher. Permission was received from the president to use the current membership list to email AVCA elementary school counselor members the IRB approved letter and the link to the SimpleForms survey. Additionally, the Guidance Directors from both Warren County and Winchester City Schools were emailed the 
information for dissemination as they are both members of AVCA and oversee the elementary school counselors in their districts.

\section{Survey of Elementary School Counselors}

\section{Survey Instrument Design and Development}

Because no instruments on this specific topic existed, a self-report survey was created by the researcher. The survey was designed to be completed online and was developed using SimpleForms, a web-based software endorsed by the West Virginia University Office of Information Technology. The purpose of the survey was to gain insight into general trends and data about counselors' familiarity and perceptions about violent video games played by students. The questions were designed and constructed to gather demographic information about possible interplay between age, experience, and perceived resources and to examine perceptions about the popularity of certain games. Additionally, there was the intent to determine what types and forms of training and professional development may benefit elementary counselors who articulated concerns about student behaviors due to violent video game exposure. Lastly, the survey helped identify potential interview participants and follow up questions.

The survey questions evolved out of the researcher's experience as an elementary school counselor and immersion in the topic of the study. The questions were specifically designed based on the literature review in order to ensure content validity and relevance. Once the content

of the survey questions was aligned with the findings from the literature review, steps were taken to insure inter-rater reliability. Specifically, a panel of three experts consisting of a counselor supervisor who serves as faculty in a school counseling preparation program, a currently practicing elementary counselor, and a public school guidance director reviewed and gave 
suggestions, which helped establish inter-rater reliability and validity of the survey tool. Their feedback also assisted in addressing potential coding limitations.

The online survey was composed of three sections. The first section consisted of a series of demographic and context questions (e.g. gender, ethnicity, years of experience, employment information, teacher training, computer literacy, school information, and number of students in their school). The next section was composed of Likert scale questions (ranging from $1=$ strongly disagree to 5 = strongly agree) specifically designed to probe school counselor perceptions about student exposure to violent video games. This section was also designed to discover frequency counts about the games students typically reference or play. The names generated for recognition were based on internet searches of the most popular video games currently played in the United States. These questions were also chosen based on the researcher's previous experience as a practitioner and questions that remain unanswered or unasked in the review of literature; specifically, information about the frequency of gaming, behavioral changes and professional development opportunities was lacking in the literature review . The final section contained open-ended prompts, which allowed school counselors to elaborate and explain their perceptions and opinions in more detail. The purpose of using self-report surveys was to generate ordinal data, which will serve as a baseline to assess the initial formative analyses of elementary school counselor perceptions of working with students who play violent video games. T-tests and basic statistical quantities were calculated using mean, median, and standard deviation when interpreting the survey results. In this case, the survey results functioned as an initial barometer about elementary school counselors' awareness in regard to working with students who have been exposed to video game violence. 


\section{Survey Procedures}

This study was submitted to the West Virginia Institutional Review Board using the online application, once the doctoral chair reviewed the application and instruments. After approval was given by the West Virginia University Institutional Review Board, the researcher contacted four organizations in order to solicit participants for the study. These four organizations were chosen because they represent national, state and local professional memberships. The researcher sent emails explaining the nature of the study and asked for permission to seek qualified volunteers. Initial emails were sent to the members' forum moderator on the American School Counselor Association website, Executive Director of the Virginia Counselors Association, President-Elect of the West Virginia Counseling Association and the President of the Apple Valley Counselors Association. Once permission was received, the IRB approved advertisement was emailed or posted to potential volunteers who were members of the previously mentioned professional organizations.

\section{Description of Survey Participants}

The participants were those elementary school counselors who received the advertisement due to their professional membership and submitted the online survey using SimpleForms. Many of the participants had given the researcher their contact information at the 2010 Virginia School Counselor Association Conference and requested an email with a link to the survey. There were approximately 60 links to the survey emailed upon request. A total of 31 elementary school counselors took the survey. Per IRB requirements, all names have been omitted to preserve anonymity. 
Table 1

Survey Participant Demographic Information

\begin{tabular}{|c|c|c|c|c|}
\hline Number & Gender & Ethnicity & Age & $\begin{array}{c}\text { Years of Experience as an } \\
\text { Elementary School Counselor }\end{array}$ \\
\hline 1 & Female & Caucasian & 25 & 1 year \\
\hline 2 & Female & African American & 28 & 3 years \\
\hline 3 & Female & Native American & 42 & 8 years \\
\hline 4 & Female & Caucasian & 58 & 15 years \\
\hline 5 & Female & Caucasian & 34 & 10 years \\
\hline 6 & Female & African American & 33 & 6 years \\
\hline 7 & Female & Caucasian & 25 & 1.5 years \\
\hline 8 & Female & Caucasian & 30 & 7 years \\
\hline 9 & Female & Caucasian & 34 & 8 years \\
\hline 10 & Female & Other & 45 & 7 years \\
\hline 11 & Female & Caucasian & 52 & 20 years \\
\hline 12 & Male & Caucasian & 28 & 2 years \\
\hline 13 & Female & Caucasian & 25 & 2 years \\
\hline 14 & Female & Caucasian & 36 & 8 years \\
\hline 15 & Female & Caucasian & 31 & 5 years \\
\hline 16 & Female & Caucasian & 57 & 8 years \\
\hline 17 & Female & Caucasian & 32 & 7 years \\
\hline 18 & Female & Caucasian & 46 & 20 years \\
\hline 19 & Female & Caucasian & 33 & 7 years \\
\hline 20 & Female & African American & 28 & 1 years \\
\hline 21 & Female & Caucasian & 29 & 3 years \\
\hline 22 & Female & Caucasian & 28 & 4 years \\
\hline 23 & Female & Caucasian & 59 & 34 years \\
\hline 24 & Female & Caucasian & 39 & 2 years \\
\hline 25 & Female & Caucasian & 28 & 3 years \\
\hline
\end{tabular}




\begin{tabular}{|c|l|l|c|c|}
\hline 26 & Female & Caucasian & 36 & 11 years \\
\hline 27 & Female & Caucasian & 54 & 11 years \\
\hline 28 & Female & Caucasian & 56 & 11 years \\
\hline 29 & Female & Caucasian & 33 & 5 years \\
\hline 30 & Female & Caucasian & 59 & 36 years \\
\hline 31 & Female & Caucasian & 53 & 22 years \\
\hline
\end{tabular}

The demographic data of Table 1 show that there were one male and 30 female participants in this study. Twenty-six were Caucasian, three were African American, one was Native American and one participant chose "Other." The participants ranged in age from 25 to 59 years of age. The range in experience as an elementary school counselor was one year to 34 years of experience.

\section{Interview of Selected Participants}

\section{Description of Interview Participants}

The researcher asked survey respondents to identify whether they were willing to be interviewed as the last question on the survey. Participants who were willing to be interviewed were asked to submit contact information so that the researcher could schedule a time for an individual interview. The interviewees were selected based on their agreement to participate; 10 survey respondents volunteered to be individually interviewed and these volunteers were emailed an IRB approved interview request (see Appendix E), which stated that interviews would take place either in person, by phone, or using technology such as Skype or Adobe Connect. The purpose of interviews was to gather more detailed information from these individual elementary school counselors who had completed the survey. Nine of the 10 volunteers participated in interviews for this study; one volunteer had schedule conflicts which prevented her from being 
able to complete the individual interview even though she had agreed to participate. Following is a synopsis of their professional qualifications and demographics.

Table 2

Interview Participant Demographic Information

\begin{tabular}{|c|l|l|c|c|}
\hline Label & \multicolumn{1}{|c|}{ Gender } & \multicolumn{1}{|c|}{ Ethnicity } & Age & $\begin{array}{c}\text { Years of Experience as an } \\
\text { Elementary School Counselor }\end{array}$ \\
\hline A & Female & Caucasian & 33 & 5 years \\
\hline B & Male & Caucasian & 28 & 2 years \\
\hline C & Female & Caucasian & 59 & 11 years \\
\hline D & Female & Caucasian & 36 & 3 years \\
\hline E & Female & Caucasian & 28 & 11 years \\
\hline F & Female & Caucasian & 56 & years years \\
\hline G & Female & Caucasian & 59 & 11 years \\
\hline H & Female & Caucasian & 25 & 54 \\
\hline I & Female & Caucasian & & \\
\hline
\end{tabular}

Elementary School Counselor A has five years of experience as an elementary school counselor and is a member of various professional organizations. Prior to becoming a school counselor, she was a high school teacher for two years. She works in a Virginia school district and has served in a leadership role in local professional organizations. She is 33 years old.

Elementary School Counselor B holds state certification in West Virginia and Virginia. He completed his second year as a counselor in June, 2010 and he currently works in a Virginia school District. He is a member of the state counseling association. He is 28 years old.

Elementary School Counselor C has two Master’s degrees with specialization in deaf and blind populations. She has a total of 36 years of teaching and counseling experience and 
currently works in a rural school in Virginia as well as adjunct faculty at a local University. She is also an executive board member in a local counselors association. She is 59 years old.

Elementary School Counselor D is both a certified school counselor in Virginia and also a National Certified Counselor. She worked in a West Virginia school district for two years and then has spent the last 9 years working in a Virginia school district. She is currently on maternity leave and does not intend to return to school counseling for the 2010-2011 school year. She is 36 years old.

Elementary School Counselor E is also both a certified school counselor in the state of Virginia and a National Certified Counselor. She has worked as an elementary school counselor in a Virginia school district for 3 years and is very involved in both state and local counselors associations. She has also been published in several professional journals. She is 28 years old.

Elementary School Counselor F has worked in private and public school settings as both a teacher and a counselor. She has 11 years of counseling experience and serves on the board of her local counseling association. She is also serves on an advisory board for a private preparatory K-8 school and is active in educational organizations. She is 56 years old.

Elementary School Counselor G is the most senior school counselor in her district. She was one of the first individuals to receive a Master's degree in School Counseling in her home state and has worked as a school counselor for 34 years. She has remained at the same school site for 20 years. She is 59 years old.

Elementary School Counselor H works in an urban school district in Virginia. She is completing her second year as a school counselor and is immersed in developing a strong school counseling program for her school and honing her professional skills. She is 25 years old. 
Elementary School Counselor I has 11 years of experience as a school counselor. She works in a rural school district in Virginia. Prior to completing her Master's degree in school counseling, she worked closely with school district personnel as a social worker. She is 54 years old.

In summary, the individual interview participants' demographics closely resembled the survey participants' demographics in terms of age, experience, and school sites. There was no discernable difference in the participants on the two groups, in terms of the variables analyzed. The only assumption that can be made is that these specific counselors who completed the survey and agreed to be individually interviewed were interested in sharing their perspectives on this topic.

\section{Interview Protocol Development}

The interview protocol was developed to gather more information on the topic at the request of the doctoral committee (see Appendix B). The researcher designed a semi-structured script, which was specifically intended to facilitate an examination of the survey questions in much greater depth. In addition, each question was constructed to address the original research questions and there were stages of development and refinement that occurred through numerous conversations with doctoral committee and cohort members, elementary school counselors and counselor supervisors.

\section{Interview Procedures}

Survey respondents received an IRB approved invitation to participate in an individual interview with the researcher (see Appendix E). Those survey respondents who agreed to be interviewed became the individual interview participants. They were asked a series of openended, flexible prompts that gave them the opportunity to discuss their experiences in working 
with students who play violent video games. Most of the prompts were worded to gather information about their responses to students who initiate conversations about video game violence and their perceptions of the actions and behaviors of these students. Furthermore, they were asked for information about resources, and training/professional development suggestions were solicited. There were also exploratory prompts included in the flexible interview script. The responses provided a primary data source and were invaluable in terms of the deeper knowledge generated from the interviews. All interviews were audio-taped and/or archived and were transcribed verbatim.

Interview transcripts and documented responses were substantiated in a variety of ways. First, all individual interview participants were given the opportunity to review their transcripts. Also, some of the counselors pulled their counseling logs or discipline referrals during the interview to verify and confirm their perceptions. Another counselor referenced her state standards for school counselors in regard to mental health issues with students that showed deficits in social skills. Yet another counselor spread out all of her professional development handouts and resources in order to confirm that no training had been available on the topic of the study. Lastly, informal conversations and field notes provided sources of secondary data.

\section{Data Analysis}

Data was collected during the spring semester of 2010 through both the online surveys and semi-structured interviews. All interviews were tape recorded and transcribed verbatim, and field notes were written during each interview. As previously mentioned, data at the school district level and building level were also used to triangulate the data. The researcher used both inductive and deductive approaches during the data collection, focusing on emerging themes and categories. In the beginning stages of categorization, the researcher adhered to principles of 
grounded theory and relied mostly on an inductive approach based on the previous work of Strauss and Corbin (1990). As the categories grew in complexity and layers, a deductive approach was used to further classify and add subcategories and themes.

Throughout the entire process of data collection, the goal was to accurately capture and portray the participants' experiences without judgment or bias. This allowed for examination of both commonalities among the participants' perceptions and divergent views of the phenomenon being studied. Expectations of what the data would eventually reveal were set aside and immersion in the world of the participant occurred, which created a tone of discovery and critical analysis. Interviewing the participants using authentic, relevant language allowed for open and thoughtful discussion about the topic to ensue. The researcher summarized the major themes and trends, using individual quotes that were particularly revealing and/or powerful. While the online survey provided needed and pertinent information about the topic of the study and served as the foundation for the study, the individual interviews provided substantive clarification.

\section{Methodology Framework}

The information collected from this research specifically attempts to capture and portray the voices of the participants. The study is a testimony to pragmatism and the practical application of theory; it is an effort to examine real world issues and explore the value of elementary school counselors' perceptions in regards to working with students who are exposed to violent video games. Grounded theory is the primary approach, which supports the conceptualization of this research topic. Glaser and Strauss (1967) developed the term in the 1960s in response to their belief that theories were born out of observations. Grounded theory is based on the premise that initial research questions about an observed phenomenon will generate common themes, given that the questions themselves are not completely inflexible. Once initial 
themes and categories begin to emerge through open coding, then further elucidation of the subcategories becomes apparent. With that approach in mind, there is an emphasis on flexible inquiry as the researcher's understanding deepens in response to gaining knowledge through the participants’ voices. Elementary school counselors were selected because their particular perceptions are information-rich and allow for insight into violent video game exposure. The primary data sources were archived records of the self-report surveys and transcripts of interviews. These sources were used to create charts conducive to analysis and visual representation of the data.

This study is unique in that it focuses specifically on elementary school counselors' perceptions of working with students exposed to violence in video games. Previous studies have been done on educators in general and there has been research about exposure to both media violence and video game violence from a developmental perspective, but there has not been a published study on this particular intersection. The research conducted in this study centered on surveys and interviews, which were analyzed for common themes and patterns. The researcher acknowledges that these themes were defined and elaborated upon through an interpretive lens; however, this is appropriate given the nature of the study. There is support for the researcher's connectedness to the study when considered in the context of heuristic inquiry and her eight years of experience as an elementary school counselor. Referencing Patton's (2002) description of this type of qualitative method helps clarify the appropriateness of this choice. He states:

The uniqueness of heuristic inquiry is the extent to which it legitimizes and places at the fore these personal experiences, reflections and insights of the researcher. The researcher, then, comes to understand the essence of the phenomenon through shared reflection and inquiry with coresearchers as they also intensively experience and reflect 
on the phenomenon in question. A sense of connectedness develops between researcher and research participants in their mutual efforts to elucidate the nature, meaning, and essence of a significant human experience. (p. 108)

The researcher drew upon professional training as a certified counselor and over 13 years of experience in a combination of K-12 and higher education settings to develop the instruments; assistance from committee members and professional colleagues was also incorporated during this process. Both the online survey and the interview protocol were designed specifically to address each research question, which provided the primary data source for the study.

The analysis strategy consisted mostly of analysis and synthesis in an effort to isolate important themes, patterns and interrelated perceptions and to also examine outliers or differing ideas. In the end, through exploration, a multi-faceted, multi-layered understanding is articulated and shared. There is a growing body of researchers who legitimize this type of conceptual approach (Lincoln \& Guba, 2000; Shwandt, 2000; Neuman, 2004). This strategy of analysis yielded rich data and is discussed in the next chapter. 


\section{CHAPTER IV}

\section{RESULTS}

This study examines elementary school counselors' perceptions and observations about the phenomenon of violent video game playing as it relates to their students. The research methodology was based on the following six research questions:

1. When elementary school counselors encounter student generated discussions of video games, what are the most frequently mentioned game names and game activities?

2. What do elementary school counselors observe students saying and/or doing that may be related to playing violent video games?

3. How do elementary school counselors respond when students initiate conversations about violent video games?

4. How do elementary school counselors respond to actions and behaviors that appear to be related to playing violent video games?

5. What kinds of professional development do elementary school counselors see as valuable in helping to work with students who play violent video games?

6. Is demographic data generated by elementary school counselors related to how they answer survey and interview questions?

\section{Overview of Data Collection and Analysis}

Data collection for this study began in the spring of 2010. A total of 31 surveys were completed by volunteers and nine participants were individually interviewed. All participants in both the surveys and interviews were selected as they are certified elementary school counselors. The primary data sources were the survey results collected through the WVU webservices platform (SimpleForms), and the recorded and transcribed individual interviews. Additionally, 
secondary data sources were examined, such as the researcher’s field notes and written reflections, professional development training manuals, counselor logs, discipline referrals, and school counseling standards.

\section{Survey Data Collection and Analysis}

The initial coding for the survey results began by exporting the SimpleForms report to an Excel spreadsheet and examining the various columns and rows for commonalities and outliers. The results showed a variety in both the age of participants and years of experience, which supported the choice of participant selection. Systematically working through each column and comparing the answers of the participants allowed for the formulation of overarching themes and impressions of the survey data. Discussion with the previously mentioned panel of experts yielded consensus about comparisons between different fields and trends, and themes began to emerge more fully using visual representations and charts. Overall, discernable trends could be traced to demographic data and to the survey respondents as a whole group.

Due to the population of school counselors in this geographic region, the survey participants were fairly homogenous. In terms of gender, only one male completed the survey. In terms of ethnicity demographics, 26 (84\%) of the respondents were Caucasian, three (10\%) were African American, one (3\%) was Native American and one (3\%) self identified as “other.” The next step was to examine the responses through frequency counts and apparent correlations.

Working systematically in order of the questions asked in the survey, some data emerged rapidly providing demographic information about the participants. 


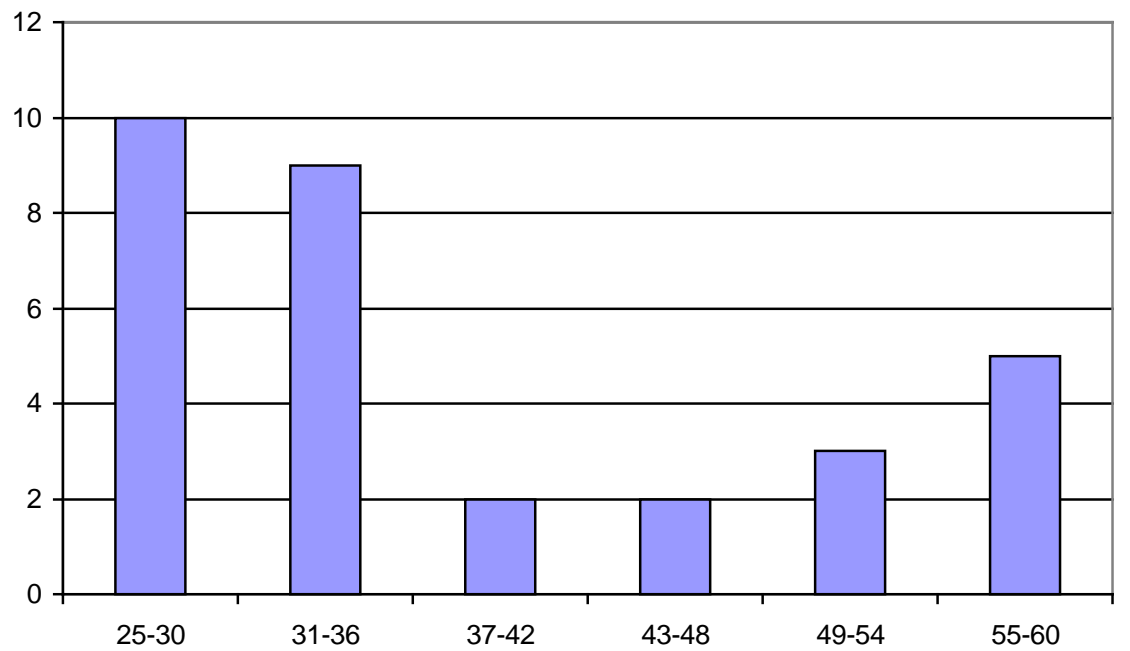

Figure 1: Age ranges of online survey participants.

As far as the age ranges, 10 participants (32\%) were in the 25-30 age range, nine participants (29\%) were in the 31-36 age range, two participants (6\%) were in the 37-42 age range, two participants (6\%) were in the 43-48 age range, three participants (10\%) were in the 49-54 age range and five participants (16\%) in the 55-60 age range.

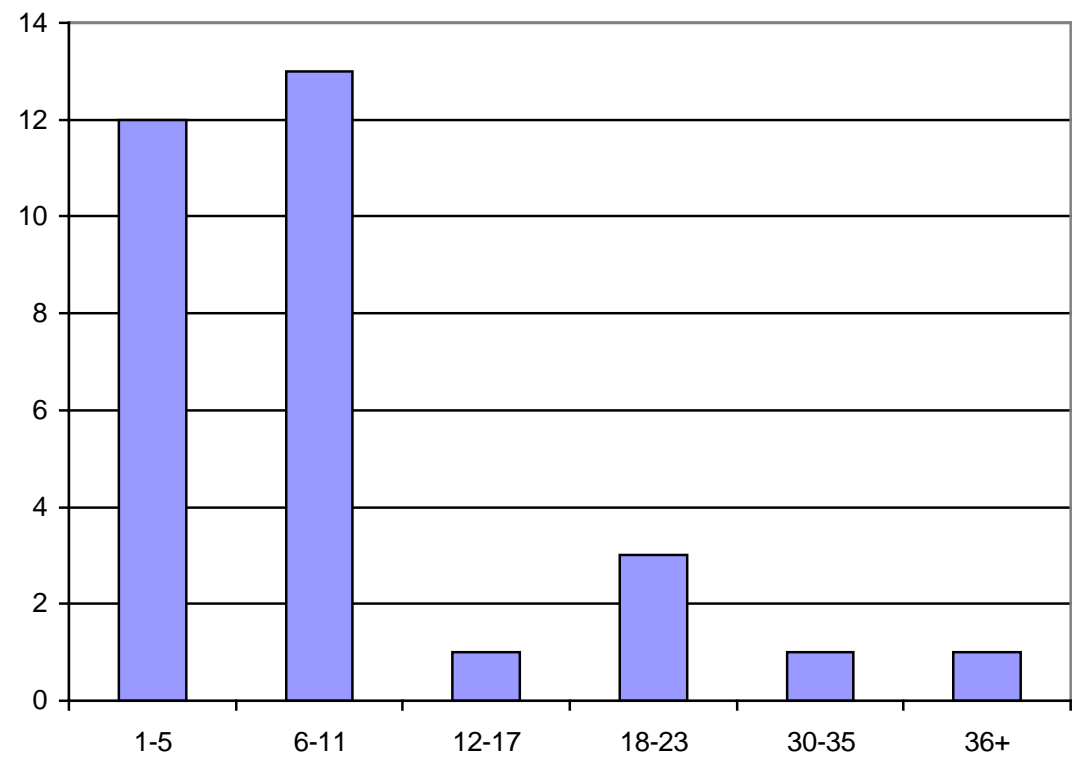

Figure 2: Online survey participants' years of work experience as an elementary school counselor. 
In terms of the amount of experience working as an elementary school counselor, the range in years of survey participants' experience was 1-36 years, with the average for the group being approximately 9-10 years of experience. Twelve of the participants (39\%) had 1-5 years of experience, 13 of the participants (42\%) had 6-11 years of experience, one participant (3\%) had 12-17 years of experience, three participants (10\%) had 18-23 years of experience, one participant (3\%) had 30-35 years of experience and one participant (3\%) had 36 years of experience.

Twenty-eight of the survey respondents (90\%) were currently working as elementary school counselors and nine of the participants (29\%) have worked previously as a secondary school counselor. Additionally, almost half of the participants (14 out of 31) have previously been employed as a K-12 school teacher. There was a mix of school site descriptions, with 15 responses (48\%) indicating a suburban school setting; nine participants (29\%) identified their school setting as urban and seven participants (23\%) identified their school setting as rural. The approximate number of students enrolled in the schools where the participants work range from 200 students per building to 900 students per building. Given the wide range in terms of the counselor caseloads and job duties, and it is not easily ascertainable as to how the number of students in a building may have impacted survey responses. 


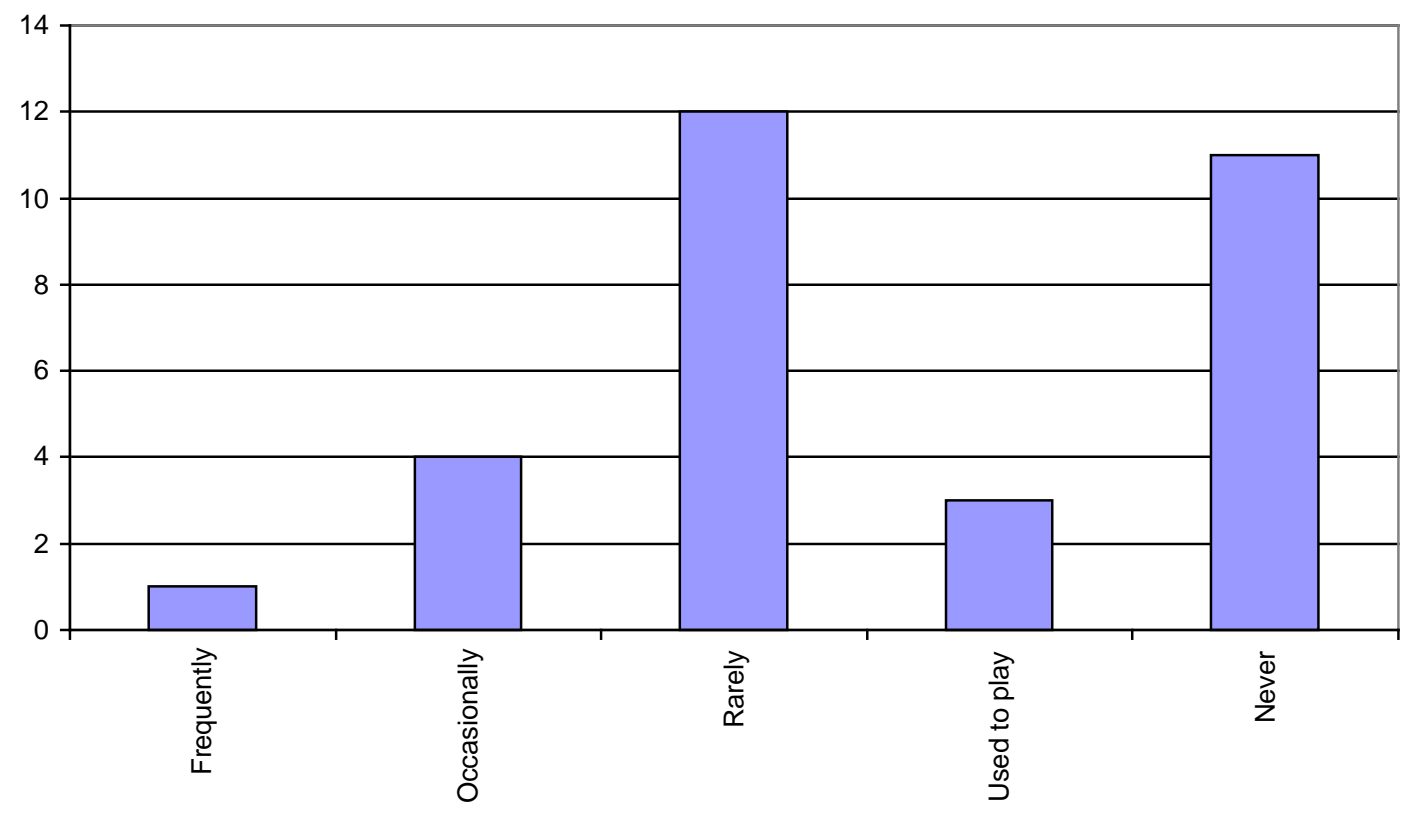

Figure 3: Online survey participants' frequency of gaming for recreation...

In terms of personal video gaming, 11 of the respondents (35\%) stated that they never play video games, 12 participants (39\%) said that they rarely play video games, four participants (13\%) said that they occasionally play video games, one participant (3\%) stated that she frequently plays video games and three participants (10\%) used to play video games but don’t currently play them. Of the video games that elementary school counselors do play personally, Wii Fit and Wii Sports were the two most frequently mentioned games, followed by Super Mario Bros.

\section{Survey Responses Aligned to Research Question 1}

In an effort to address research questions about popularity of video games among students, participants were given the opportunity to rate the statement, "Playing video games is a common activity in my student population.” Twenty-eight participants strongly agreed with the statement, and two agreed. There was one non-response. 


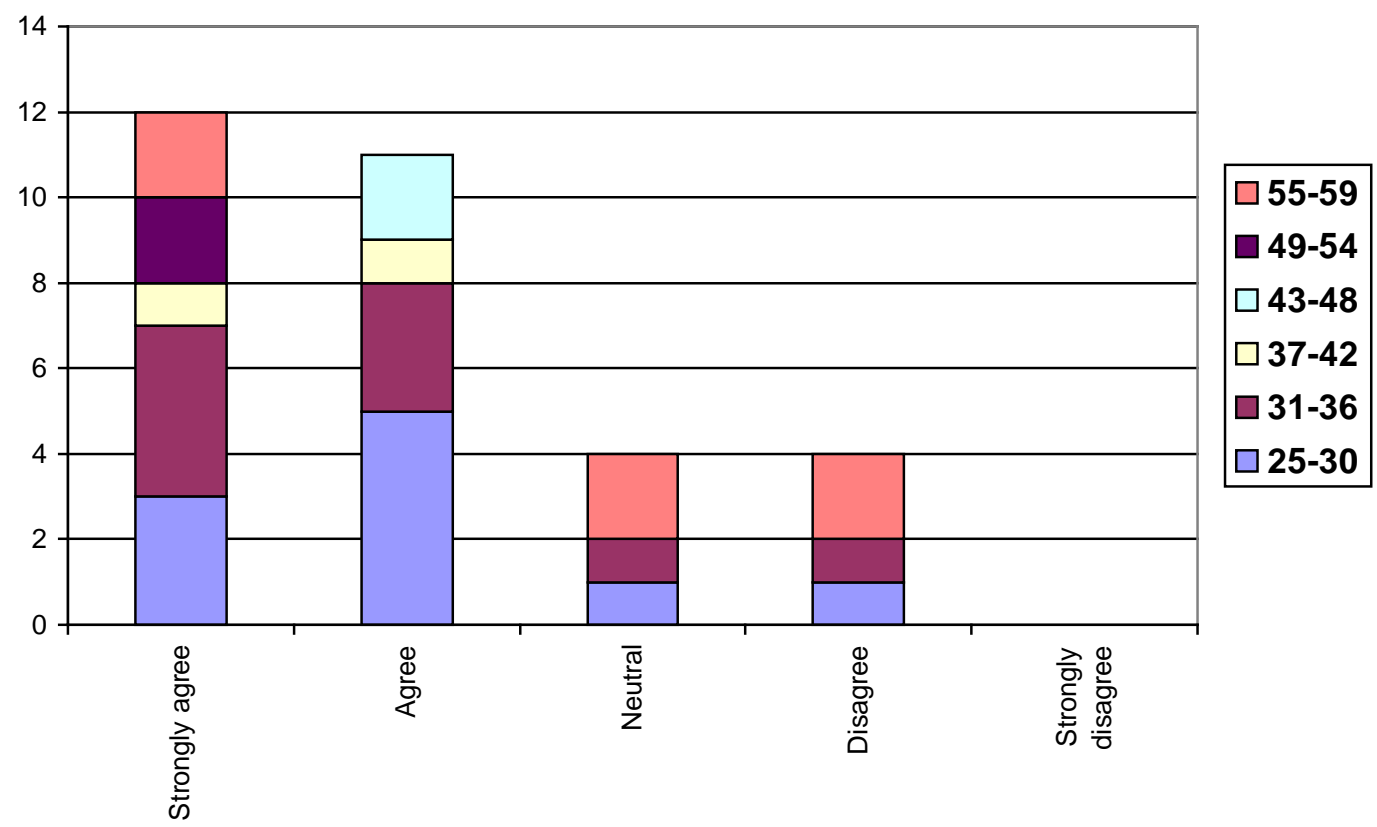

Figure 4: Online survey participants' responses to the prompt, "Students frequently discuss playing violent video games in my presence" displayed by age ranges.

To address how often students were discussing violent video games in the presence of elementary school counselors, participants had the opportunity to respond about the frequency of student generated gaming discussions or references to playing violent video games. Twelve (39\%) strongly agreed that students frequently discuss playing violent video games, 11 (35\%) agreed, four (13\%) were neutral and four (13\%) disagreed. Figure 4 depicts the survey responses by the participants’ age ranges; the data show that students are discussing violent video games with school counselors of all ages.

The next section of the survey had to do with familiarity of specific video games. In order to answer the first research question about how frequently certain violent video games are mentioned, it was important to examine the responses about each video game named in the survey. 


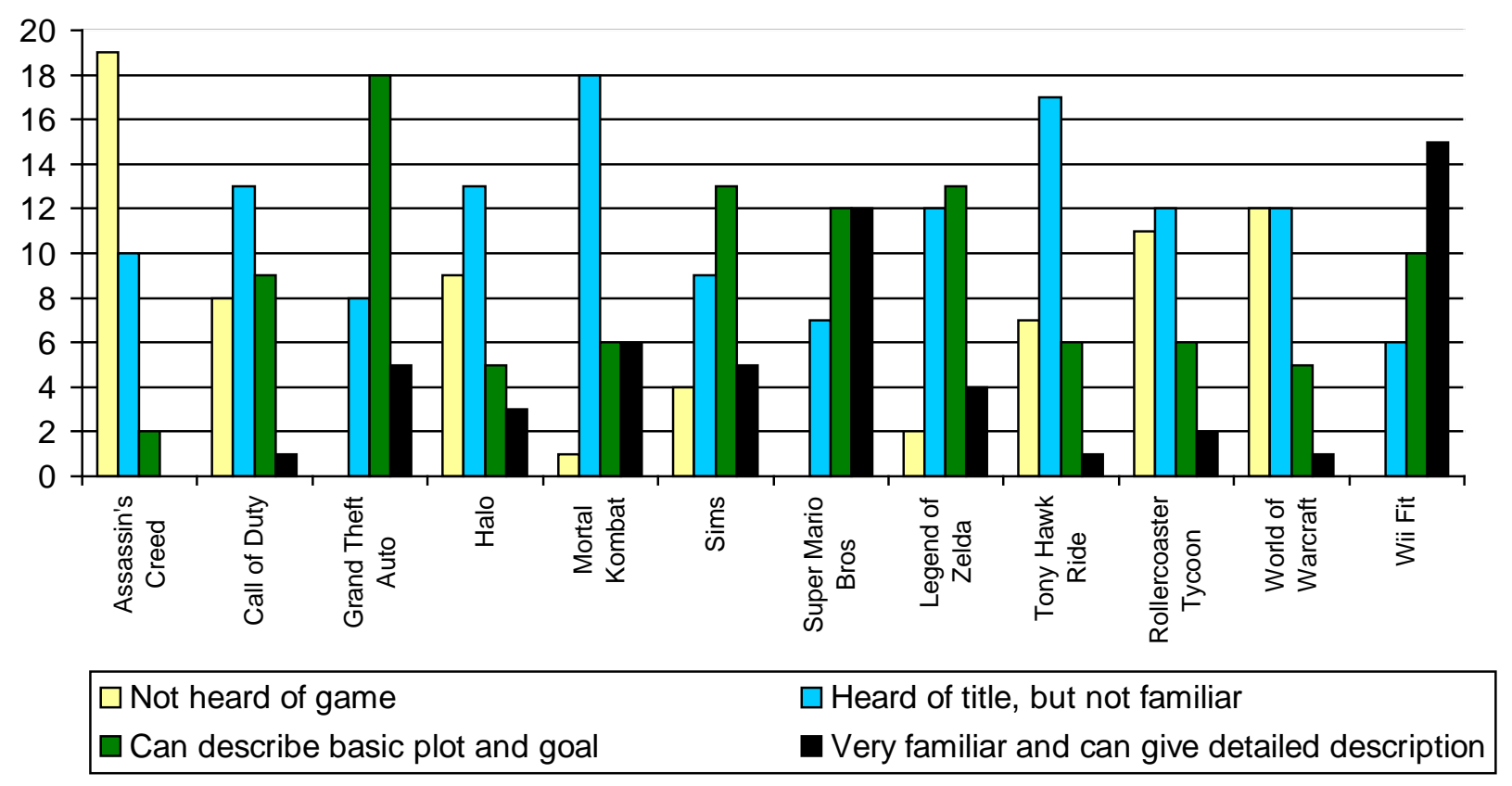

Figure 5: Online survey participants' familiarity with popular video game titles.

The researcher generated a list of video games after conducting several searches on the most popular video games currently played in the United States. These games were included deliberately in the researcher's survey in an effort to determine how familiar elementary school counselors were with the games that their students most likely play or watch. The top 11 games were chosen and participants were asked to rate their familiarity with each game. Assassin's Creed, Mortal Kombat, and World of Warcraft are considered fantasy/adventure games. There is significant violence involved as the player has motives and incentives to kill other characters. Call of Duty and Halo are both war simulation games, again with large amounts of violence as the player assumes a first person shooter role. Halo has aspects of science fiction woven into its plot line. Grand Theft Auto is an action adventure series, and the player/protagonist's goal is to rule a criminal underworld. Sims and RollerCoaster Tycoon are both simulation games containing minimal violence. Figure 5 illustrates elementary school counselors’ familiarity with 
these popular titles. For example, when asked about the game Assassin’s Creed, 19 participants (61\%) indicated that they had not heard of the game, 10 participants (32\%) had heard of the title, but weren't familiar with the game and two participants (6\%) stated that they could describe the basic plot and goal of the game.

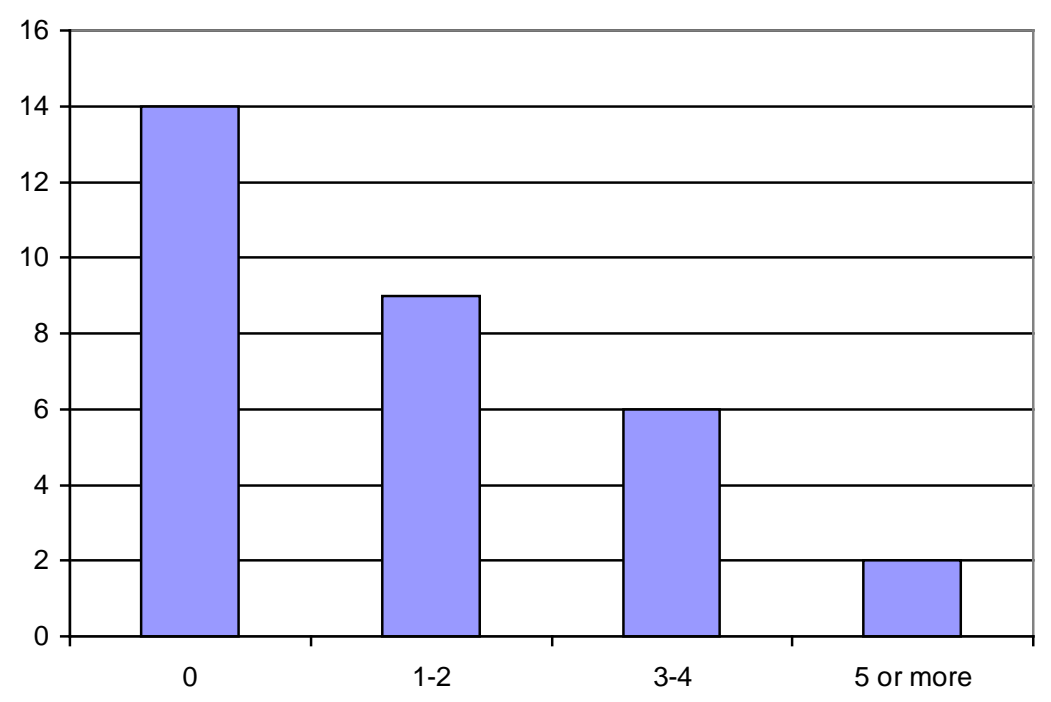

Figure 6: The number of video game titles online survey participants named when asked to list games that students discuss.

Survey participants were given the opportunity to write about the names and types of games that their students reference playing. Four participants (13\%) stated that they could not remember the names, but that their students were talking about gaming. Seven participants (23\%) left that section of the survey blank, and two (6\%) stated that they were "not sure." However, a majority of the participants, 17 (55\%), were able to list or mention specific video games by name; three others (10\%) did not mention game titles, but provided information about the types of games (e.g. war/combat) or gaming systems (e.g. Nintendo DS). Their individual responses about their familiarity with games did not show any relationship to their age or experience. 


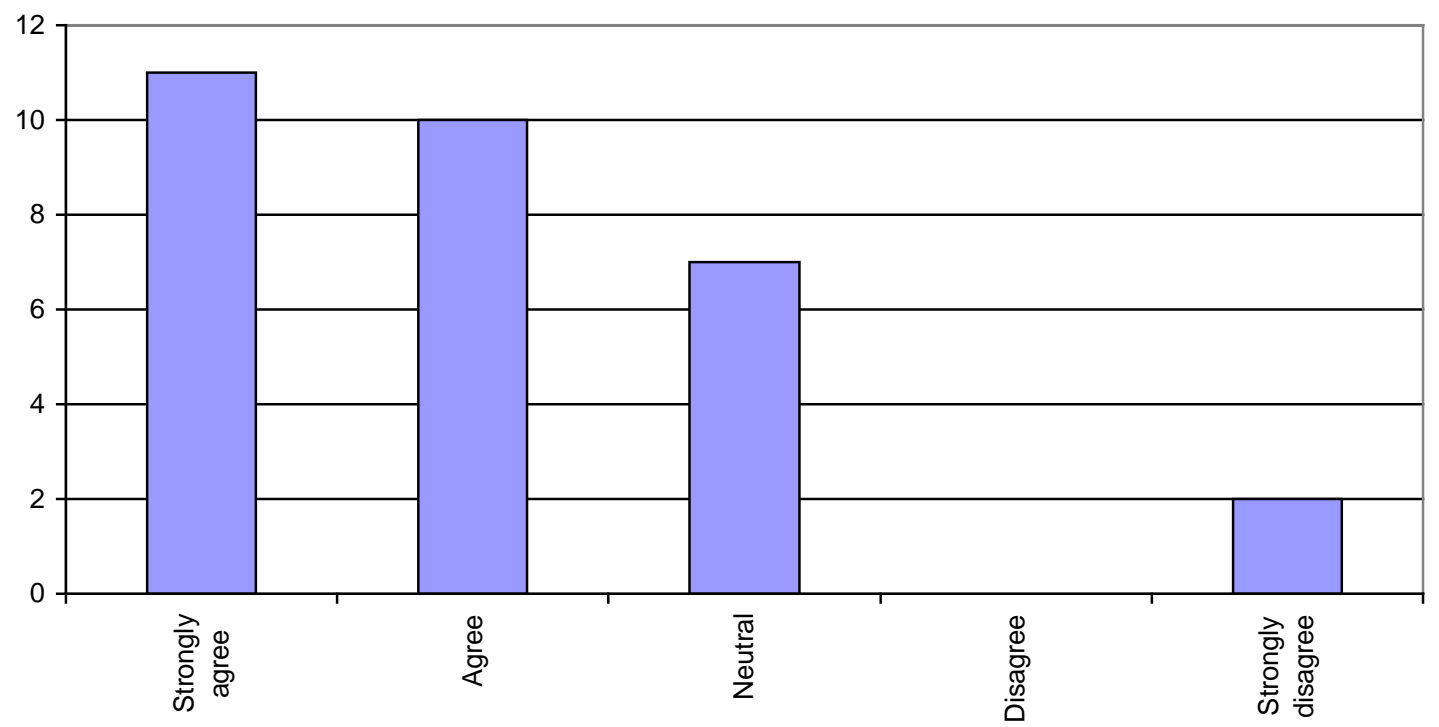

Figure 7: Online survey participants' responses to the prompt, "My school does not have resources available which name and describe common video games."

Participants were asked to agree or disagree with the statement, "My school does not have resources available which name and describe common video games.” Eleven (35\%) strongly agreed with the statement, 10 (32\%) agreed, seven (23\%) were neutral and two participants (6\%) strongly disagreed.

\section{Survey Responses Aligned to Research Question 2-4}

After the section about familiarity with video games that students play, there were a series of survey questions that are aligned with research questions 2-4. These survey questions were designed to gather information about how elementary school counselors respond to students who discuss violent video games and their observations of student behaviors that may be related to playing violent video games. 


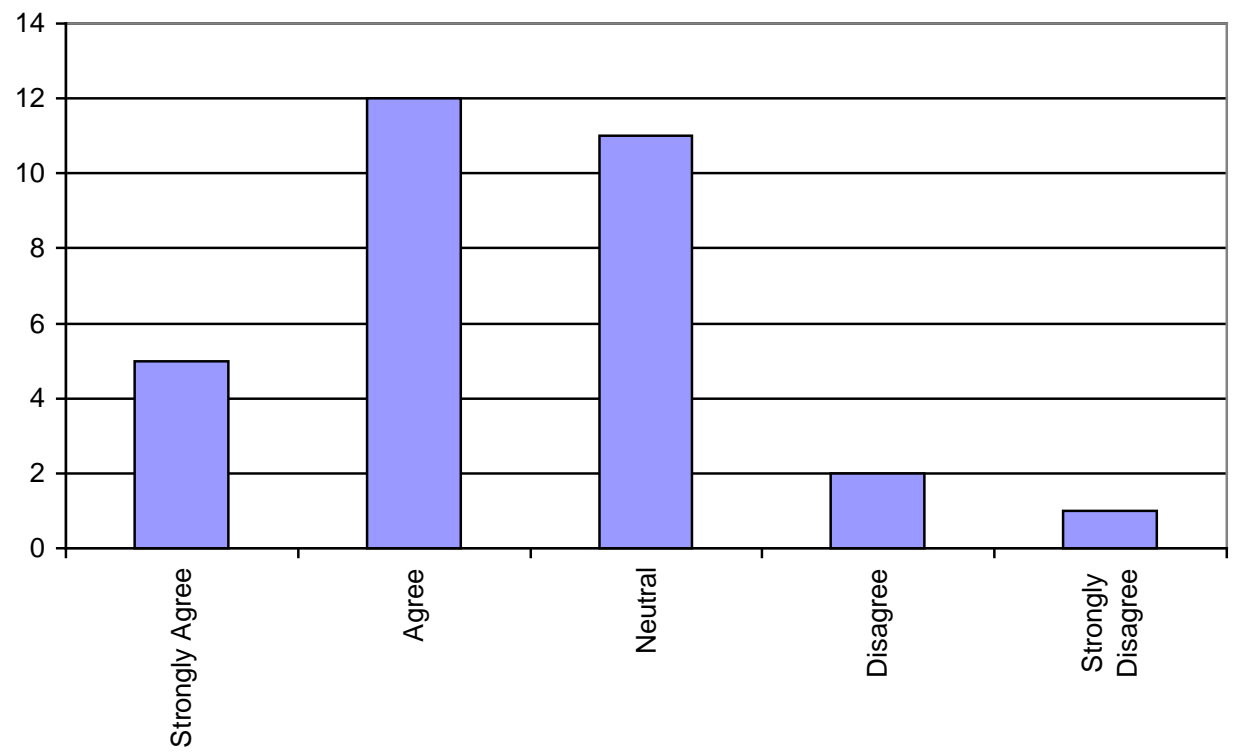

Figure 8: Online survey participants' responses to the prompt, "There is research readily available about how playing video games may impact children."

The next survey question addressed whether or not elementary school counselors felt that there was readily available research about the potential impact of video gaming on children. Five participants (16\%) strongly agreed that research was readily available, 12 (39\%) agreed with the statement, 11 participants (35\%) were neutral on the topic, two (6\%) disagreed with the statement and one participant (3\%) strongly disagreed about the availability of research on this subject.

It was important to examine whether or not elementary school counselors believe that children's exposure to video games is a cause for concern. In response to this question, the results were very homogenous with 27 participants (87\%) strongly agreeing with the statement and four (13\%) who agreed. Additionally, when asked about whether or not some discipline referrals may be related to playing violent video games, eight participants (26\%) strongly agreed, 17 (55\%) agreed, five (16\%) were neutral and one participant (3\%) disagreed. Participants were also asked whether or not they had discussed a student's video game usage with the parent or 
guardian. Nine participants (29\%) strongly agreed, 13 (42\%) agreed that they had contacted parents about the students' gaming habits, one (3\%) was neutral, seven (23\%) disagreed with the statement and one participant (3\%) strongly disagreed.

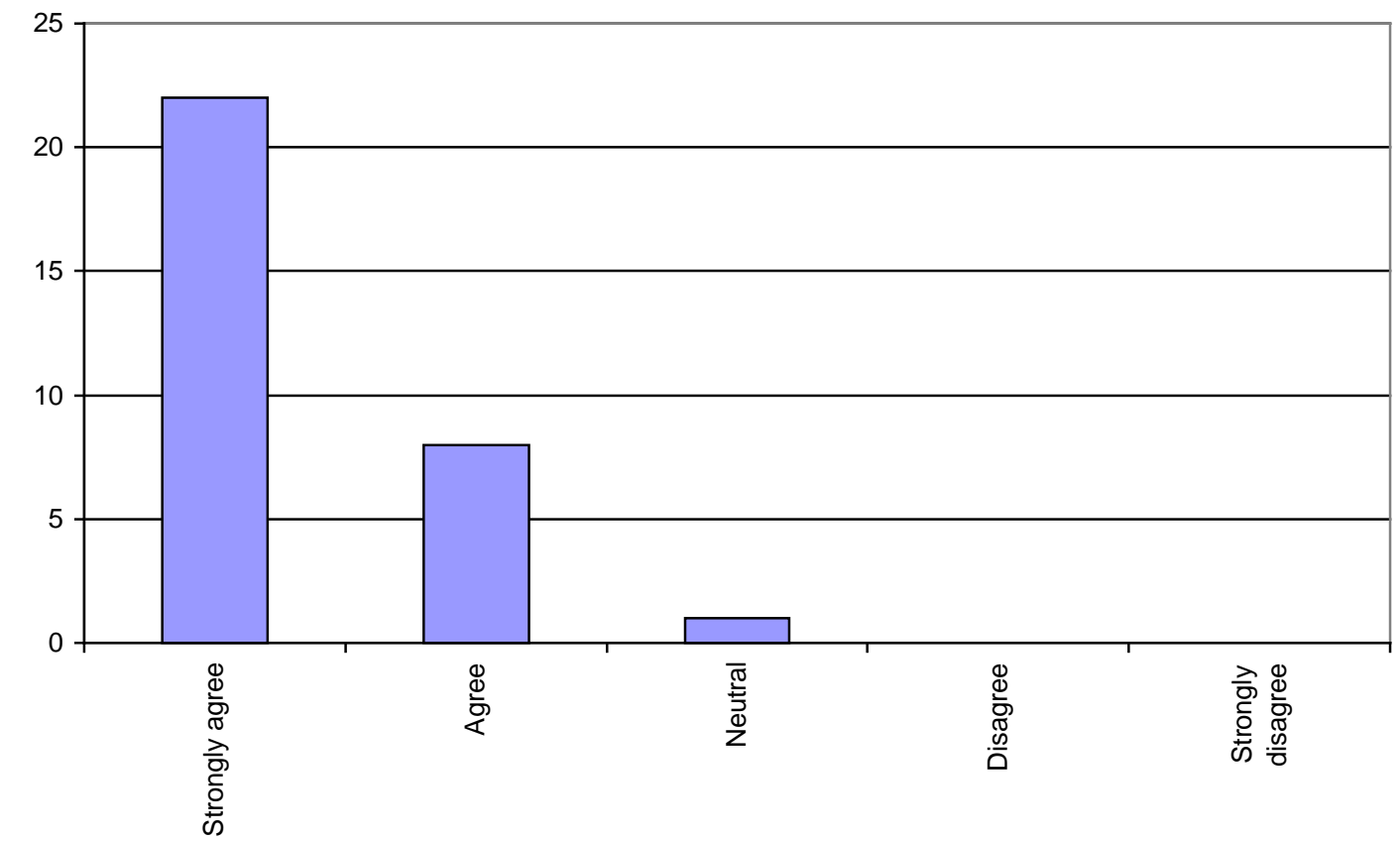

Figure 9: Online survey participants' responses to the prompt, "There is a need to educate adults about children's exposure to violent video games."

Elementary school counselors were asked whether or not they felt that adults need to be educated about children’s exposure to violent video games. Twenty-two participants (71\%) strongly agreed with the need for adult education on this topic, eight (26\%) agreed and one participant (3\%) was neutral. Participants were also asked to respond to the statement, "I have never heard student descriptions of video game violence which I felt were too graphic or inappropriate for the student.” One participant (3\%) strongly agreed, one (3\%) agreed, one (3\%) was neutral, 13 (42\%) disagreed and 15 (48\%) strongly disagreed. 


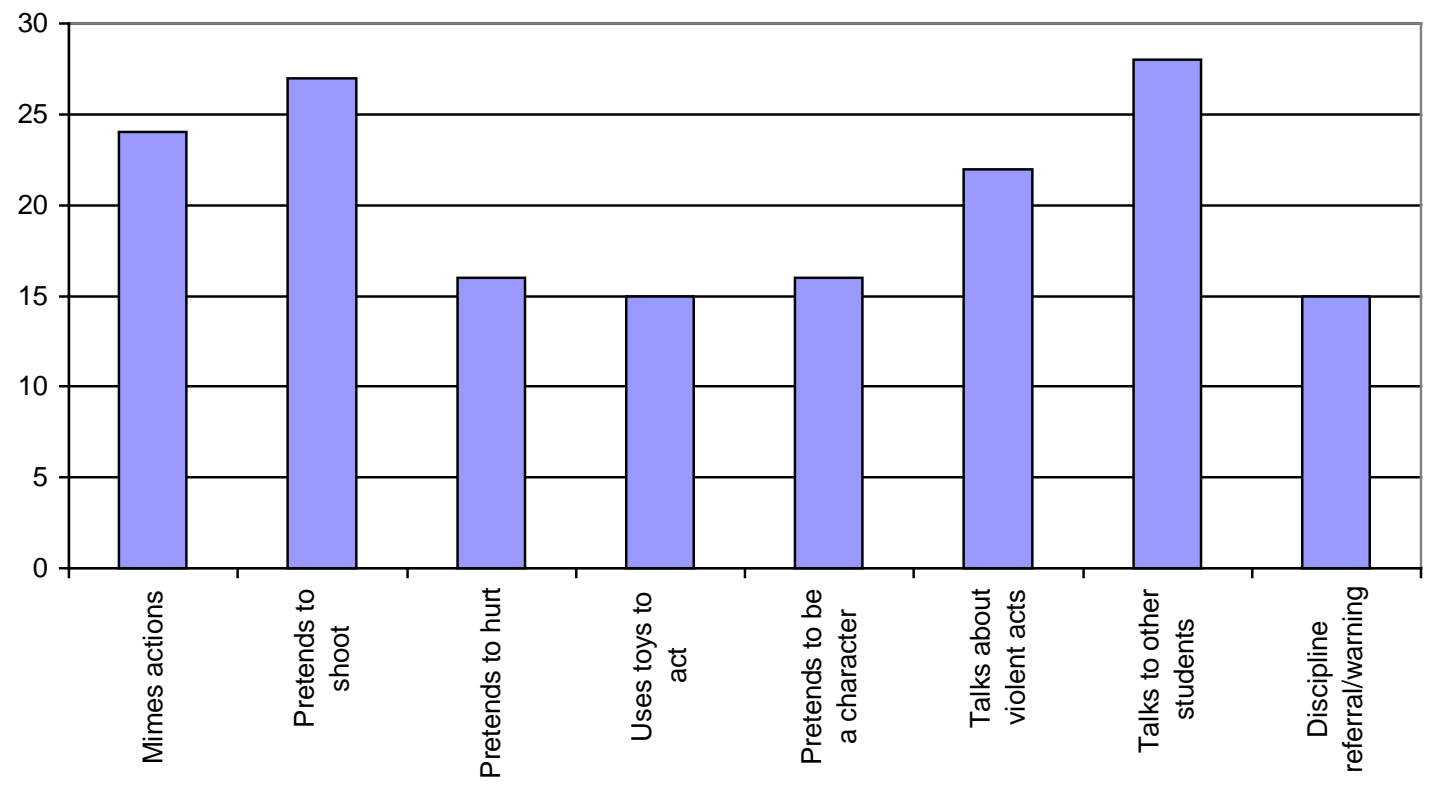

Figure 10: Behaviors online survey participants believe may be related to playing violent video games.

Survey participants were asked to respond to the prompt, "Students often model, reenact and verbally process what they observe. Please indicate any of the following student actions and/or behaviors that you've either observed or heard about which may be related to violent video games based on student self-disclosure about gaming habits.” They were able to select from the following behaviors: student mimes punching, hitting, shoving or kicking; student pretends to shoot other students or objects; student pretend to hurt others physically; student uses puppets, toys, or action figures to act out a video game scene; during free time and/or recess, student pretends to be a video game character; student talks about the violent acts in a video game; student talks to other students about playing video games; student received a discipline referral or teacher warning for hurting or threatening another student. The survey participants were able to choose from any of the behaviors listed. They could select any number of the choices provided and/or all of the behaviors. The following results are listed in order of the highest to lowest number of selections. Twenty-eight (90\%) selected that students talk to peers 
about playing video games. Twenty-seven (87\%) noted that students pretend to shoot others or objects. Twenty-four (77\%) noticed students miming punching, hitting, shoving, or kicking. Twenty-two participants (71\%) have heard students talk about the violent acts portrayed in the games. Sixteen participants (52\%) selected that students pretend to hurt others physically and that students pretend to be a video game character. Finally, 15 (48\%) noted that students use a toy to act out a video game scene and that students have received referrals/warnings for hurting or threatening other students and attributed these actions to playing video games.

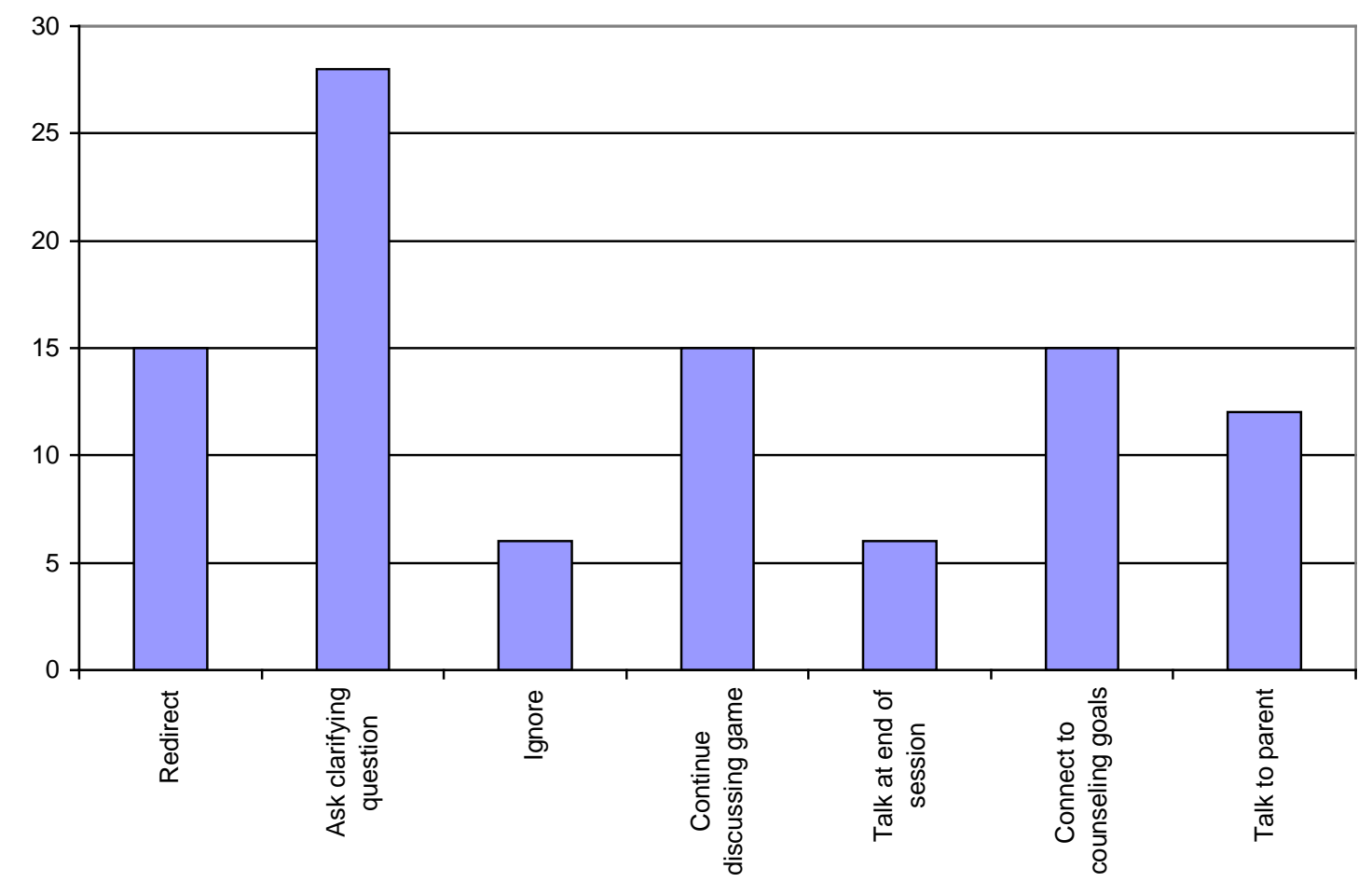

Figure 11: Online survey participants' typical responses when students initiate the topic of video games in counseling sessions.

When asked how they typically respond when students initiate the topic of video games in counseling sessions, participants were able to select from any of the options offered. Twentyeight participants (90\%) selected, "I ask clarifying questions about the video game, such as the name and frequency of play.” Fifteen (48\%) answered, "I redirect the student.” Fifteen (48\%) 
also answered, "I respond to the student's prompt and continue to discuss the video game” and "I try to connect the student enjoyment of video games to our counseling goals.” Twelve participants (39\%) selected, “I ask the parents or caregivers for more information about the gaming habits of the student." Six (19\%) stated, "I ignore the reference" and "I tell the student we can talk about the game at the end of our session or during free time.”

Overall, it appears that there are a variety of responses that school counselors use when working with students exposed to violent video games. For survey respondents, it was most common to ask clarifying questions and continue discussion about the game rather than change the topic.

Another question in the survey was designed to give elementary school counselors an opportunity to provide greater detail about how they believed playing violent video games impacts their students. Counselors were asked to type answers into an open text box.

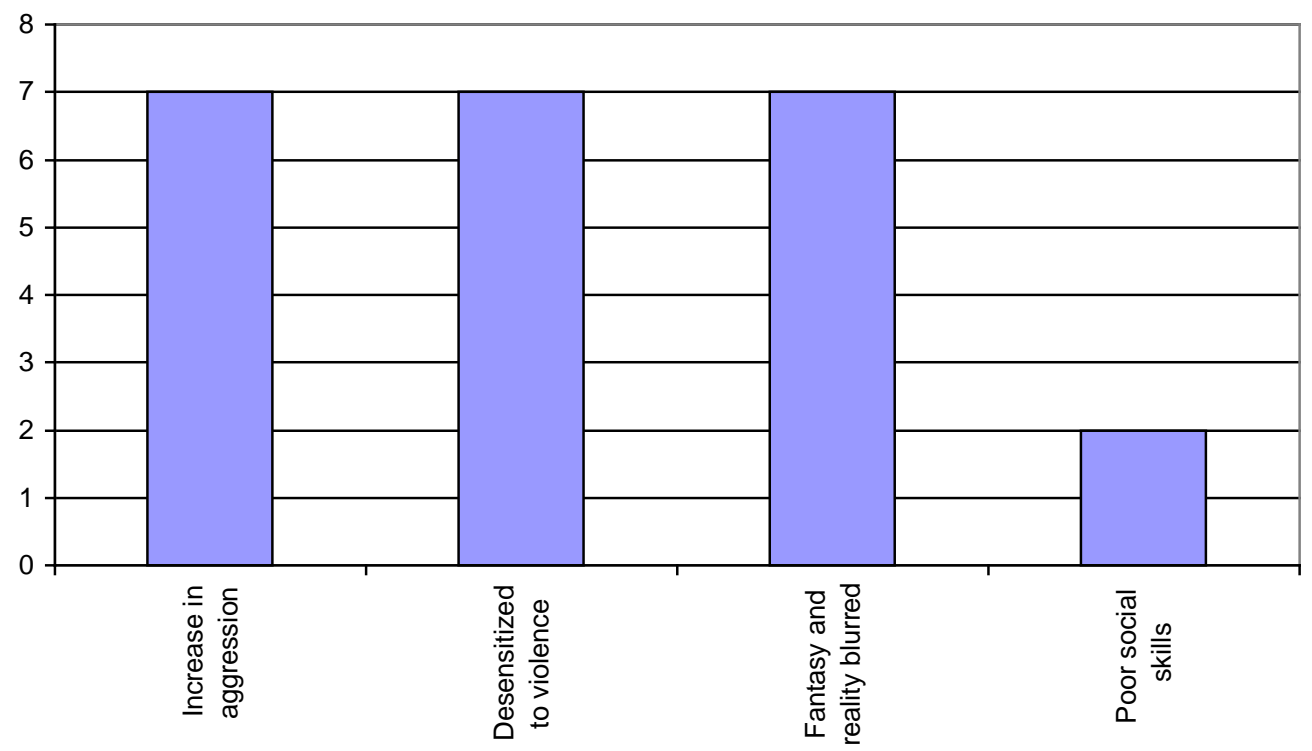

Figure 12: Common themes found in online survey participants' open-ended responses when asked how they believe video game violence impacts students. 
Participants were also asked to describe the potential ramifications of students playing violent video games. One of the most common responses reflected that participants (23\%) believe students exposed to video game violence act more aggressively toward others (e.g. "Usually they are aggressive towards others and often show disrespectful and disruptive behaviors in class"; "Sometimes, they tend to respond more quickly with violent reactions to conflicts with others.”) Seven participants (23\%) also directly mentioned that they feel students who play these games are "desensitized to violence." An equally common response was that the difference between reality and fantasy is blurred for some students playing violent video games. Two participants (6\%) voiced concerns about the social skills of students who play violent video games frequently.

One of the purposes of the study was to learn about professional development for school counselors in regard to this topic. To that end, survey participants were asked if they believed attending professional development on the topic of working with students who play violent video games was important. Nine participants (29\%) strongly agreed that it was important to attend professional development on this topic, 16 (52\%) agreed and six (19\%) were neutral.

Finally, elementary school counselors had the chance to list professional development or training activities they had attended on the topic and to describe training activities that would be beneficial to school counselors. Eight of the participants (26\%) mentioned they would like professional training on how to discuss the effects of violent video games and/or excessive gaming with parents.

\section{Individual Interview Data Collection and Analysis}

Upon completion of data collection for survey results, the researcher began the second phase of data collection in the form of individual interviews of survey respondents. This was an 
effort to delve more deeply into the experiences, perceptions, and beliefs of elementary school counselors in regard to working with students exposed to violent video games. The intent was to gather information that would correspond to the research questions and the statement of the problem. By comparing and contrasting the responses and demographics from nine individual interview participants, greater depth and understanding arose about this complicated issue. Perhaps one of the most enlightening discoveries of the interview data was how interviewing survey respondents shed light on their survey responses. To analyze the interviews, the researcher initially listened to each to review for content, sound quality and overall congruence with the field notes taken during each interview. Next, the researcher constructed themes and categories based on the field notes and first impressions, relying on open coding as suggested in the grounded theory model (Strauss \& Corbin, 1998). The researcher listened again and tallied and organized participant responses using both the auditory records and the transcripts of the interviews. Member checking occurred during this period as interviewees were given the opportunity to review the transcript of their interviews and/or to listen to the original digital recordings of the interviews.

\section{Emergent Themes for Interview Participants}

The themes that emerged in response to the interview prompts were guided by the original research questions. In summary, the counselor responses during the individual interviews addressed the following topics: how frequently students reference playing violent video games; student conversations and behaviors that may reflect exposure to violent video games; typical counselor responses to student discussions of violent video game playing and redirecting techniques; counselor perceptions of impact; critical analysis with students; 
familiarity with ESRB; resources/training/professional development and needed or beneficial resources recommended by interview participants.

The interviews were based on a flexible script, which provided the researcher with the opportunity to ask clarifying questions when needed (See Appendix B). While each individual interview participant was asked the same set of questions, the participants' varied responses added rich detail to the initial information generated during from the survey data. This also allowed for freedom to probe about any surface discrepancies from data in the survey responses. In fact, one of the largest benefits of conducting individual interviews was the deeper understanding received about the survey responses. The information presented in this section is organized according to the alignment between the individual interview prompts and the research questions that guided this study.

\section{Individual interview prompts aligned with research question one.}

Individual interview participants were asked to describe how frequently their students reference playing violent video games; they were also asked to supply any names and/or descriptions of games commonly mentioned. This prompt was aligned with the first research question of this study which is, "When elementary school counselors encounter student generated discussions of video games, what are the most frequently mentioned game names and game activities?”

In describing how frequently students reference violent video games, most of the interview participants mentioned that boys talk about shooter, zombie, and war games extensively. Following are some of the verbatim quotes, which support this finding.

One counselor succinctly summed it up by saying, "If I'm working with a male student, then he’s going to be talking about video games." Another counselor stated, "Students typically 
reference video games when asked, 'What did you do over the weekend?' or a similar question. It is very likely that video games will come up in the average conversation with a student, especially males. Games students have talked about include: Halo, Call of Duty, Mario Brothers, Wii, Gran Tourismo, and Grand Theft Auto.” Yet another counselor said, "I would say I hear a student mention a violent video game at least daily...sometimes just mentioning it and sometimes going into great description. One that comes to mind because it caught my attention as not being appropriate was Grand Theft Auto. It seemed to be a favorite with several students.” Another also commented, “I’m appalled at what these kids describe_zombies and dead soldiers and things that would give anyone nightmares, let alone a 7-year old.”

The participants tended to elaborate on their answers to this question by talking in more detail about their concerns about what students were viewing and how strongly students engage in gaming. The majority of the counselors interviewed had the perception that students are addicted to the games they play. Words like "hyper-focused," "super-animated," "perseverate,” and “obsessed” were used to describe students who play video games extensively. One counselor observed, "I have champion equestrians and star baseball players at my school, and they have boundaries - they don't talk about their horses and ball games the way some of these kids talk about playing video games; it's like it's their life.” One of the more extreme examples came from a counselor who stated, "Last year I had a first grader who seemingly could not come out of the video game world. He apparently watched his father play video games every waking hour. I was frustrated and unable to make any progress because he refused to talk about anything other than video games.” This counselor did not mention any specific efforts to follow up with the parents of this student. 
This also led to conversations about how students who game frequently don't have the social skills to realize that others are not interested in hearing about video games. As one counselor described, “I'll say so and so, do you realize that from my body language, I don’t like talking about video games? Can you tell that I'm not interested in hearing about it?” The same counselor added later, "Seriously, it's like they're in a trance. I could leave the counseling room and get a cup of coffee and come back and the student will still be talking about playing video games_-I don’t even think he would notice or care.” Another counselor said, "This is bad to admit because I'm supposed to be an active listener but I get glassy-eyed hearing them go on and on about playing their video games. It’s just mind-numbing.”

\section{Individual interview prompts aligned with research question two.}

Another interview prompt was an attempt to gather more information about the second research question, which asked, "What do elementary school counselors observe student saying and/or doing that may be related to playing violent video games?” When asked about examples of student conversations and/or behaviors that the counselors have observed that seem to reflect exposure to violent video games, the most common answer was shooting. Five of the interview participants (56\%) mentioned this action. As one counselor put it, "I think the act of shooting someone—you know, points finger, makes shooting noise and imitates recoil—is a result of playing video games where you are rewarded for shooting an opponent.” Another counselor described that "boys raise up out of their seats and act out what they do in the games. The only other time I see boys that animated is when they are describing hunting and killing an animal.” Another prevalent theme in response to this question was the perception that students' brains are being altered by overexposure to video games. This concern was mentioned by most of the counselors interviewed, along with frustration about a lack of research on the effects of gaming 
from a developmental standpoint. Counselors commented that students seem to have more trouble paying attention during school in comparison with previous generations. As one counselor said, “It’s like their brains get rewired to need constant stimulation—-they can’t pay attention to what's happening in real life because it's too dull and too slow. It's no wonder we can't keep them focused long enough to learn anything in school.” Another counselor stated, "I don't want technology and gaming to change their brain, but I really think it does. I don't have any research to back that up, but it just seems like it does.”

\section{Individual interview prompts aligned with research question three.}

The third research question was, "How do elementary school counselors respond when students initiate conversations about violent video games?” In response to the interview prompt on this topic, there was agreement that a variety of responses may be appropriate depending on the student involved and the surroundings. This attitude prevailed throughout discussion on the subject of the best way to respond to students who frequently discuss playing violent video games. In an effort to gather information about potential counseling strategies that are useful in helping students think critically about violent video games, counselors were asked to describe any of their attempts to help students analyze or consider the violence in the games they are viewing. One counselor stated, "I have briefly mentioned to students before about how much time these games tend to take away, and how it's healthier to be outside getting exercise and enjoying the fresh air. To date, I have not seen the need or taken the opportunity to specifically address this with a student in a session, nor have I known how to do this effectively and maybe that's the reason why I haven't done it." Another counselor commented that she tries "getting them to talk about and think about how much time is spent on the game, how do they feel when 
they are playing and after playing and rating their level of frustration if things don't go well in the game."

\section{Individual interview prompts aligned with research question four.}

Research question four was, "How do elementary school counselors respond to actions and behaviors which appear to be related to playing violent video games?” In general, the counselors tailored their responses to both the situation and the student involved. As one counselor said, "Sometimes I ignore the video game reference and redirect the conversation.

Other times I will ask details about the game if I'm unfamiliar with it. If it seems inappropriate, I will ask the student where their parents are or if adults are around. Sometimes I ask if they have day or night dreams about the video game and sometimes, I'll just go 'huh.”’ One counselor said that she “always remains calm, because I don't want to reinforce the shock value of what they are describing." Most of the counselors interviewed stated that they allow more discussion and acting out of behaviors in the counseling room, than in other settings in schools, such as classrooms and hallways. Some interview participants mentioned using discussion of favorite video games to build rapport with a student. One counselor in particular was very open to discussing games with her students. As she explained it, “There are some people who think that video games are completely bogus. They would probably take even more time getting information about gaming habits than I would because I accept video games as part of the culture. I could beat Super Mario Bros. right now if I wanted to and I talk to kids about that.” Another counselor had a similar comment. She stated, "I'm still willing to go there-I can say, when I was a kid, we played this and when I sit down with a group of boys, I'll talk about beating games and high scores.” One counselor had an interesting theory about allowing students to talk about video games during a counseling session. As she explained, "One student 
in particular has really significant behavior problems and doesn't have strong relationships with any adults in the school. So, when he wants to talk about video games, I go along with it because it helps build our relationship. Then, later when I need to cash that in to get him out from under a desk or whatever, we have that relationship.”

\section{Individual interview prompts aligned with research question five.}

Research question number five asked, "What kinds of professional development do elementary counselors see as valuable in helping to work with students who play violent video

games?” To gain background information on this subject, individual interview participants were first asked about professional development and/or training they had attended that was related to working with students who are exposed to violent video games. The responses from the interview participants were unanimous; none had received any training or workshops on this topic. One counselor stated, “In five years, I’ve never received anything-not one professional document on video game violence.” When asked about specific types of resources or professional development that may be beneficial to elementary school counselors, the majority of the individual interview responses confirmed the survey responses; five participants (56\%) said “Any!” There were also suggestions about concrete information that is often needed in order for counselors to be more effective and conscious. One counselor said, "I think we need to see the games; I think we need inservices where we are seeing what it looks like on the screen.” Another commented, "I wish someone would do research on the correlation between school achievement and playing video games.” A specific suggestion was provided by one counselor. She said, "Everyone wants clear strategies and directions, not scientific or obtuse scripts—no psychobabble — to use in educating parents.” Another counselor felt that it was important to 
develop "interventions" that could be used when students begin to act out in ways that suggest exposure to video game violence.

\section{Exploratory individual interview prompts.}

In an effort to gather deeper, more revealing information about the perceptions of elementary school counselors on working with students who are exposed to video game violence, exploratory prompts were included in the flexible interview script. The first exploratory prompt was, "There is a great deal of debate on whether violent video game exposure is harmful to children. Based on your experience as an elementary school counselor, what are your thoughts on this topic?” In response to this prompt about whether violent video game exposure is harmful to children, the most common theme among the individual interview participants was the belief that playing violent video games desensitizes students to violence and fuels students' perceptions that violence is an acceptable way to resolve conflicts. One counselor stated emphatically, "Violent ideation is directly linked to behavioral issues." Another said, "I think that the desensitization I see in my students is strongly correlated with violent video games; so many students have a complete lack of empathy.” Yet another stated, “Absolutely, playing violent video games directly affects non-compassion.” One counselor explained in more detail, "I think violent video games undoubtedly have a negative effect on how kids view violence. Repeated exposure and playing of these games desensitizes them to it and makes it much more natural for them to carry it out on a real person. This could be much more harmful than simply watching a violent move or TV show, because with video games, the kid is an active participant.”

Another exploratory prompt was, “Are students who play violent video games impacted by the activity, in your experience?” Counselors mentioned their concerns that playing games constantly impacted students' perceptions of reality and fantasy and reinforced escapism. One 
counselor said, "I have to remind my students all the time that the characters aren’t real.” Another recalled a long counseling session with some boys during an anger management group. She was frustrated by the solutions the boys were generating about solving conflicts because they continuously referenced killing people like the soldiers in video games. When she explained that in real life, violence has consequences, the boys scoffed. She recounted telling them, "In a gun battle on the beaches of Normandy, I don't think they had extra lives. If your head really got blown off, you'd be dead!” Another counselor commented that playing violent war games is condoned by the public as a reflection on patriotism and she feels this impacts children's views on killing as a means to end conflict. She stated, “See, because it's war and they are playing an American soldier, it's acceptable to show the gruesome killing of the enemy, no matter how gory it might be.”

Yet another exploratory prompt was, “Given that elementary school counselors often assist parents in informed decision making, could you describe your understanding of the video game content rating system, designed by the ESRB (Entertainment Software Rating Board), that is currently used in the United States?” This question was included in the interview because counselors are a resource in assisting parents about developmentally appropriate activities for elementary students. Most of the interview participants had passing knowledge of the rating system but were not able to name each category. As one counselor stated, "I think that ' $E$ ' means for everyone, sort of like ' $G$ ' in movies, and I know that ' $M$ ' means mature, possibly like an 'R' rating. I'm not aware of the other ratings, but I know there are more.” For the most part, the counselors did not express an opinion as to whether or not they thought the rating system was useful and/or used by parents. 
This question tended to lead to a variety of related topics, most noticeably discussions with parents about students’ gaming habits and also why parents aren’t monitoring and debriefing their children in regard to violent video game exposure. In fact, one of the most prevalent themes in the interviews was parent involvement or lack thereof in deciding how often and what games their children could play. This is one of the areas where survey responses were misleading without additional clarifications from individual interview responses. For example, one counselor mentioned that she answered "disagree” to the survey question about discussing a student's video game usage with a parent or guardian. She explained that she often felt like having that conversation, but was not sure how to broach the topic and was also uncomfortable with the boundary issues involved in telling parents what their children should or should not be doing outside of school. She went on to say that if she had resources about how to have a positive, productive conversation with parents on this subject, she would be willing to approach them. This need for more resources in working with parents was voiced by the majority of the participants.

In reviewing the transcripts and field notes, the researcher noted that this topic of parent involvement was dominant in the individual interviews; every participant made comments about the parent or caretaker's role in a student's gaming habits. On the topic of parenting and video games, there were many sub-themes. These included: the use of video games as baby-sitters; parents who game themselves and expose their children to inappropriate games; the permissive style of today's parents; fathers who use video games to bond with their sons; and whether gaming is a beneficial bonding activity for families. It was also interesting to note that there seemed to be a dichotomy in the voiced opinions as to whether counselors had the right to contact parents about their children’s gaming habits. The responses were fairly equally split with 
some counselors feeling like they had a professional obligation to discuss their concerns with parents and guardians, while the other half felt that it was inappropriate to tell parents their children should not be playing certain games. This outlook seemed to be aligned with experience in that the less experienced counselors were not comfortable confronting parents. The more experienced counselors generally felt confident in discussing this issue with parents and guardians. One of the more outspoken counselors stated, "I’d like to see it [video gaming] become more of an incentive because that's what I tell parents all the time-and I actually wrote a newsletter article about this—if it's plugged in, then it's a privilege. They should be earning the rights to do their plugged in activities. Everything else should be physical and creative play; that's my opinion.” Three other participants also mentioned that they had no hesitation in calling parents or requesting a conference to discuss their concerns about a student's gaming habits.

\section{Outliers and Discrepant Views}

By and large, there was homogeneity in both the survey and individual interview responses in terms of prevalent themes. There were some interesting findings that did not correspond with the perceptions of the majority of participants. In particular, there was one respondent who was an outlier when compared to all other participants. This counselor felt that playing video games was “just another trend, another blip on the screen” and did not notice any impact in student behaviors that differed from any other fads in the past, such as Pokemon, Rubik’s cubes, Cabbage Patch dolls, etc. She did not believe that students talked about video games any more than other topics, but she then added that she is directive in turning any conversations in her counseling room towards counseling goals. Additionally, she felt there was no need for resources to address working with students exposed to violent video games, as the techniques and strategies for helping any children were similar and embodied in good counseling 
skills. When asked if she noticed whether other counselors were concerned about student exposure to video game violence, she replied, "You know, it’s just really not on my radar...I mean, yeah, I've heard counselors mention their concerns about video games, but we deal with so many issues and it’s just one more challenge. I really don't consider it to be a major issue.”

Another area of divergent ideas occurred when interview participants discussed parenting styles. Specifically, there were differing viewpoints on why parents allow children to watch and/or play violent video games that are clearly intended for an older audience. As previously mentioned, several of the participants voiced opinions on parents being too permissive and/or too uninvolved. However, there were some alternative perceptions on the subject that are worth noting in this section. One counselor felt that parents, especially those with a lower economic status, felt they were being good parents by providing their children with the latest and most popular games. She noticed that parents were empowered by the ability to bring their children such enjoyment and to give them what they wanted most. Another counselor made connections to what she deemed as the failure of her generation to bring up their children properly, which she strongly feels contributes to the current generation's issues and lack of parental support. As she says about the parents of today's students, "We made the mistake of praising everybody for everything—you were applauded for breathing...everybody got a trophy no matter what and that sense of entitlement created a huge lack of responsibility.”

There were also differences in opinions as to which genres and games counselors thought were appropriate. For example some believed that allowing children to play war games was preferable to playing Grand Theft Auto, zombie games, and/or fantasy games, because they were based on reality. Most counselors also had more concern about students playing inappropriate video games than watching inappropriate movies and television shows, because of the nature of 
active participation in gaming. In contrast, one counselor felt that movies (such as the Saw films) were much more detrimental from a developmental point of view as they were depicted as reality. She was very agitated that parents were letting elementary children watch graphic images of blood and gore in films and television. As she explained, she simply could not fathom why parents would let children watch humans torture each other; that was not her idea of family entertainment. Differing views such as the ones just described added richness and depth to the findings of this study and support more research on this topic.

\section{Reflections on Results}

For the most part, the results from this study showed a fairly cohesive set of perceptions as voiced by elementary school counselors on the subject of student exposure to violent video games. By and large, the predominant theme that was perceived at the conclusion of the interviews was that elementary school counselors are greatly concerned about student exposure to violent video games. In seeking to find answers to the research questions, a relevant of information was generated by the participants, which both confirmed the rationale for this study and validated the need for further exploration. While the primary data sources of the survey results and the individual interview transcripts provided the bulk of the data, secondary data sources such as state counseling standards, discipline referrals, field notes, and counselor logs also corroborated the perceptions of the participants and served to buttress the findings generated during data analysis. Given the detailed information gained from responses to survey questions and individual interview prompts, the elementary counselors who participated in this study seemed eager to share their perceptions in an effort to contribute to the body of knowledge about this topic. 


\section{CHAPTER V}

\section{CONCLUSIONS}

The conclusions drawn from this research were generated from the responses of certified elementary school counselors. Their responses supplied novel information on the topic of working with students who play violent video games, however, the answers provided also led to many more questions. This chapter contains a summary of the major findings in regard to the original research questions, potential professional development and training implications and implications for future research.

\section{Responses to Research Question 1}

\section{RQ1. When elementary school counselors encounter student generated discussions of video games, what are the most frequently mentioned game names and game activities?}

There was a consensus among both survey participants and individual interview participants that elementary students play a wide variety of games and that they game frequently. This finding was supported by the literature review in which it was noted that children are spending more time playing violent video games (Sherry, 2007). Given that the popularity and time spent playing violent video games continues to increase, school counselors will need training and professional development in order to increase their understanding of the games students are playing and to educate parents about the rating system used to determine which games children should be permitted to play.

All of the participants of the individual interviews made the distinction that gaming was a very frequent activity among their male students. When elementary school counselors responded to a specific prompt about which games were most frequently mentioned, war games and fantasy/action adventure games were commonly referenced. Many counselors stated that while 
they didn't know the names of the games, they knew about the plots and/or genre based on students’ descriptions of playing.

In regard to violent video games, the majority of the responses indicated that elementary students were playing violent video games as evidenced by student descriptions to the counselors and other students. Out of 31 survey participants, 27 answered “strongly agree,” and four answered “agree” to the survey question, “There is cause for concern about children’s exposure to video game violence.” Additionally, most of the individual interview participants discussed their concerns that elementary school children were playing violent video games, such as Grand Theft Auto, that are clearly intended for mature audiences. The counselors interviewed felt that playing inappropriate games could have far reaching implications in terms of a decrease in prosocial behaviors, conflict resolution skills, and violent ideation. As numerous researchers (Anderson, 2004; Bailey, West, \& Anderson, (in press); Gentile \& Stone, 2005) have stated that for some children aggressive behaviors increase in conjunction with violent video game playing, this concern seems warranted in the views of the survey participants. This researcher agrees that more research and attention to this specific concern is needed.

\section{Responses to Research Question 2}

\section{RQ2. What do elementary school counselors observe students saying and/or doing that may be related to playing violent video games?}

The survey responses indicated that elementary school counselors both hear and see a wide range of student behaviors that may be related to playing violent video games. There are frequent conversations about video games that contain violence occurring in the classrooms, hallways and counseling rooms in elementary schools. This was evidenced in responses to a survey question that allowed school counselors to choose from a variety of student behaviors. 
The most commonly chosen response among survey participants was "student talks to other students about playing video games”; 28 of the 31 survey participants had selected this choice. Again, this is reinforced by the literature, which shows that gaming is a very prevalent activity among the nation's youth (Buchman \& Funk, 1996). The most commonly cited student action among both survey participants and individual interview participants was the act of pretending to shoot a gun. Twenty-seven survey participants and five individual interview participants felt that their students were acting out gun battles they play in violent video games. While it should be noted that elementary students, particularly male students, have been pretending to shoot guns for decades, the concern voiced by the elementary counselors in this study is the participatory nature of violent video games and the graphic violence involved. Students have been watching shootings on screens for years, but they did not have the opportunity to engage in first person shooter scenarios in which the child becomes the killer who is rewarded for gunning down others. There is research that suggests that this ability to take on the role of assassins, soldiers, and criminals in video games has a stronger impact on aggression than watching shooters kill in television shows and movies (Anderson, Carnagey, Flanagan, Benjamin, Eubanks, \& Valentine, 2004; Funk, 2003). Conversely, other research finds that television and movies containing violence have a stronger impact on aggressive behaviors in children (Sherry, 2001).

The individual interview participants were able to provide more information about the behaviors of students that suggested, in their views, exposure to violent video games. While they also cited many of the student actions chosen by the survey participants, there was more discussion about student attitudes and conversations that worried them. For example, individual interview participants mentioned that students who are exposed to violent video games seem to have more difficulty generating peaceful solutions to conflicts, and they relished discussions 
about bloody and gruesome scenes in the video games they play. Most of the individual interview participants mentioned that they observed a lack of empathy towards others in the students who reported playing violent video games frequently. This was also correlated to numerous comments about "desensitization” and the student's tendency to find extremely violent acts as humorous and entertaining as opposed to feeling compassion for the victims in the games. Given that there is research that also supports these counselor observations (Bartholow, Bushman, \& Sestir, 2006), attention should be give to this particular outcome. The counselors felt in some way that this inability to relate to others carried over into real life scenarios and created more bullying and aggressive acts in their schools. While the research is inconclusive as to whether playing violent video games increases bullying behaviors, the counselors in this study felt strongly that they noticed a difference in the amounts of empathy displayed by students who played violent video games versus students who do not reference playing violent video games. These findings about the various negative ramifications that the counselors in this study perceive are legitimized by the researchers who feel strongly that playing violent video games can be detrimental. What is not clear is whether these perceptions are being influenced by the public opinion that violent video games are to blame for many problems in our society. Another consideration is that school counselors often work with the most troubled and at risk youth, and their perceptions may be skewed in regard to the negative effects of playing violent video games. It is possible that the students they typically counsel are more aggressive and less empathetic than most of the students in the school's population and therefore the counselors are incorrectly making causal connections between playing violent video games and behavioral and academic problems. Again, the answer lies in more research. Ideally, studies will be designed that look for relationships between bullying behaviors and the amount of violence contained in the video 
games that elementary school children are playing. While there is always the question about whether children who prefer violent video games are simply more prone to aggressive behaviors, there is not enough research to assert a causal effect. Future research would include studies that track both levels of aggression and empathetic behaviors in children in relationship to the amount of time spent playing violent video games. Control groups would include children who do not play violent video games and children who are exposed to violent video games and t-tests could be used for comparisons between the groups.

\section{Responses to Research Question 3}

\section{RQ3. How do elementary school counselors respond when students initiate conversations about violent video games?}

Both survey and individual interview responses indicated that elementary school counselors determine how to respond to student conversations about violent video games based on a variety of factors. They take into account the school surroundings, the individual student, the peer groups involved, and the specific time of the occurrence when deciding on an appropriate response. In the counseling room, counselors are more likely to explore and ask questions about the specific games students are playing. Counselors are curious about what may be impacting their students and also use discussion of video games as a way to build rapport with students and to show unconditional acceptance. As one counselor explained, "For me, it depends on the student and the reasons they are seeing me. Sometimes letting them talk and questioning why it is so important to them can lead to good discussions.” The participants understand the value of entering the student's world and finding out what motivates and excites him or her and why. However, elementary counselors are also aware of time constraints and counseling goals when working with students; for that reason, most of the participants mentioned frequently 
redirecting the student towards more productive conversations. Both in the survey and individual interview responses, there was an awareness of using discussions of video game violence as a "teachable moment” in how to respond to real life conflicts.

One of the themes that arose from this specific question was the need for guidelines in talking to students about what they are viewing during video games. Talking to students about whether a game is inappropriate for their age level can be a difficult topic to broach, according to some of the individual interview participants. On the other hand, at least two participants described how students really do not seem to care whether or not the counselor thinks they should not play certain video games. As one counselor explained, "For other students, I usually let them know that I know the game is violent or M-rated and they kind of giggle and say ' $\mathrm{I}$ know' or 'so'? I usually don't take it much further than that. They are thinking that adults just don't get it...I remember thinking in school, 'old Mrs So-and-So is going on and on' and I hated it." She went on to state that in her experience students do not care when she tries to talk to them about violent video games. That perception was also reinforced by three other individual interview participants. Often, it seemed that the student's indifference reflected how their parents responded to the counselors who attempted to have phone or face to face conferences. Only two counselors mentioned that they had parents broach them for advice on setting limits to video gaming and/or exposure to violent games. Given that students seem to play constantly, according to the respondents, it is surprising that more parents are not seeking advice from counselors about healthy limits and restrictions on gaming. One of the theories mentioned by an individual interview participant was that the first generation of heavy gamers are now raising the elementary children she counsels and they are too busy gaming to monitor their kids’ gaming habits. Hopefully, more discussion and dialogue among school counselors and other educators 
will help establish practical guidelines for how and when to respond to student initiated discussions of violent video games in schools. Some suggestions for resources in this area include: parent nights and/or PTA presentations to raise awareness on this topic, inviting students and parents to take part in focus groups about violence in video games, and including a link on the school webpage on this topic.

\section{Responses to Research Question 4}

\section{RQ4. How do elementary school counselors respond to actions and behaviors which}

\section{appear to be related to playing violent video games?}

Individual interview participants were given the opportunity to expand on the survey questions regarding how elementary school counselors respond to student initiated discussions of violent video games and what types of behaviors are being observed that may be related to playing violent video games. All of the individual interview participants related the behaviors associated with violent video game playing as aggressive or anti-social action. While one counselor stated that she does not correct behavior unless it is flagrantly against school rules or detrimental to other students, most took a disciplinary tone when they saw certain behaviors that they associated with violent video game playing. It should be noted however that counselors in general would address any negative behaviors at school and it is hard to discern whether pretending to shoot another student was due to watching a movie, playing a game, or both. Most of the participants attempted to set boundaries about what was acceptable behavior at school. As one counselor said about observing students who act out or use language that suggests violent video game exposure, "I tell them we don't act that way or use that kind of language at school.” Another explained, "I ask them to stop and explain that people do not behave in that manner in real life. I point out that real life violence is scary. With more mature students, I point out the 
fact that, if faced with a real instance of violence, they would not react like a video game character.”

Two themes were apparent in these responses. One is that school should be a safe place and that certain behaviors are absolutely not acceptable. This may not address the larger issue of how students are acting outside of school, but it seems apparent that counselors are committed to creating a respectful, caring environment in their schools.

The second theme is that elementary counselors want their students to understand how unrealistic the violence being perpetrated by the students in violent video games is in the context of daily life. There is a zero tolerance policy on students acting out their violent game scenes in school settings and an emphasis on how unnatural the character responses in violent video games are compared to reality. Because most of the individual interview participants mentioned their concerns about desensitization to violence and a lack of empathy in students who play violent video games, these reactions show a pragmatic approach to working with those students. Given that school counselors recognize how unnatural or blasé their students are in the context of virtual violence, how could we teach students that humans naturally respond to real violence in very different ways? There is a need to help children and adolescents understand that the affect and emotions incurred during episodes of virtual violence differ dramatically from the emotions that occur during real life violence and school counselors should have resources that assist in helping children make this important distinction. One example would be for counselors to teach a guidance unit to students on war veterans and PTSD and compare that to the portrayal of soldiers in video games.

It should be noted that these concerns were reflected in responses to the exploratory prompt, "There is a great deal of debate on whether violent video game exposure is harmful to 
children. Based on your experience as an elementary school counselor, what are your thoughts on this topic?” All of the individual interview participants except for one felt strongly that exposure to violent video games was harmful to children. As one counselor commented, "I really don't know how people can honestly argue that exposure to violence in games and movies has no effect on students! Studies have shown that this exposure increases aggressive thoughts and actions in children. Personally, I feel that it desensitizes students to the pain of others and sometimes causes a fascination with violence.” This counselor was one of two who mentioned that she has attempted to find research and educate herself on the effects of violent video game exposure in young students. Her statements reflected the research she found that supported her observations of her students who play violent video games. Based on the responses from the individual interview participants, it remains to be determined as to the most effective counselor responses to student behaviors and actions that may be related to playing violent video games. The participants of this study took a decidedly pragmatic approach to how they handled these actions by ensuring that any inappropriate behaviors in a school environment were discussed and/or corrected when possible.

\section{Responses to Research Question 5}

\section{RQ5. What kinds of professional development do elementary school counselors see as}

\section{valuable in helping to work with students who play violent video games?}

Repeatedly, in both the survey and individual interviews, the response to this question was often "ANY!" The preceding question to what type of professional development would be valuable to school counselors was a request to list prior professional development on the topic of working with students exposed to violent video games. Not one participant in the study listed any professional development or training on this topic. This could be because violent video 
game playing is not viewed as harmful enough to warrant training or it could simply be that other issues in education are taking precedence. In retrospect, the researcher of this study is not aware of trainings and professional development on any kind of media violence exposure; trainings about working with children exposed to violence are usually in regard to domestic violence or child soldiers as reported by these elementary counselors. Given the responses of participants in this study, professional development opportunities are welcomed. Additionally, the counselors surveyed and interviewed felt that adults in general should be made aware of the potential negative effects of violent video games and that schools should have resources on violent video games.

A comparison of the charts depicting participant responses about the need for adult education on the topic of video game violence and current availability of school resources on the topic demonstrates the need for more resources. To recap, out of 31 survey participants, 30 strongly agreed or agreed that there is a need to educate adults about children's exposure to violent video games. In response to the question about the resources available in their schools that name and describe common video games, only two participants indicated that resources were available, while seven were neutral or not sure. Twenty-one participants indicated that there were no resources available in their schools. These findings were supported by the requests for training which would expose elementary counselors to the games their students play. This finding has many implications for both professional development and future research. First, studies and programs that are geared towards adult education on this topic need to be designed and implemented. Given that the literature review showed a lack of resources available that will assist adults in understanding the potential effects of playing violent video games, this remains a 
challenge. Once these resources become more prevalent, school counselors will need to advocate for training on this topic and in turn, become trainers themselves.

\section{Responses to Research Question 6}

\section{RQ6. Is demographic data generated by elementary school counselors related to how they answer survey and interview questions?}

The analysis that assisted in answering this question consisted of organizing the responses from the survey and individual interview participants into tables and figures and looking for patterns. The demographic variables in this study included: gender of participants, ethnicity of participants, age of participants, years of experience as a school counselor, schoolrelated employment before becoming a school counselor, description of school setting, and the approximate number of students enrolled in the counselor's school. Next, frequency counts were conducted to determine the most common responses and averages of numerical values, such as the age range and years of experience. Overall, both the survey respondents and the interview participants were fairly homogenous in terms of both ethnicity and gender. There was more variation in the age ranges and years of experience for this study’s participants; in general, participants were representative of the larger population of elementary school counselors in the geographic region in which the participants reside.

Two noticeable trends were that both in terms of age and experience, there was less representation in the middle of the spectrum for the individual interview participants. Four of the individual interview participants had five or less years of experiences, while five of the participants had 10 or more years of experience. This means that perceptions of the individual interview participants represented either more novice counselors or veteran counselors. Despite this trend, eight of the individual participants, regardless of age and/or experiences, had very 
similar responses. There was one very experienced counselor whose perceptions on working with students exposed to violent video games were discrepant from the rest of the counselors' perceptions.

In summary, the demographics of the survey and individual interview participants did not appear to determine how they responded to survey and individual interview questions. For the

most part, the responses of all participants presented a cohesive and common set of concerns and viewpoints on the topic of violent video games. Important points to consider are whether the inclusion of more diverse respondents in terms of ethnicity and gender would reflect differing assessments and opinions from this study’s participants. For example, since the research shows that more male adults than female adults play video games (ESA, 2009), would a larger number of male participants have responded in a more neutral manner to students’ exposure to violent video games? Questions such as these remain areas for future research.

\section{Implications for Future Professional Development}

In preparing to embark upon this topic of study, the researcher sought out resources and professional development that addresses the need for more information about working with students exposed to video game violence. Specifically, a search for techniques and strategies to be used with students who seem to have behavioral issues that are potentially exacerbated by playing violent video games was undertaken. Surprisingly, there was no evidence of any training opportunities geared for school counselors on this topic. Considering that elementary school counselors are expected to function as social-emotional learning consultants, this lack of professional development opportunities was of concern in light of all of the research that does suggest that exposure to violent video games may harmfully impact students. Obviously, it is hoped that this study helps to pave the way towards the development of training materials on this 
topic. There are three main areas of need according to the survey and individual interview participants. These are: guides and scripts that outline how to talk to parents about violent video games, resources on the rating system and the content of violent video games, and information about the symptoms and behaviors that students may display who are at-risk for increased aggression due to violent video game exposure.

One of the more definitive findings in this study centers on the lack of resources available that are specifically tailored to school counselors who want and need more information regarding how to talk to students and parents about exposure to violent video games. The most common request by the participants of this study was a specific, concrete plan in approaching parents about their child's violent video gaming habit. Elementary counselors felt this was a gray area and noted that some parents are very defensive and reactive when they feel that the counselor is criticizing their child's recreational activities. Counselors stated that an outline or script about the potential negative effects of exposure to violent video games would help parents work with counselors to set parameters on the amount of gaming and the types of games that students play. As one individual interview participant explained, "It would be helpful to have training on how to effectively address concerns about video games with parents— - how to address it to groups of parents (i.e back-to-school night, in newsletters, etc.) and to individual parents when there is a concern about a student's exposure to violent games.” Another counselor stated, "I think it would be helpful for school counselors to hear more on appropriate responses to students who are discussing these games, signs to look for when it crosses the line, and [when] a student may be at-risk in the future of violent behavior and how to help parents better understand about the risks of too much exposure to these games.” One of the more specific suggestions in dealing with parents involves helping children choose activities that expose them to a variety of settings 
and situations. The counselors in this study found that the students who were involved in extracurricular activities were less likely to be playing violent video games excessively. Also, the students who were given specific time limits on gaming and had parental expectations about spending time in constructive activities were perceived as more well-rounded and not impacted negatively by violent video game exposure.

The participants also expressed an interest in learning more about the content of the violent video games the students are referencing. As the findings indicated, the majority of the elementary counselors in this study was not very familiar with the games students play and also had only passing knowledge of the ESRB rating system. They discussed the need for site-based training in which they had the opportunity to actually see the violence in the video games and learn the names of the games that were most violent. This training could also be in the form of webinars in which counselors could meet in a central location and attend training as a group. One counselor clarified, "We need to actually watch what these kids are watching, so we understand what they are exposed to and then we can talk to them from a position of knowing what they view as entertainment-it doesn't help us to stick our heads in the sand and ignore the violence they are describing just because it’s not real.” There was also discussion about more exposure to the ESRB rating system so that counselors can educate parents on how to monitor the games their children are playing. Currently, there is debate over whether parents and other concerned parties are familiar with the ESRB rating system. In fact, one of the questions in the researcher's survey addresses elementary school counselors' familiarity with the ESRB rating system in an effort to gather more information about educator awareness of ESRB rating symbols. The ESRB maintains that parents do use their rating system as a guide in deciding which video games their children may play as evidenced by several research studies. According 
to one study conducted by Peter D. Hart Research Associates (as cited in ESA, 2009) 87\% of parents knew about the rating system and 76\% said that they routinely check the rating information before making a video or computer game purchase. Counselors in this study mentioned their concerns that either parents were not actively monitoring what video games their children play and/or that parents were uneducated about the potential negative side effects of exposure to violence for elementary children. As one counselor put it, “I just can’t fathom how parents think it's fine for their children to play these games like Grand Theft Auto, but it's like they can't get into the developmental mindset of their 7-year old. They think because the game is funny to them, it's okay for their child, not realizing that a young child thinks what they see on a screen is real to some extent.” This fear corresponded with the espoused need for a checklist or comprehensive guide to the abnormal behaviors that a student may exhibit if they were suffering detrimental effects from exposure to video game violence.

While not specifically mentioned in the responses of survey and individual interview participants, the researcher also felt that it would be beneficial for elementary school counselors to have training on how video games could potentially be helpful. One counselor had mentioned her beliefs that video games could serve to be a bonding activity for families and another counselor talked about her theory that some students got a self-esteem boost from being good at video games. As she said, “The student I'm thinking of really has difficulty in school... academics are just never going to come easy to him and he gets really frustrated and upset at school by his inability to process things and comprehend. But, he’s phenomenal at video games and it gives him status among his classmates, and I think that saves him from feeling like a complete failure.” 
At some point in the future, it seems reasonable to expect that there may be pro-social or "helping” video games developed, which could be used to assist students in emotional growth. Envision a world where video games are used for the greater good and teach better social skills or conflict resolution techniques. Those games may be on the horizon. Alternatively, elementary counselors could harness the enthusiasm of students and create a guidance lesson that centers around a new video game that features non-violence and peaceable actions. Older elementary students could be challenged to design a video game on a specific guidance topic, such as respecting diversity or preventing bullying. It is likely that students would enjoy a lesson that allows them to be innovative game developers. In short, video games are not likely to phase out of our society, and it would be best to use them as teaching tools and incentives when appropriate.

In conclusion, it is hoped that this particular study will be used to formulate a plan of action in addressing the need for more dialogue with counselors about working with students who are exposed to video game violence. Specific trainings and professional development could evolve from this study as well as elementary guidance curricula targeted towards helping students think critically about video game violence. Research shows that students exposed to a comprehensive school counseling program that includes both whole group and individual student support can significantly reduce discipline problems in schools (Baker \& Gerler, 2001). Based on the counselor perceptions in this study, some discipline referrals may be related to exposure to violent video games; proactive measures are needed to counteract any negative effects from playing these games. 


\section{Implications for Future Research}

The counselors in this study referenced a few main themes in terms of areas for future research. One of their most consistently cited needs was research in regard to the effects of violent video game playing, and the potential moderators that may offset any negative effects. They noted that there is limited research and evidence about environmental and contextual factors that may mitigate negative behavioral reactions to video game violence. Elementary school counselors need more specific information to help them work with students at-risk for violence. They want to know more about the factors that may cause some students to become more aggressive and whether violent video games exacerbate that tendency. For example, there were questions about whether playing violent video games with others as opposed to playing alone decreases, increases, or has no effect on pro-social behaviors. Studies need to be designed that specifically focus on elementary students' gaming habits and examine the variables discussed by the counselors who were surveyed and interviewed during this research. The variables that need to be addressed in future research include: amount of violence, time spent playing violent video games, gaming alone or with others, academic performance and the number of discipline referrals a student receives.

\section{Exposure to All Media Violence}

Additionally, while this study focused on video game violence, the counselor perceptions of the amount and frequency of exposure to violence encompassed the other media, such as popular television shows, movies, music videos, YouTube, and websites such as "Who Would You Kill” and Rotten.com. Their concerns about video game violence were often situated in the context of the violence that our society seems to endorse and condone. As the vanguards of the emotional, mental, and social health of the nations' children, attention should be paid to their 
pleas for more studies on this topic of gratuitous violence. Specific suggestions include: creating modules or courses that can be taught to both students and parents that address $21^{\text {st }}$ century media literacy skills and how those skills apply in the context of bullying, cultural sensitivity, diversity, and character education; having students study and critically reflect on the media violence they observe; and embedding media literacy skills into other content areas such as Language Arts or Social Studies.

Much research remains to be done before there is a clearer picture on how viewing violence in a variety of forms, including video games, may be altering the behaviors and thoughts of children. Based on feedback from the counselors in this study, there are numerous gaps in the current literature on the effects of violent video game exposure in regard to elementary aged children. One individual interview participant discussed the need for longitudinal studies documenting children's violent media exposure from pre-school age through elementary school that would allow for examination of developmental changes. This discussion, along with the review of the literature, strongly suggests a need for research that examines young children's behaviors and beliefs in conjunction with exposure to violent video games in the context of developmental issues. For example, do children who are exposed to violent video games have more attachment disorders? Is there comorbidity between playing violent video games and oppositional defiant disorder diagnoses? Are children who play violent video games progressing through developmental milestones at the same rate as children who don’t play violent video games? Do the students who play violent video games have observable behaviors that differ significantly from students who aren’t exposed to violent video games? To this end, studies that compare any behavioral and developmental differences in elementary students who self-report as specifically preferring violent video games as opposed to preferring games that 
don't contain a large amount of violence would also be useful. Studies that focus on how students at different developmental levels process the violence they are acting out or observing are also needed.

\section{Updated Violence Prevention Programs and Classroom Guidance Curricula}

According to this study’s participants, one step in the right direction may be to incorporate media literacy techniques and strategies into violence prevention programs and classroom guidance lessons with an emphasis on helping students think critically about video game violence and how it impacts their emotions and actions. In order to determine how to best design and execute these interventions, more research must be conducted to explore how elementary school counselors could potentially help students to critically reflect on video game violence they consume. Specifically, more studies need to be done on the efficacy of both violence prevention programs and classroom guidance curricula that address exposure to violence in video games and other forms of social media. Before this can occur, development and implementation of modules and lessons about violent entertainment must take place; ensuring that the new material is relevant and engaging to elementary students is critical. One of the newer trends in education is a focus on brain-based learning and this topic factored into implications for future research.

\section{Brain-based Research}

The need for brain-based research was mentioned frequently by the participants of this study. There is a concern that exposure to violent video games may be altering certain areas of the brain that control empathy, compassion, and aversion to watching pain and suffering. Given the recent strides in technology, it seems entirely possible that research can be conducted that may allow comparisons in brain activity between children who are exposed to violent video 
games and those that are not. Recently, studies have been conducted using both positron emission tomography (PET) and functional magnetic resonance imaging (fMRI) technologies (Gentile, 2009). The intent was to determine how adult brain activity and neurotransmitters were impacted during violent video gaming. The studies showed marked changes in the brain activities of the players, which supports the notion that brain function may be altered due to exposure to violent video games. More research is needed to understand how these changes are impacting players.

Additionally, there is a need for brain-based research on teaching and learning so that effective lessons can be designed by school counselors that address exposure to violent entertainment. By understanding how a child's brain works in the context of education, instruction can be purposeful and powerful.

\section{Gender Issues in Violent Video Game Playing}

One of the most prevalent themes discussed by the participants in this study was gender differences in violent video game players. Every participant commented that boys talked much more frequently about playing violent video games. The counselors reported that very few girls discussed violent video games. Girls reported playing mostly non-violent games such as Sims, Rollercoaster Tycoon and Wii games. One of the major findings of this study was that counselors viewed violent video game playing as a predominantly male activity. They commented that their male students were playing with other male family members such as fathers, brothers, cousins, and uncles and male friends and neighbors. This finding was interesting given that there are more adult female gamers than adolescent male gamers (ESA, 2009). Research is currently ongoing as to whether the number of females who prefer playing violent video games is on the rise. According to one recent study of $7^{\text {th }}$ and $8^{\text {th }}$ grade students, 
playing M-rated video games is a fairly common occurrence among both boys and girls (Olson, Kutner, Almerigi, Baer, Nicholi, \& Beresin, 2007). Out of 1126 participants who listed the titles of games they frequently play, $67.9 \%$ of the males and $29.2 \%$ of the females reported playing at least one violent, mature rated game regularly. Also, in this study, the second most popular game among girls was Grand Theft Auto. The most popular game was Sims. The researchers reported that one out of five girls in the study reported playing Grand Theft Auto very frequently over a six month period. His finding leads to questions about when girls begin to enjoy playing violent video games. Perhaps the elementary female students of the participants in this study were not discussing their gaming habits as openly as male students. Or it may be that some females begin to prefer more mature games during later childhood. Research that focuses specifically on both male and female gaming habits during their elementary school years would be beneficial and informative for school counselors. Studies that examine the decrease or increase in empathy and pro-social skills in each sex after exposure to video game violence would also be useful.

\section{Unanswered Questions}

In relationship to implications for future research, the researcher wrote in the field notes a series of questions that were not posed to the participants. While it was beyond the scope of this study to delve into these specific questions, they generated topics that should be addressed in future research. The questions were:

- Why do you think students enjoy violent video games?

- Do you feel that playing violent video games serves a purpose or meets a need for some students?

- How do you assess/evaluate the impact of violent video games on your students? 
- What distinguishes those students who can play violent video games with no illeffects from those students who are negatively impacted by the activity?

- In your opinion, is it appropriate for school counselors to discuss boundaries and limits on violent video game playing with parents and caretakers?

In summary, the findings of this study and a review of the literature suggest numerous areas for future research. It may be more appropriate for researchers to focus on how and why playing violent video games causes cognitive and behavioral changes in children, based on the current research that suggest both direct and latent effects from exposure to video game violence. Much like previous studies on exposure to violence on television, the study of this topic will continue to evolve so that a more accurate understanding emerges through skillful research. In reviewing the above questions, it is apparent that children need to become participants in studies on this topic. This would be a very effective means in finding out what the students themselves think and feel; interviews and focus groups with children of different ages would yield information on many levels, including cognitive, emotional, and developmental responses to playing violent video games.

\section{Reflections}

There will always be discrepant and conflicting research findings, particularly in the field of social sciences; the topic of this study reflects that fact. What is important to keep in mind is the continual improvement in researching areas of interest. While previous studies related to this study focused on effects of violent video games, violence prevention, and statistics on the prevalence of video games, there was the intent to capture a very specific audience's perceptions on the potential developmental impact of the cultural phenomenon that is video gaming. 
In retrospect, one of the challenges of this study was the realization that the role of video games, especially violent video games, in modern day childhood is a very complex, multifaceted issue. Given the polarizing effects of violent video game research, society's inconsistent, almost love-hate relationship with violent video games, and the amount of money and time spent on violent video games, it became apparent that many factors and variables were involved. As a nation, we are conflicted about violent video games. On one hand, citizens scapegoat and place blame for aggression and crime on violent video games; yet, most children are readily given access to the very games that are under threat of being banned. Schools are often a microcosm of society at large, so it is not surprising that school counselors are concerned about the effects of playing violent video games. What was surprising is that in spite of the mixed research findings, the school counselors in this study were adamant that children are being impacted by playing violent video games. Equally compelling was the richness and diversity in the participants’ beliefs about why playing violent video games is so appealing to students and why parents allow children to play violent video games. The researcher gained a much broader understanding of the complexities of this topic upon completing the data analysis. The counselors' experiences working with students exposed to violent video games both paralleled and expanded the researcher's experiences as a practitioner and heightened the desire to continue to focus on this topic professionally.

In keeping with the firm belief that school counselors are change agents and student advocates, it makes sense to continue gathering information from the individuals who would be familiar with the behavioral changes that may be reflected in students who play violent video games. By taking a determined step in the direction of open inquiry and having the willingness to "listen" to the data, a researcher is blessed with new understandings about the topic of interest. 
This in turn inspires and motivates both the researcher and others who can benefit from the shared knowledge that is captured in systematic research. It is hoped that the findings presented here serve to encourage and support future researchers who are interested in elementary school counselors' perceptions on working with students exposed to video game violence. 


\section{REFERENCES}

Acuff, D. S. (2005). Kidnapped: How irresponsible marketers are stealing the minds of your children. Chicago, IL: Dearborn Trade.

American School Counselor Association. (2003). The ASCA National Model: A framework for school counseling programs. Alexandria, VA.

Anderson, C. A. (2004). An update on the effects of playing violent video games. Journal of Adolescence, 27, 113-122.

Anderson, C. A., Carnagey, N. L., Flanagan, M., Benjamin, A. J., Eubanks, J., \& Valentine, J. C. (2004). Violent video games: Specific effects of violent content on aggressive thoughts and behavior. Advances in Experimental Social Psychology, 36, 199-249.

Anderson, C. A., Gentile, D. A., \& Buckley, K. E. (2007). Violent video game effects on children and adolescents: Theory, research, and public policy. New York: Oxford University Press.

Bailey, K., West, R., \& Anderson, C. A. (in press). The influence of video games on social, cognitive, and affective information processing. Chapter in J. Decety \& J. Cacioppo (Eds.) Handbook of Social Neuroscience. New York: Oxford University Press.

Baker, S. B., \& Gerler, E. R. (2001). Counseling in schools. In D. C. Locke, J. E. Myers, and E. L. Herr (Eds.), The Handbook of Counseling, Thousand Oaks, CA: Sage Publications.

Bandura, A., Ross, D., \& Ross, S. A. (1961). Transmission of aggression through imitation of aggressive models. Journal of Abnormal and Social Psychology, 63, 575-582.

Bandura, A. (2006). Adolescent development from an agentic perspective. In F. Pajares \& T. Urdan (Eds.). Self-efficacy beliefs of adolescents, (Vol.5), 1-43. Greenwich, CT: IAP Information Age Publishing. 
Bartholow, B. D., Bushman, B. J., \& Sestir, M. A. (2006). Chronic Violent Video Game

Exposure and Desensitization to Violence: Behavioral and Event-Related Brain Potential Data,” Journal of Experimental Social Psychology, 42(4), 532-539.

Bates, A. L. (1995). Weeder in the garden of the Lord: Anthony Comstock's life and career. Lanham, MD: University Press of America.

Becker, K., \& Jacobsen, D. M. (2005). Games for Learning: Are Schools Ready for What's to Come? Paper presented at the DiGRA 2005 2nd International Conference, “Changing Views: Worlds in Play”, Vancouver, B.C., June 16-20, 2005.

Bijvank, M. N., Konijn, E. A., Bushman, B. J., \& Roelofsma, P. (2009). Age and violent-content labels make video games forbidden fruits for youth. Pediatrics, 123, 870-876.

Buchman, D. D., \& Funk, J. B. (1996). Video and computer games in ‘90’s: Children’s time commitment and game preference. Children Today, 24, 12-16.

Bureau of Justice Assistance. (n.d.). Guide for Preventing and Responding to School Violence ( $2^{\text {nd }}$ ed.). Retrieved from http://www.ojp.usdoj.gov/BJA/pdf/IACP_School_Violence.pdf

Bushman, B. J., \& Anderson, C. A. (2001). Media violence and the American public: Scientific facts versus media misinformation. American Psychologist, 56, 477-489.

Bushman, B. J., Rothstein, H. R., \& Anderson, C. A. (2010). Much ado about something: Violent video game effects and a school of red herring-Reply to Ferguson and Kilburn (2010). Psychological Bulletin 136(2), 182-187.

Carnagey, N. L. \& Anderson, C. A. (2004). Violent video game exposure and aggression: A literature review. Minerva Psichiatrica (45), 1-18. 
Carnagey, N. L., Anderson, C. A., \& Bartholow, B. D. (2007). Media violence and social neuroscience: New questions and new opportunities. Current Directions in Psychological Science, 16(4), 178-182.

CED Magic (n.d.) 1971: Computer space - the first arcade video game. Retrieved from http://www.cedmagic.com/history/computer-space.html

Center for Media Literacy. (n.d.). CML MediaLit Kit. Retrieved from http://www.medialit.org/cml-medialit-kit.

Creswell, J. W. (2003). Research design: Qualitative, quantitative, and mixed methods approaches ( $2^{\text {nd }}$ ed.). Thousand Oaks, CA: Sage Publications.

D’Andrea, M. (2004). Comprehensive school-based violence prevention training: A developmental-ecological training model. Journal of Counseling \& Development, 82. 277-286.

Eggen, P., \& Kauchak, D. (2001). Educational psychology: Windows on classrooms (5th ed.). Upper Saddle River, NJ: Prentice Hall.

Electronic Software Rating Board. (n.d.) Game ratings and descriptor guide. Retrieved from http://www.esrb.org/ratings/ratings_guide.jsp

Electronic Software Rating Board. (n.d.) Frequently asked questions. Retrieved from http://www.esrb.org/ratings/faq.jsp\#18

Entertainment Software Association (2009). 2009 sales, demographic and usage data: Essential facts about the computer and video game industry. Retrieved from http://www.theesa.com/facts/pdfs/ESA_EF_2009.pdf

Ferguson, C. (in press). The modern hunter-gatherer hunts aliens and gathers power-ups: The evolutionary appeal of violent video games and how they can be beneficial. In N.Koch. 
Evolutionary psychology and information systems research: A new approach to studying the effects of modern technologies on human behavior. New York, New York: Springer.

Flannery, D. J. (1997). School violence: Risk, preventive intervention and policy. Monograph for the Institute of Urban and Minority Education, Columbia University and the ERIC Clearinghouse for Education, Urban Diversity, Series No. 109.

Freedman, J. L. (2001). Evaluating the Research on Violent Video games. Retrieved from http://culturalpolicy.uchicago.edu/papers/2001-video-games/freedman.html

Freedman, J. L. (2002). Media violence and its effect on aggression: Assessing the scientific evidence. Toronto: University of Toronto Press.

Funk, J. B. (2003). Children and violent video games: Strategies for identifying high risk players. In D. Ravitch and J. Viteritti (Eds.). Kid Stuff: Marketing violence and vulgarity in the popular culture. Baltimore: Johns Hopkins University Press.

Gee, J. (2003). What video games have to teach us about learning and literacy. New York, New York: Palgrave Macmillan.

Gentile, D. (2003). Media violence and children. Westport, CT: Praeger.

Gentile, D. (2009). Video games affect the brain-for better and worse. The Dana Foundation. Retrieved from http://dana.org/news/cerebrum/detail.aspx?id=22800

Gentile, D. A., \& Anderson, C. A. (2006). Video games. In N. J. Salkind (Ed.), Encyclopedia of Human Development (pp. 1303-1307). Thousand Oaks, CA: Sage Publications.

Gentile, D., \& Gentile, J. (2008). Violent video games as exemplary teachers: A conceptual analysis. Journal of Youth and Adolescence, 37(2), 127-141.

Gentile, D. A., \& Stone, W. (2005).Violent video game effects on children and adolescents: A review of the literature. Minerva Pediatrica, 57, 337-385. 
Gettler, J. (n.d.). The first video game? Retrieved from http://www.bnl.gov/bnlweb/history/higinbotham.asp

Glaser, B. G., \& Strauss, A. L. (1967). The discovery of grounded theory: Strategies for qualitative research. Chicago: Aldine Publishing Company.

Goldstein, J. (2001). Does Playing Violent Video Games Cause Aggressive Behavior? Retrieved from http://culturalpolicy.uchicago.edu/papers/2001-videogames/goldstein.html

Gonzalez, L. (2010). When two tribes go to war: A history of video game controversy. Retrieved from http://www.gamespot.com/features/6090892/

Grossman, D. (1995). On killing: The psychological cost of learning to kill in war and society. New York: Little, Brown and Co.

Grossman, D. \& DeGaetano, (1999). Stop teaching our kids to kill: A call to action against TV, movie and video game violence. New York: Crown Publishers.

Guerra, N. G., Boxer, P., \& Kim, T. E. (2008). Principles of best practice. In R. Hoge, N. G. Guerra, \& P. Boxer (Eds.), Treating the juvenile offender (pp. 79-102). New York: Guilford Press.

Guinness World Records. (2009, 26 February). Guinness World Records Gamer’s Edition reveals the top 50 console games of all time. Retrieved from http://gamers.guinnessworldrecords.com/news/270209_top50.aspx

Gunter, B. \& Furnham, A. (1984). Perceptions of television violence: Effects of programme genre and type of violence on viewers' judgements of violence portrayals. British Journal of Social Psychology, 23, 155-164. 
Hevesi, D. (2009, March 14). Thomas T. Goldsmith, a TV technology pioneer, dies at 99. The New York Times. Retrieved from http:/www.nytimes.com/2009/03/15/arts/television/15goldsmith.html?_r=3

Hoagwood, K. (2000). Research on youth violence: Progress by replacement, not addition. Journal of Emotional and Behavioral Disorders, 8(2), 67-70.

Honeywell, S. (n.d.). Custer's revenge. All Games Guide, Digital Press video game database. Retrieved from http://www.answers.com/topic/custer-s-revenge-1

Huesmann, L. R., \& Guerra, N.G. (1997). Children’s normative beliefs about aggression and aggressive behavior. Journal of Personality and Social Psychology, 72, 408-419.

Jones, G. (2002). Killing monsters: Why children need fantasy, super heroes, and make-believe violence. New York: Basic Books.

Kent, S. L. (2000). The first quarter: A 25-year history of video games. Bothell, WA: BWD Press.

Kirsh, S. J. (2006). Children, adolescents, and media violence: A critical look at the research. Thousand Oaks, CA: Sage.

Kohler, C. (2009, July 29). July 29 ${ }^{\text {th }}$, 1994: Videogame makers propose ratings board to congress. Retrieved from http://www.wired.com/thisdayintech/2009/07/dayintech_0729/

Kreuter, F., Presser, S., \& Tourangeau. (2008). Social desirability bias in CATI, IVR, and web surveys: The effects of mode and question sensitivity. Public Opinion Quarterly, 72(5). 847-865.

Kutner, L., \& Olson, C. K. (2008). Grand theft childhood: The surprising truth about violent video games and what parents can do. New York: Simon and Schuster. 
Lincoln, Y. S., \& Guba, E. G. (2000). Paradigmatic controversies, contradictions, and emerging confluences. In N. K. Denzin \& Y. S. Lincoln (Eds.), Handbook of qualitative research (2nd ed., pp. 163-188). Thousand Oaks, CA: Sage Publications.

Loguidice, B., \& Barton, M. (2009). Vintage games: An insider look at the history of Grand Theft Auto, Super Mario, and the most influential games of all time. Burlington, MA: Elsevier.

Mansfield, D. (2003). CGSOCIETY, Society of Digital Artists. Grand Theft Auto makers fight lawsuit. Retrieved from http://forums.cgsociety.org/archive/index.php/t-102252.html

Neuman, W. L. (2004). Social research methods: Qualitative and quantitative approaches (4 ${ }^{\text {th }}$ Ed.). London: Allyn and Bacon.

Nicoll, J., \& Kieffer, K. M. (2005). Violence in video games: A review of the empirical research. Saint Leo University; Session 2185, 1:00 - 1:50 PM, Friday, August 19, Washington Convention Center, Level 2, Halls D \& E [N-7].

Olson, C. K. (2004). Media violence research and youth violence data: Why do they conflict. Academic Psychiatry, 28 , 144-150.

Olson, C. K., Kutner, L. A., Warner, D. E., Almerigi, J. B., Baer, L., Nicholi, A. M. Jr., \& Beresin, E. V. (2007). Factors correlated with violent video game use by adolescent boys and girls. Journal of Adolescent Health, 41(1), 77-83.

Paik, H. \& Comstock, G. (1994). The effects of television violence on antisocial behavior: A meta-analysis. Communication Research, 21(4), 516-546.

Park-Higgerson, H. K., Perumean-Chaney, S. E., Bartolucci, A. A., Grimley, D. M., \& Singh, K. P. (2008). The evaluation of school-based violence prevention programs: A metaanalysis. Journal of School Health, 78, 465-479. 
Patton, M. Q. (2002). Qualitative research and evaluation methods. Thousand Oaks, CA: Sage Publications.

Perkins, G. W., Brumfield, K. A., Collins, E. N., \& Morris, N. T. (2010). Working with gamers: Implications for counselors. Retrieved from http://counselingoutfitters.com/vistas/vistas10/Article_65.pdf

Ratner, C. (1998). Prologue to Vygotsky’s collected works (Vol. 5). New York: Plenum.

Scherba de Valenzuela, J. (2002). Sociocultural Theory. Albuquerque, NM: University of New Mexico. Retrieved from http://www.unm.edu/\%7Edevalenz/handouts/sociocult.html

Sherry, J. L. (2001). The effects of violent video games on aggression: A meta-analysis. Human Communication Research, 27(3), 490-431.

Sherry, J. L., (2007). Violence in video games. In J.J. Arnett (Ed.), Encyclopedia of Children, Adolescents and the media. Thousand Oaks, CA: Sage Publications.

Shwandt, T. A. (2000). Three epistemological stances for qualitative inquiry: Interpretivism, hermeneutic, and social constructivism. In N. K. Denzin \& Y. S. Lincoln (Eds.), Handbook of Qualitative Research (2nd ed.). Thousand Oaks, CA, Sage Publications.

Smith, T. (2005). The Register. Grand Theft Auto firm faces ‘murder training' lawsuit. Retrieved from http://www.theregister.co.uk/2005/02/17/taketwo_gta_lawsuit/

Strauss, A., \& Corbin, J. (1990). Basics of qualitative research: Grounded theory procedures and techniques. Thousand Oaks, CA: Sage Publications.

Strauss, A. \& Corbin, J. (1998). Basics of qualitative research: Techniques and procedures for developing grounded theory $\left(2^{\text {nd }}\right.$ ed.). Thousand Oaks, CA: Sage Publications.

Unsworth, G., Devilly, G. J., \& Ward, T. (2007). The effect of playing violent videogames: Are adolescents doomed to violence? Psychology, Crime \& Law, 13, 383-394. 
Wilson, S. J., Lipsey , M. W., \& Derzon, J. H. (2003). The effects of school-based intervention programs on aggressive behavior: A meta-analysis. Journal of Consulting \& Clinical Psychology, 71, 136-149.

Wolf , M. (Ed.) (2002). The medium of the video game. Texas: University of Texas Press.

Wolf, M. (2008). The video game explosion: A history from PONG to playstation and beyond. Westport, CT: Greenwood Press.

Woodard, E. H., \& Gridina, N. (2000). Media in the home 2000: The fifth annual survey of parents and children. Philadelphia: University of Pennsylvania. 


\section{ONLINE SURVEY USING SIMPLEFORMS}

Dear Elementary School Counselor, Thank you very much for agreeing to participate in my dissertation research exploring elementary school counselors' perceptions about students' exposure to video game violence. The following is a self-report survey that is intended to gather information about your experiences with this topic as an elementary school counselor. The purpose of this research study is to determine themes and trends regarding student exposure to violent video games from the perspectives of elementary school counselors. This study is conducted in partial fulfillment of the requirements for the degree of Doctor of Education in Curriculum and Instruction.

Your participation should not pose any discomfort, risks, or conflicts of interest. You may notice an increase of awareness or interest in this topic as a result of your participation in this research. If you have questions, concerns, or comments for me, the researcher, please contact me at twoody@mix.wvu.edu or at 304.724.2848.

Thank you again for your participation.

Respectfully,

Tammy Lynn Woody

West Virginia University Doctoral Candidate

Demographics and Employment Information

1) Please indicate with which gender you identify:

Female

Male

Transgender

2) What is your age?

3) Please indicate with which race/ ethnic group(s) you identify most closely: $\checkmark$ African American

Asian

American Indian

Caucasian

Hispanic

Pacific Islander

4) How many years of experience do you have as an elementary school counselor?

5) Are you currently employed as an elementary school counselor?

Yes

No

5a If no, when was your last year of service as an elementary school counselor? 
6) Have you ever been employed as a middle or high school counselor?

$\square$ Yes

$\square$ No

6a) If so, how many years of experience do you have as a middle or high school counselor?

$\square$ less than a full school year

1-5 years

6-10 years

11-15 years

16 or more years

7) Have you ever held a teaching certificate or been employed as a teacher?

$\neg$ Yes

$\neg$ No

7a)If so, how many years of experience do you have as a teacher?

$\square$ less than a full school year

$1-5$ years

6-10 years

$11-15$ years

16 or more years

8) Would you describe your current school site(s) as rural, suburban, or urban?

rural

suburban

$\square$ urban

9) Please provide the approximate number of enrolled students in your school.

10) Please choose the most accurate statement which describes your personal experiences with playing video games for recreational purposes.

$\square$ I never play video games

$\square$ I rarely play video games

$\square$ I occasionally play video games

$\square$ I frequently play video games

$\square$ I used to play video games, but I don't currently play them

11) If you play video games for recreational purposes, please list the names of the games you play: 
Indicate the extent of your agreement with the following statements concerning video games.

\begin{tabular}{|c|c|c|c|c|c|c|}
\hline & & $\begin{array}{l}\text { Strongly } \\
\text { agree }\end{array}$ & Agree & Neutral & Disagree & $\begin{array}{l}\text { Strongly } \\
\text { Disagree }\end{array}$ \\
\hline & $\begin{array}{l}\text { Playing video games is a common } \\
\text { activity in my student population }\end{array}$ & 0 & 0 & 0 & 0 & 0 \\
\hline 2. & $\begin{array}{l}\text { There is research readily available } \\
\text { about how playing video games may } \\
\text { impact children }\end{array}$ & 0 & 0 & 0 & 0 & 0 \\
\hline 3. & $\begin{array}{l}\text { There is cause for concern about } \\
\text { children's exposure to video game } \\
\text { violence }\end{array}$ & 0 & 0 & 0 & 0 & 0 \\
\hline 4. & $\begin{array}{l}\text { I believe some discipline referrals may } \\
\text { be related to playing violent video } \\
\text { games }\end{array}$ & 0 & 0 & 0 & 0 & 0 \\
\hline & $\begin{array}{l}\text { I have discussed a student's video game } \\
\text { usage with the parent or guardian }\end{array}$ & 0 & 0 & 0 & 0 & 0 \\
\hline 6. & $\begin{array}{l}\text { There is a need to educate adults about } \\
\text { children's exposure to violent video } \\
\text { games }\end{array}$ & 0 & 0 & 0 & 0 & 0 \\
\hline 7. & $\begin{array}{l}\text { I have never heard student descriptions } \\
\text { of video game violence which I felt were } \\
\text { too graphic or inappropriate for the } \\
\text { student }\end{array}$ & 0 & 0 & 0 & 0 & 0 \\
\hline 8. & $\begin{array}{l}\text { My school does not have resources } \\
\text { available which name and describe } \\
\text { common video games }\end{array}$ & 0 & 0 & 0 & 0 & 0 \\
\hline 9. & $\begin{array}{l}\text { Attending professional development on } \\
\text { the topic of working with students who } \\
\text { play violent video games is important }\end{array}$ & 0 & 0 & 0 & 0 & 0 \\
\hline & $\begin{array}{l}\text { Students frequently discuss playing } \\
\text { violent video games in my presence }\end{array}$ & 0 & 0 & 0 & 0 & 0 \\
\hline
\end{tabular}

Rate your familiarity with the following electronic games

\begin{tabular}{|l|c|c|c|c|}
\hline & $\begin{array}{l}\text { I have not } \\
\text { heard of this } \\
\text { game }\end{array}$ & $\begin{array}{l}\text { I have heard of this } \\
\text { title, but I'm not } \\
\text { familiar with the } \\
\text { game }\end{array}$ & $\begin{array}{c}\text { I could } \\
\text { describe } \\
\text { the basic } \\
\text { plot and } \\
\text { goal of this } \\
\text { game }\end{array}$ & $\begin{array}{l}\text { I am very familiar with } \\
\text { this game and can } \\
\text { provide a detailed } \\
\text { description }\end{array}$ \\
\hline 1.Assassin's Creed & 0 & 0 & 0 & 0 \\
\hline 2. Call of Duty & 0 & 0 & 0 & 0 \\
\hline 3.Grand Theft Auto & 0 & 0 & 0 & 0 \\
\hline 4. Halo & 0 & 0 & 0 & 0 \\
\hline 5. Mortal Kombat & 0 & 0 & 0 & 0 \\
\hline 6. Sims & 0 & 0 & 0 & 0 \\
\hline 7. Super Mario Bros & 0 & 0 & 0 & 0 \\
\hline $\begin{array}{l}\text { 8.The Legend of } \\
\text { Zelda }\end{array}$ & 0 & 0 & 0 & 0 \\
\hline 9.Tony Hawk Ride & 0 & 0 & 0 & 0 \\
\hline
\end{tabular}




\begin{tabular}{|l|c|c|c|c|}
\hline $\begin{array}{l}\text { 10. Rollercoaster } \\
\text { Tycoon }\end{array}$ & 0 & 0 & 0 & 0 \\
\hline $\begin{array}{l}\text { 11. World of } \\
\text { Warcraft }\end{array}$ & 0 & 0 & 0 & 0 \\
\hline 12. Wii Fit & 0 & 0 & 0 & 0 \\
\hline
\end{tabular}

How do you respond when students discuss violent video games in a counseling session? Check all that apply:

$\square$ I redirect the student

$\square$ I ask clarifying questions about the video game, such as the name and frequency of play

$\square$ I ignore the reference

$\square$ I respond to the student's prompt and continue to discuss the video game

$\square$ I tell the student we can talk about the game at the end of our session or during free time

$\square$ I try to connect the student enjoyment of video games to our counseling goals

$\square \mathrm{I}$ ask the parents or care-givers for more information about the gaming habits of the student

Students often model, reenact and verbally process what they observe. Please indicate any of the following student actions and/ or behaviors that you've either observed or heard about which may be related to violent video games based on student self-disclosure about gaming habits.

$\square$ Student mimes punching, hitting, shoving or kicking

$\square$ Student pretends to shoot other students or objects

$\checkmark$ Student pretend to hurt others physically

Student uses puppets, toys, or action figures to act out a video game scene

$\square$ During free time and/or recess, student pretends to be a video game character

$\checkmark$ Student received a discipline referral or teacher warning for hurting or threatening another student

$\checkmark$ Student talks about the violent acts in a video game

$\square$ Student talks to other students about playing video games

\section{Open-ended Questions}

1. Which video games are popular with students?

2. In your opinion, how are students who self-disclose about playing violent video games impacted by this activity?

3. Please describe any professional development and/or training activities you have attended which addressed concerns about student exposure to violent video games.

4. What training activities would be useful when working with students who play violent video games?

If you are willing to be individually interviewed about this topic, please provide your contact information and/or email the researcher at twoody@mix.wvu.edu Interviews will be conducted via telephone, in person, or through Skype/Adobe Connect. 


\section{APPENDIX B}

\section{FLEXIBLE INTERVIEW PROTOCOL FOR WOODY DOCTORAL RESEARCH}

January 10, 2010

Hello and thank you for agreeing to be interviewed. My name is Tammy Lynn Woody and I am conducting this research study under the supervision of Ardeth Deay, Ph.D., and Joy Saab, Ph.D., faculty in the College of Human Resources and Education at West Virginia University. The purpose of this study is to determine themes and trends regarding student exposure to violent video games from the perspectives of elementary school counselors. This study is conducted in partial fulfillment of the requirements for the degree of Doctor of Education in Curriculum and Instruction. You are welcome to review the interview questions before we begin. This interview is semi-structured in that clarifying questions may be asked based on your responses. I would like to audiotape or archive this interview in order to accurately represent what you say and I will transcribe the interview verbatim at a later date. May I have your permission to record this interview? The interview should last approximately 45 minutes. Before we begin, I would like to notify you of the following:

- You must be 18 years of age or older to participate.

- Your participation is entirely voluntary. You may choose not to answer certain questions or stop the interview at any time

- Your responses will remain anonymous and confidentiality will be maintained.

- No negative consequence will result for choosing not to participate.

- West Virginia University’s Institutional Review Board acknowledgement of this project is on file.

Thank you again for your willingness to participate in this study.

Respectfully,

1. Please give a brief description of your credentials and work experience as an elementary school counselor. (RQ6)

2. Describe how frequently your students reference playing violent video games. Please supply any names and/or descriptions of games commonly mentioned. (RQ1)

3. Please give examples of student conversations and/or behaviors that you've observed which you believe reflect exposure to violent video games. (RQ2)

4. What are some of the ways you respond when students discuss playing violent video games with you? (RQ3)

5. What do you do when a student acts out, mimics, or uses language that seems to be a direct result of playing violent video games? (RQ4) 
6. There is a great deal of debate on whether violent video game exposure is harmful to children. Based on your experience as an elementary school counselor, what are your thoughts on this topic? (Exploratory)

7. Are students who play violent video games impacted by the activity, in your experience? (Exploratory)

8. Please talk about your attempts to help your students analyze or think critically about playing violent video games, if this course of action has been necessary when counseling a student. (Exploratory)

9. Given that elementary school counselors often assist parents in informed decision making, could you describe your understanding of the video game content rating system, developed by the ESRB (Entertainment Software Rating Board), that is currently used in the United States? (Exploratory)

10. Describe any resources and/or training to which you've been exposed that address violent video game playing. (RQ5)

11. Please share your thoughts on counselor training in regard to student exposure to violent video games. Specifically, what, if any, training or professional development activities would benefit elementary school counselors on this topic. Is there a need for this specific training in your opinion? (RQ5)

Last question-What final comments would you like to share on this subject? 


\section{LETTER TO SURVEY PARTICIPANTS}

\section{Department of Curriculum \& Instruction/Literacy Studies WestVirginiaUniversity. \\ College of Human Resources and Education}

\section{Dear Participant,}

This letter is a request for you to take part in a research project to examine elementary school counselors' perceptions of working with students exposed to violent video games. This project is being conducted by Tammy Lynn Woody, Doctoral Candidate in Curriculum \& Instruction, under the supervision of principal investigator, Dr. Joy Saab and Dr. Ardeth Deay, Doctoral Chair. The contact information for the principal investigator is Joy.Saab@mail.wvu.edu or you may call 304-293-4084.Your participation in this project is greatly appreciated and will take approximately 25 minutes to complete the online survey. Additionally, should you choose to be interviewed after completion of the survey, the researcher will set up a time at your convenience. The interview will take approximately 45 minutes. Before we begin, I want to make sure that you understand the following:

- Your involvement in this project will be kept as confidential as legally possible. All data will be reported in the aggregate.

- You must be 18 years of age or older to participate. I will not use identifiers in the reporting of data.

- Your participation is completely voluntary. You may skip any question that you do not wish to answer and you may discontinue at any time.

- West Virginia University's Institutional Review Board acknowledgement of this project is on file.

I hope that you will participate in this research project, as it could be beneficial in understanding elementary school counselors' experiences in working with students who play violent video games. Thank you very much for your time. Should you have any questions about this letter or the research project, please feel free to contact Tammy Lynn Woody at 304.724.2848 or by e-mail at twoody@mix.wvu.edu

Respectfully,

Tammy Lynn Woody

602 Allen Hall PO Box 6122 Morgantown, WV 26506-6122

Phone: 304-293-3441 Fax: 304-293-3802

Equal Opportunity / Affirmative Action Institution 


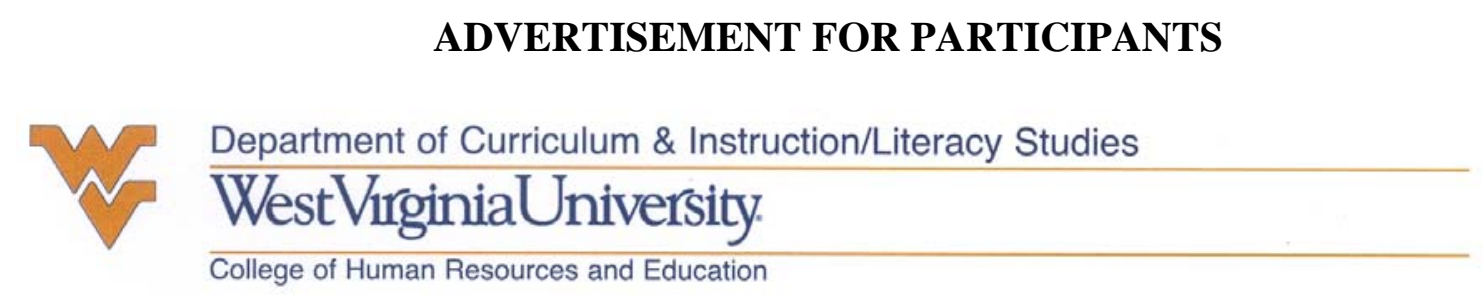

\section{PARTICIPANTS NEEDED}

\section{VOLUNTEERS NEEDED FOR DOCTORAL RESEARCH ABOUT ELEMENTARY SCHOOL COUNSELORS' PERCEPTIONS OF STUDENT EXPOSURE TO VIOLENT VIDEO GAMES}

This is a research project supervised by Dr. Joy Saab and Dr. Ardeth Deay, faculty in the College of Human Resources and Education at WVU. Dr. Saab is the principal investigator in this study and she may be reached at Joy.Saab@mail.wvu.edu. The West Virginia University Institutional Review Board (IRB) has acknowledgment of this study on file. The purpose of this research is to describe elementary school counselors' perceptions of working with students who play violent video games. All volunteers must be currently certified school counselors.

We are seeking participants who are willing to complete a short online survey. Additionally, if participants are willing to be individually interviewed after completion of the survey, they will have the opportunity to provide the appropriate contact information (email address) in the section of the survey which asks whether participants are willing to be interviewed on this topic.

Participants may choose not to answer questions and they can discontinue the survey and/or interview at any time. This is a needed study as little formal research has been conducted on this particular topic. Any information generated from this study will be used to contribute a unique body of knowledge to existing research.

Participants may log into the online survey at a time of their convenience and interviews will also be conducted based on participant availability. The approximate time frame for completion of surveys and interviews is May, 31, 2010. Interviews will be conducted in person, by phone, or by Adobe Pro Connect/Skype. All interviews will be archived and/or videotaped with the participant's prior permission and will be transcribed at a later date. Data will be destroyed after the study is complete and no identifiers will link participants with the reported data. There is no known risk for participation.

FOR ADDITIONAL INFORMATION OR TO VOLUNTEER TO PARTICIPATE, GO TO THIS SITE (to be completed) OR CONTACT: 


\section{Tammy Lynn Woody, Doctoral Candidate \\ Department of Curriculum \& Instruction}

Email: twoody@mix.wvu.edu

Telephone: (304) 724-2848 


\section{REQUEST FOR INTERVIEW}

\section{Department of Curriculum \& Instruction/Literacy Studies WestVirginiaUniversity. \\ College of Human Resources and Education}

\section{Dear Participant,}

Thank you for your willingness to be interviewed and for your participation in this study regarding elementary school counselors' perceptions of working with students who play violent video games. At this point, you will have already completed the survey on this topic. This interview is an effort to gain a deeper understanding of elementary school counselors' experiences. Every effort will be made to complete these interviews at your convenience. We have options in how we conduct these interviews based on your needs and preference. Please reply to this email and let me know whether you would prefer to have a face to face interview, a phone interview, or interview in a virtual setting using Skype or Adobe Pro Connect. Also supply information about what times of day are best for you to be interviewed. The interview will take approximately 45 minutes of your time.

Please keep in mind the following in regard to your participation:

- Your involvement in this project will be kept as confidential as legally possible. All data will be reported in the aggregate.

- You must be 18 years of age or older to participate. I will not use identifiers in the reporting of data.

- Your participation is completely voluntary. You may skip any question that you do not wish to answer and you may discontinue at any time.

- West Virginia University's Institutional Review Board acknowledgement of this project is on file.

Please feel free to contact Tammy Lynn Woody at 304.724 .2848 or by e-mail at twoody@mix.wvu.edu for further clarification. I look forward to our interview and appreciate your time.

Respectfully,

Tammy Lynn Woody

602 Allen Hall PO Box 6122 Morgantown, WV 26506-6122

Phone: 304-293-3441 Fax: 304-293-3802

Equal Opportunity / Affirmative Action Institution 


\title{
TAMMY LYNN WOODY
}

\author{
77 CONGRESSIONAL CT., MARTINSBURG, WV. 25405 \\ PHONE: 304.433.0803 EMAIL: WOODYT73@YAHOO.COM
}

\section{EDUCATION}

2003-2010 West Virginia University Morgantown, WV

Doctor of Education, Concentration: Curriculum \& Instruction

Dissertation Topic: Elementary School Counselors' Perceptions of Student Exposure to Violent Video Games

1998-2000 West Virginia University Morgantown, WV

Master of Arts in Counseling, Concentration: School/Guidance

1993-1995 James Madison University Harrisonburg, VA

Bachelor of Science, Major: Psychology Minor: Women’s Studies

\section{PROFESSIONAL EXPERIENCE}

2008-Present American Public University System Charles Town, WV

\section{Director of Education Internships and Certification}

- Manage and supervise both the Certification Department and the Office of Field Experience for the APUS School of Education

- Created and implemented policies and procedures for both departments as the APUS School of Education was formed and received WV state approval in late 2007

- Review and approve or deny all applicants to the School of Education

- Advise all prospective and current graduate students on educator certification policies and field placement procedures

- Monitor and track every student from program admission through program completion to ensure student success

- Assist students with scholarship and research grant applications

- Serve as the University liaison for both K-12 school districts and state departments of education

- Personally responsible for fostering over $100 \mathrm{~K}-12 /$ University Partnerships in a variety of locations to include all 50 states and 12 countries.

- Present data driven analyses about program retention and course completion on a monthly basis using both qualitative and quantitative data

- Train and collaborate with all program directors for the School of Education

- Conducted gap analyses to realign the Guidance and Counseling Program with 2009 CACREP Standards

- Facilitate schedules, conferences, and virtual meetings between University Supervisors, Pre-service Candidates, Cooperating Mentors and District Representative/Field Placement Coordinators

- Create, Maintain, and Edit all School of Education Website Content using a Content Management System 
- Coordinate and host bi-monthly virtual open houses for current and prospective graduate students

- Designed and implemented a “drip campaign” using Intelliworks to bolster program completion and student retention

- Host and lead multi-departmental meetings on a monthly basis

- Conduct faculty training on certification policy and field placement procedures on a quarterly basis

- $\quad$ Serve as faculty in the Masters of Education: Guidance and Counseling Program

- Institutional Representative at State level Educator Preparation Standards Reviews

2000-2008 Frederick County Public Schools Winchester, VA

\section{Elementary Guidance Counselor}

- Design guidance curriculum for both small group and classrooms correlated with Virginia's state standards

- Provide individual and group counseling on a variety of topics such as self-esteem, social skills, anger management, study skills and grief/loss

- Create and implement short and long range goals for academic success

- Coordinate school wide programs such as character education, mentoring program and conflict resolution

- Lead meetings such as IEP evaluations, Child Study, School Improvement, ParentTeacher Conferences, and Crisis Preparedness

- Consult and exchange written and verbal information with parents, teachers, administrators, school psychologists, school nurses, social workers and other counselors (both school and private)

- Designed the first and only Blackboard site for elementary counselors in Frederick County

- Utilize technology such as smart boards, United Streaming, and PowerPoint to teach students and staff

\section{2-2004}

Sylvan Learning Center

Winchester,VA

\section{Teacher}

- Planned and taught lessons to mixed age/ability students

- Evaluated performance and submitted written assessments of each student's progress

- Revised and implemented positive reinforcement schedule via token economy

- Assembled and correlated new objectives using the Sylvan Matrix

- Trained and supervised new teachers

\section{Substitute Teacher}

- Interpreted and taught lessons on all subjects in grades K-12

- Created supplemental activities and lesson plans as needed

- Applied behavior management techniques to challenging students

- Requested for several long term subbing positions due to positive feedback from administrators and teachers

\section{Lead Teacher}

- Designed weekly curriculum for students aged 4-6

- Reviewed and monitored state accreditation standards

- Created and produced weekly newsletters

- Coordinated and Supervised Bi-Weekly Fieldtrips

- Monitored and reported child's progress to parents via weekly written assessments 
- Collaborated with teachers and parents to enhance the personal, social and academic growth of each student

\section{RELEVANT SERVICE AND/OR LEADERSHIP EXPERIENCE}

- Member of the Mid-Atlantic Association for Employment in Education (MAEE)

Executive Board-currently chair of research and scholarships

- Co-Chair, 2009 Annual Job Fair, MAEE

- Co-Chair, Program Planning for the 2009 MAEE Annual Conference

- EPPAC Advisory Council, American Public University System

- Virginia Association for Counselor Education and Supervision (VACES), Panel Reviewer for 2009 Graduate Student Research Conference

- VACES, Reviewer for Research Grant Applicants. 2009, 2010

- Vice President of Apple Valley Counselor's Association (regional association comprised of counselors within a 5 county region in VA) Elected in 2003-present

- Service on Virginia State Executive Board of Counselors as the Shenandoah Valley Regional representative

- Guest Lecturer at Shepherd University on numerous occasions

- Chosen to mentor and supervise practicum students and interns 3 times more often than peers

- Co-presented workshop about cyber bullying in 2007 for AVCA

- Chosen by doctoral chair to serve as moderator for online doctoral class

- Service on Curriculum Committee to review and revise Virginia State School Counseling Standards, Frederick County Public Schools, VA

- Faculty Senate Representative for Senseny Road and Redbud Run Elementary Schools

- Director/Head of the Student Council Association at Senseny Road School

\section{PROFESSIONAL AFFLIATIONS}

Mid-Atlantic Education

NASDTEC Institutional Representative

Site/ACES

VCA

VCES

Apple Valley Counselors Association

West Virginia Counselors Association

American School Counselors Association

National Education Association

Association for Supervision and Curriculum Development

RELEVANT TEACHING EXPERIENCE

EDUC 505 (The Professional School Counselor)

EDUC 515 (Helping Relationships)

EDUC 518 (Educational Psychology)

EDUC 530 (Assessment, Evaluation \& Testing I)

EDUC 696 (Counseling Practicum-University Supervisor)

EDUC 699 (Counseling Internship-University Supervisor)

\section{TECHNOLOGY SKILLS}

Proficient in all Microsoft Office Tools

Trained in Content Management System and manage all School of Education webpage content 
Trained in Intelliworks CRM (Constituent Relationship Management) Software

Trained in the Educator LMS (Learning Management System)

Adept using Skype, Adobe Pro Connect, Blackboard, Wimba Live, E-Campus, and Audacity

Presented at the West Virginia Statewide Technology Conference, 2009. Conference Theme was

"Learning \& Living in a Digital World" and my presentation was titled "The Use of Educational

Technology in Online Educator Preparation Programs”

References Available Upon Request 